\title{
Arbitragem nos mercados financeiros: uma proposta Bayesiana de verificação
}

\author{
Fernando Valvano Cerezetti
}

TESE APRESENTADA

AO

Instituto de MATEMÁtica e Estatística

DA

Universidade de São Paulo

PARA

OBTENÇÃO DO TÍTULO

DE

DOUTOR EM CIÊNCIAS

Programa: Estatística

Orientador: Prof. Dr. Julio Michael Stern 


\title{
Arbitragem nos mercados financeiros: uma proposta Bayesiana de verificação
}

\begin{abstract}
Esta versão da tese contém as correções e alterações sugeridas pela Comissão Julgadora durante a defesa da versão original do trabalho, realizada em 20/05/2013. Uma cópia da versão original está disponível no Instituto de Matemática e Estatística da Universidade de São Paulo.
\end{abstract}

Comissão Julgadora:

- Prof. Dr. Julio Michael Stern (orientador) - IME-USP

- Prof. Dr. Carlos Alberto de Bragança Pereira - IME-USP

- Prof. Dr. Adriano Polpo de Campos - UFSCar

- Prof ${ }^{\mathrm{a}}$. Dr ${ }^{\mathrm{a}}$. Laura Letícia Ramos Rifo - UNICAMP

- Prof. Dr. Marcelo de Souza Lauretto - EACH-USP 


\section{DEDICATÓRIA}

Dedico esse trabalho a minha familia e, especialmente, a Karina, quem se mostrou uma verdadeira companheira. 


\section{AGRADECIMENTOS}

Agradeço muitíssimo ao Prof. Dr. Julio Michael Stern por todo o esforço e dedicação concedidos ao trabalho.

Agradeço ao Prof. Dr. Marcelo Lauretto pelo inestimável auxílio.

Agradeço ao Departamento de Estatística do IME/USP pelo apoio ao trabalho. 


\section{Resumo}

CEREZETTI, F. V. Arbitragem nos mercados financeiros: uma proposta Bayesiana de verificação. 2013. 87f. Tese - Instituto de Matemática e Estatística, Universidade de São Paulo, São Paulo, 2013.

Hipóteses precisas são características naturais das teorias econômicas de determinação do valor ou preço de ativos financeiros. Nessas teorias, a precisão das hipóteses assume a forma do conceito de equilíbrio ou da não arbitragem. Esse último possui um papel fundamental nas teorias de finanças. Sob certas condições, o Teorema Fundamental do Apreçamento de Ativos estabelece um sistema único e coerente para valorização dos ativos em mercados não arbitrados, valendo-se para tal das formulações para processos de martingal. A análise da distribuição estatística desses ativos financeiros ajuda no entendimento de como os participantes se comportam nos mercados, gerando assim as condições para se arbitrar. Nesse sentido, a tese defendida é a de que o estudo da hipótese de não arbitragem possui contrapartida científica, tanto do lado teórico quanto do empírico. Utilizando-se do modelo estocástico Variância Gama para os preços dos ativos, o teste Bayesiano FBST é implementado com o intuito de se verificar a existência da arbitragem nos mercados, potencialmente expressa nos parâmetros destas densidades. Especificamente, a distribuição do Índice Bovespa é investigada, com os parâmetros risco-neutros sendo estimados baseandose nas opções negociadas no Segmento de Ações e no Segmento de Derivativos da BM\&FBovespa. Os resultados aparentam indicar diferenças estatísticas significantes em alguns períodos de tempo. Até que ponto esta evidência é a expressão de uma arbitragem perene nesses mercados ainda é uma questão em aberto.

Palavras-chave: teoria do valor, não arbitragem, hipótese precisa, FBST, Variância Gama. 


\section{Abstract}

CEREZETTI, F. V. Arbitrage in financial markets: a Bayesian approach for verification. 2013. 87f. Tese - Instituto de Matemática e Estatística, Universidade de São Paulo, São Paulo, 2013.

Precise hypotheses are natural characteristics of the economic theories for determining the value or prices of financial assets. Within these theories the precision is expressed in terms of equilibrium and non-arbitrage hypotheses. The former concept plays an essential role in the theories of finance. Under certain conditions, the Fundamental Theorem of Asset Pricing establishes a coherent and unique asset pricing framework in non-arbitraged markets, grounded on martingales processes. Accordingly, the analysis of the statistical distributions of financial assets can assist in understanding how participants behave in the markets, and may or may not engender conditions to arbitrage. On this regard, the dissertation proposes that the study of non-arbitrage hypothesis has a scientific counterparty, theoretically and empirically. Using a variance gamma stochastic model for prices, the Bayesian test FBST is conducted to verify the presence of arbitrage potentially incorporated on these densities parameters. Specifically, the Bovespa Index distribution is investigated, with risk neutral parameters estimated based on options traded in the Equities Segment and the Derivatives Segment at the BM\&FBovespa Exchange. Results seem to indicate significant statistical differences at some periods of time. To what extent this evidence is actually the expression of a perennial arbitrage between the markets still is an open question

Keywords: value theory, non-arbitrage, precise hypothesis, FBST, variance gamma. 


\section{Sumário}

1 INTRODUÇão 1

1.1 Iluminismo e Pensamento Econômico.........................................................................1

1.2 Epistemologia Construtivista e Hipóteses Precisas................................................ 3

1.3 Arbitragem e Verificação Empírica.................................................................

2 TeOrias do VAlor: EQUiLíbrio E Não ARbitrageM

2.1 Sistemas Mecânicos e Teorias Econômicas...............................................................

2.2 Modernas Teorias de Finanças.......................................................................... 10

2.3 Teorias de Apreçamento: Não Arbitragem........................................................15

3 TeOrias de APREÇAMENTo de Derivativos: Não ARbitragem 19

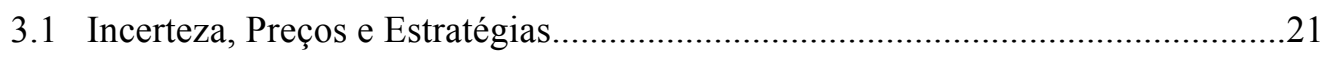

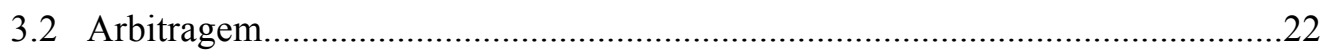

3.3 Teorema Fundamental do Apreçamento de Ativos (TFAA)..............................25

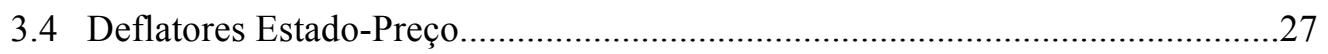

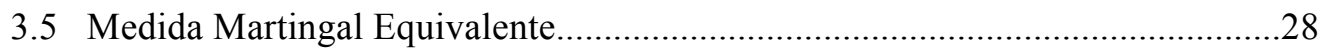

3.6 Preço de Mercado do Risco............................................................................

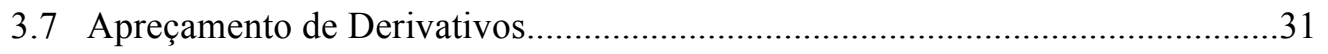

4 InSTRUMental PaRa HiPÓteses Precisas 33

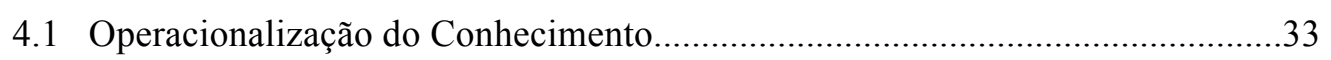

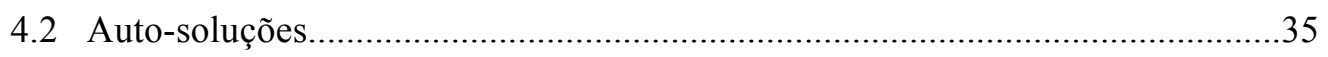

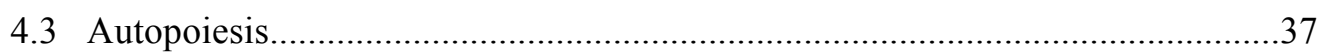

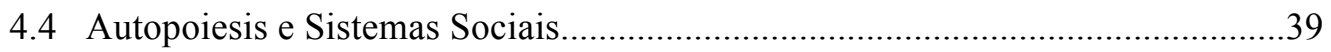

4.5 Teste de Hipóteses Bayesianos...........................................................................

4.6 FBST: Formulação Metodológica....................................................................4

4.7 Avaliação dos Procedimentos de Teste..................................................................48

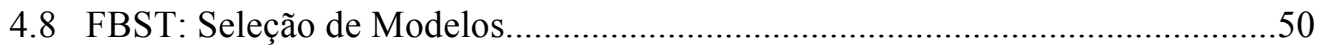

5 ARbitragem nos Mercados FinanCeiros: UMA PROPOSTA de TESTE 55

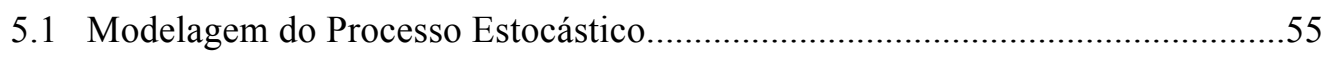

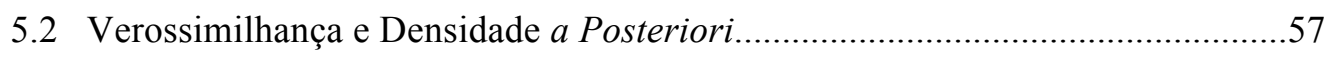

5.3 Não Arbitragem, Hipótese de Teste e Informações de Mercado...........................59

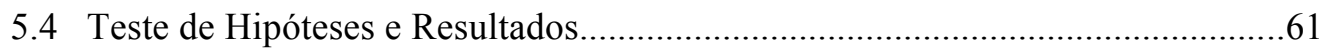


6 Conclusão $r$

$\begin{array}{lr}\text { A EBEB 2012 } & 72\end{array}$

$\begin{array}{ll}\text { REFERÊNCIAS BIBLIOGRÁFICAS } & 74\end{array}$

$\begin{array}{lr}\text { GLOSSÁRIO DE TERMOS FINANCEIROS } & 79\end{array}$ 


\section{Capítulo 1}

\section{Introdução}

\subsection{Iluminismo e Pensamento Econômico}

O movimento iluminista, que surge em fins do século XVII e se estende ao longo do século XVIII, ao priorizar o uso da razão frente à submissão aos princípios da religião, impele os teóricos a procurar as motivações dos acontecimentos. De acordo com Segal (2001), a doutrina da causalidade, proposta por Issac Newton (1643-1727), saciou a busca incansável pela objetividade da ciência, penetrando profundamente o modo de pensar da humanidade. Assim, é a concepção de realidade, emersa nesse período, que ajuda a explicar a necessidade intrínseca pela causa dos acontecimentos.

A doutrina da causalidade sugere que a evolução de todo sistema físico é controlada por leis rigorosas, através das quais os estados presente, passado e futuro podem ser determinados, uma vez conhecido seu ponto inicial. Essas leis são formuladas através da lógica dedutiva, sendo sempre corroboradas empiricamente. Nesse sentido, o mundo é concebido como uma grande máquina, na qual as ações e vontades humanas não interferem, mas cujo funcionamento cabe ao cientista decifrar. Para Segal (2001), nem mesmo as contribuições revolucionárias de Albert Einstein (1879-1955), associadas à teoria da relatividade e à mecânica quântica, dirimiriam a herança deixada nos cientistas modernos de que o mundo funcionaria como um "relógio gigante".

As novas perspectivas, vivenciadas no século XVIII, inserem-se em um contexto no qual observou-se na sociedade europeia um fortalecimento no reconhecimento de novos problemas centrais de identidade e ordem. Esses engendraram o aparecimento de novas teorias e métodos de reflexão, não apenas nas ciências ligadas à natureza, como apresentado acima, mas também naquelas voltadas ao social, como as teorias políticas, epistemológicas, econômicas, filosóficas, entre outras.

Sem minimizar a vastidão da transformação vivenciada nesse período, pode-se argumentar que o novo movimento esteve caracterizado pela presença de fundações reflexivas em suas teorias. Em termos específicos, a ideia era a de que os mecanismos geradores das leis também são regulados e baseados em leis. Por exemplo, as teorias econômicas se alicerçam em princípios econômicos de comportamento inerentes ao próprio agente. Além disso, e talvez mais importante, cabe ressaltar que essas novas teorias exibiam uma autonomia auto-referenciada, o que as levaram a reivindicar uma validade universal. 
A riqueza e profundidade do movimento iluminista europeu permearam os desenvolvimentos teóricos associados à compreensão da entidade social por muito tempo. Pode-se argumentar que essa influência esteve associada à concepção dos sistemas sociais a partir da identificação de funções, normas de ação e papéis para os entes sociais. A participação dos agentes dentro dos sistemas sociais seria definida por seus papéis, cuja competência para executá-los seria gerido por um sistema de funções. Cada agente, ao desempenhar sua função, contribui para organização do sistema, garantindo a estabilidade e equilíbrio do mesmo.

Um outro aspecto do movimento foi a busca pela crescente formalização dos conceitos e proposições. Conforme destacado em Ingrao e Israel (1990), capítulo 2, o rigor científico era muitas vezes confundido com a clareza e precisão que a caracterização matemática engendrava. $\mathrm{O}$ anseio de firmar as proposições sobre o ente social como ciência encontrou no processo de formalização uma via de acesso. Não estranhamente, ainda segundo os autores, é possível perceber uma tentativa de aproximação dos métodos de análise presentes no pensamento sociológico com aqueles inerentes em outros ramos do conhecimento, principalmente a física. A herança do movimento sobre os teóricos permeou a fronteira do tempo e dos ramos do conhecimento, encontrando solo fértil dentro do pensamento econômico.

Nos mais de cem anos que decorreram desde as primeiras publicações de Léon Walras (1834-1910), feitas entre 1874-77, até a presente data, a descrição da economia através de sistemas mecânicos, formalizados a partir da linguagem matemática, tem sido uma constante. Walras, com sua obra intitulada "Elementos da Economia Política Pura", foi o primeiro autor a dar uma forma analítica ao que cem anos antes Adam Smith havia denominado de a "mão invisível" da economia. Valendo-se de um sistema de equações matemáticas, o autor foi capaz de relacionar a atitude "egoísta" dos agentes econômicos com o estado de uma economia. Vilfredo Pareto (1848-1923), o sucessor de Walras na escola de Lausanne, avançou com o processo ao formalizar o comportamento e função dos agentes econômicos.

Hicks (1939) e Samuelson (1947) tiveram um papel fundamental na disseminação do reducionismo mecânico entre os economistas. As teorias do valor, que desde a revolução Marginalista de 1870 com Jevons, Menger e Walras já possuíam seus principais componentes delineados, ganham com esses autores precisão e coesão de fundamentos microeconômicos rigorosos. As modernas Teorias de Finanças, que emergem a partir de 1950 questionando o papel descritivo e institucional de seus antecessores, voltam-se para o formalismo de Hicks e Samuelson a fim de demostrarem um carácter científico e aceito pelos economistas. Os trabalhos de Markowitz (1952), Debreu (1959), Arrow (1964), Sharpe (1964) e Lintner 
(1965) estão entre as referências mais importantes nesse processo de transição da literatura de finanças.

Um dos temas centrais dessas modernas Teorias de Finanças torna-se a determinação do valor dos ativos financeiros. Dentre as distintas classes de literatura que surgem com o intuito de caracterizar o fenômeno dos preços, pode-se apresentar duas: aquelas que recorrem à modelagem do comportamento dos agentes econômicos, como exemplo Merton (1973a), Rubinstein (1976), Lucas (1978), Breeden (1979) e Grossman e Shiller (1981) e aquelas que têm no princípio da não arbitragem seu fundamento, tais como Black e Scholes (1973), Merton (1973b), Harrison e Kreps (1979) e Harrison e Pliska (1981).

A dinâmica evolutiva de uma parte da literatura do pensamento econômico, suscintamente referenciada acima, esteve intimamente associada a um processo crescente de reducionismo mecânico e formalização matemática. Mais especificamente, as principais contribuições teóricas sobre a determinação do valor se utilizaram, em maior ou menor grau, de caracterizações particulares de estados da economia, seja através do conceito de equilíbrio ou do princípio da não arbitragem. ${ }^{1} \mathrm{O}$ valor dos bens, ou o preço dos ativos financeiros, representa realizações específicas de um estado dos mercados de uma economia. O Capítulo 2 e Capítulo 3 buscam discorrer em mais detalhes sobre essas ideias. Enquanto o Capítulo 2 procura ilustrar a história da utilização desses conceitos pelas teorias do valor, o Capítulo 3 aborda a caracterização do princípio da não arbitragem, evidenciando sua relação com as equações de apreçamento de ativos.

\subsection{Epistemologia Construtivista e Hipóteses Precisas}

Se o equilíbrio se caracteriza por um ponto de solução de um sistema de equações, a não arbitragem está associada a unicidade das distribuições de probabilidade dos retornos futuros dos ativos. De um modo ou de outro, sob a utilização desses conceitos, está-se implicitamente supondo a ocorrência de estados particulares para os fenômenos econômicos e para a dinâmica de funcionamento dos mercados. Nessa acepção, uma economia está suscetível a múltiplos pontos de equilíbrio, contudo, dificilmente terá um conjunto contínuo de estados como tal. A estados particulares desse tipo denomina-se também de precisos. Assim, equilíbrio e a não arbitragem representam hipóteses precisas da teoria econômica.

O tratamento e verificação de hipóteses precisas engendram dificuldades tanto do ponto de vista da sua conceituação epistemológica quanto do instrumental analítico necessário para avaliá-la. Do ponto de vista da geração de conhecimento científico, para algumas abordagens, as hipótese precisas são consideradas implausíveis, conforme apresentado no argumento "It is rare, and perhaps impossible, to have a null hypothesis that

\footnotetext{
${ }^{1}$ Os leitores não familiarizados com a terminologia encontram essas e outras definições pontuais no
} 
can be exactly modeled as $\theta=\theta_{0}$ " (Berger e Delampady, 1987, pág. 320). Em muitos casos, o interesse do pesquisador acaba se voltando para a determinação das inter-relações presentes no sistema, e não na avaliação de uma realização específica da interação dos seus elementos.

Sob essa perspectiva, as proposições da epistemologia construtivista, originadas no trabalho de Maturana e Varela (1980), fornecem um respaldo teórico relevante. Valendo-se de conceitos como sistemas autopoiéticos e auto-soluções, as hipóteses precisas aparecem como uma condição natural do desenvolvimento científico. Sistemas autopoiéticos são recursivos, e a possibilidade de recorrência de estados internos da entidade os tornam sistemas inferenciais. No entanto, não se trata de previsões sobre eventos em particular, mas sobre um conjunto de interações, expressas na forma das auto-soluções.

Se as hipóteses precisas podem ser consideradas epistemologicamente coerentes, seu processo de verificação empírica não é trivial. Os métodos estatísticos tradicionais, por vezes, se valem de premissas ad hoc para tratá-las, uma vez que em espaços de probabilidade contínuos suas medidas são nulas. Inversamente, o Full Bayesian Significance Test, FBST, proposto por Pereira e Stern (1999 e 2001), foi especificamente desenvolvido para a verificação de hipóteses precisas. Concomitantemente, o teste exibe uma série de características estatísticas importantes, como a adequação ao Princípio da Verossimilhança e a propriedade de ser Full Bayesian. O tratamento e verificação de hipóteses precisas são apresentados em detalhes no Capítulo 4.

\subsection{ARBITRAGEM E VERIFICAÇÃo EMPÍRICA}

Do ponto de vista econômico, a hipótese delineada pelo princípio da não arbitragem para a caracterização dos mercados surge como uma condição natural do seu funcionamento. Por meio dessa estrutura, o Teorema Fundamental do Apreçamento de Ativos permite auferir um conjunto de implicações, não apenas sobre o comportamento estatístico dos preços, as denominadas densidades risco-neutras, mas também para a determinação de seu valor presente. Nesse sentido, ao se inverter a ordem da relação, é possível obter uma série de proposições teóricas sobre o fenômeno da não arbitragem a partir dos preços. Em particular, a unicidade das densidades estatísticas, que caracteriza o princípio da não arbitragem, pode ser transformada em uma hipótese de teste a ser verificada.

Baseando-se no modelo de apreçamento Variância Gama (VG) para ativos financeiros, as densidades risco-neutra são estimadas a partir de dados de mercado sobre os preços. Caracterizadas a partir da tríade de parâmetros $\sigma, v$ e $\mu$, os quais estão associados respectivamente com a volatilidade, curtose e assimetria da distribuição, a hipótese da não arbitragem pode ser expressa como $H:\left[\sigma_{a}, v_{a}, \mu_{a}\right]=\left[\sigma_{b}, v_{b}, \mu_{b}\right]$, na qual os subescritos visam 
indicar mercados distintos para um mesmo ativo financeiro. Sob essa proposição, diferenças estatisticamente significantes entre os parâmetros seriam um indicativo de oportunidades de arbitragem, dado que densidades distintas para um mesmo ativo engendrariam preços não homogêneos.

A fim de se verificar a existência de diferentes condições de mercado que permitam algum tipo vantagem econômica sem risco, isto é, a arbitragem, selecionou-se as opções sobre o Índice da Bolsa de Valores de São Paulo, denominado por Ibovespa, transacionadas no Segmento de Ações da BM\&FBovespa, mercado (a), e as opções sobre Futuro de Ibovespa operadas no Segmento de Derivativos da mesma instituição, mercado (b). Embora sejam dois ambientes distintos de negociação e que aparentemente referenciem-se a tipos de contratos diferentes, operam, em última instância, o mesmo ativo-objeto. Complementarmente, exibem outros atributos contratuais e de mercado que validam a proposta de comparação, tais como data de vencimento, tipo de exercício e a liquidez mais concentrada nos dois meses anteriores ao vencimento.

O principal instrumental estatístico aplicado na verificação das hipóteses é o FBST. No entanto, para fins de comparação, o teste da razão de verossimilhança também é exibido. A implementação dos testes utiliza informações dos negócios de opções de compra para três vencimentos distintos, Fev./2012, Abr./2012 e Jun./2012, perfazendo um total de 1.080 observações, agrupadas em blocos semanais. As informações foram cuidadosamente tratadas para se evitar interferência do processo de captura na aferição dos resultados, especialmente no que tange a sincronia temporal.

Os resultados de ambas as técnicas de teste evidenciam que em alguns períodos o comportamento dos investidores, traders, parece divergir entre os segmentos, sugerindo existirem condições temporárias para arbitrar. Intrigantemente, esses períodos tendem a ser marcados por uma tendência de baixa no mercado de seu ativo-objeto, o Ibovespa. Em particular, é possível observar uma mudança de regime entre os negócios que marcam o final de 2011 e primeiras semanas de 2012 e aqueles que ocorrem ao longo de 2012. O Capítulo 5 apresenta esses resultados, e toda a formulação estatística necessária para implementação do FBST. Por fim, no Capítulo 6 tecem-se as últimas considerações.

Sob essa ordenação de ideias dos capítulos, a tese defendida é a de que hipóteses precisas são epistemologicamente e empiricamente pertinentes dentro das teorias econômicas do valor ou preço dos ativos financeiros. Epistemologicamente, busca-se mostrar que a ocorrência de hipóteses precisas acompanhou a evolução das teorias econômicas do valor, principalmente no que tange aos modelos de apreçamento desenvolvidos nas modernas Teorias de Finanças, seja sob o conceito de equilíbrio, seja sob o princípio da não arbitragem 
6 INTRODUÇÃO

nos mercados. Empiricamente, é proposto mostrar que hipóteses precisas são suscetíveis de verificação, pois os conceitos que as definem possuem uma expressão matemática bem definida. 


\title{
Capítulo 2
}

\section{Teorias do Valor: Equilíbrio e Não Arbitragem}

\begin{abstract}
Whoever tries to take these apparently vague parallels between economic equilibrium theory and physics seriously and adopts a critical stance toward Arrow and Hahn's claim that there is no proof that the concept of economic equilibrium has its roots in analogy with mechanical equilibrium, finds himself confronted with a buried city. (Ingrao e Israel, 1990, prefácio).
\end{abstract}

Historicamente, os desenvolvimentos vivenciados nas teorias econômicas do valor nos últimos cem anos têm, em maior ou menor grau, se valido de conceitos como estado de equilíbrio, unicidade e estabilidade para caracterizar o fenômeno dos preços nas economias. Tais teorias de determinação do valor evoluíram e se transformaram ao longo do tempo. Contudo, não sucumbiu aos anos a hipótese de que os preços ou valores dos bens representam estados muito particulares dos mercados econômicos. Como apresentado na sequência, durante o período, toda uma formalização matemática e sistemática das teorias foi elaborada para acomodar e sustentar esses conceitos.

\subsection{Sistemas MecânICOS E TEORIAS ECONÔMICAS}

Com papel de destaque dentro da literatura da história do pensamento econômico, o trabalho de Adam Smith intitulado "A Riqueza da Nações", publicado em 1776, é considerado o marco inicial da Economia como ramo do conhecimento separado da filosofia. Nesse, é possível identificar as primeiras caracterizações formais, mas não analíticas, da concepção dos mercados como sistemas funcionais, regido por relações bem definidas entre seus elementos, os agentes econômicos, e entre estes e o todo, a própria economia. Em uma de suas ideias mais célebres, a da mão invisível, o autor propõem existir uma relação "misteriosa" entre a atitude egoísta dos indivíduos e a riqueza das nações, evidenciando a caracterização de aspectos funcionais de um possível sistema.

Léon Walras, com seu trabalho "Elementos da Economia Política Pura" de 1900, pode ser considerado o primeiro "economista" a efetivamente criar uma estrutura analítica para descrever o funcionamento das economias. ${ }^{2}$ Ele desenvolveu um modelo teórico para o equilíbrio geral das economias, utilizando-se da analogia entre o funcionamento de um sistema interdependente de mercados e o estado de equilíbrio em sistemas mecânicos. Por

\footnotetext{
${ }^{2}$ A data de 1900 marca a publicação da quarta e última edição do trabalho. Segundo Ingrao e Israel (1990), capítulo 3, a primeira publicação está datada entre os anos de 1874 e 1877.
} 
meio de sua teoria foi-se capaz de desvendar a mão invisível que relaciona a atitude dos agentes com o estado da economia. Em específico, Walras propôs uma completa integração entre as teorias da utilidade, que explicam o comportamento dos agentes, com a determinação geral de preços.

Um sucessor natural de Walras foi Vilfredo Pareto, conforme sugerido por Ingrao e Israel (1990), capítulo 5. De acordo com os autores, Pareto intensificou a analogia entre a teoria do equilíbrio geral das economias com o equilíbrio em sistemas mecânicos. Uma das contribuições mais importantes nesse sentido foi a tentativa de criar um lógica de atitude para os agentes econômicos,

From a correct historiographical perspective, Pareto's contribution to general equilibrium theory is to be regarded as the most explicit and consistent attempt to construct a rational mechanics of economic behavior on the model of the nineteenth-century physics and mathematics (Ingrao e Israel, 1990, pág. 115).

Com o intuito de ilustrar as estruturas desse sistema mecânico do equilíbrio geral das economias, considere a caracterização simples da economia na sequência. Inicialmente, suponha a existência de dois agentes econômicos, as firmas e os indivíduos, conceituados à época como produtores e consumidores. ${ }^{3}$ Nessa economia são transacionados " $n$ " bens, na qual $b=\left(b_{1}, b_{2}, \ldots, b_{n}\right)$ representa um vetor de quantidades e $S=\left(S_{1}, S_{2}, \ldots, S_{n}\right)$ o vetor de preços dos " $\mathrm{n}$ " bens. Além disso, seja $\omega=\left(\omega_{1}, \omega_{2}, \ldots, \omega_{n}\right)$ o vetor de disponibilidades na economia dos bens, de modo que $b_{g} \leq \omega_{g}$ para $g=\{1,2, \ldots, n\}$. Por fim, defina a existência de apenas um período de tempo. Em outros termos, os agentes econômicos interagem apenas uma única vez e decidem nessa data apenas a produção e o consumo dos demais períodos.

Seja "i" um consumidor representativo, $x_{i}=\left(x_{i, 1}, x_{i, 2}, \ldots, x_{i, n}\right)$ um potencial vetor de alocação/consumo deste indivíduo e $\omega_{i}=\left(\omega_{i, 1}, \omega_{i, 2}, \ldots, \omega_{i, n}\right)$ seus recursos iniciais. Se $w_{i}=S_{1} \omega_{i, 1}+S_{2} \omega_{i, 2}+, \ldots,+S_{n} \omega_{i, n}$, então $w_{i}$ representa a riqueza inicial do consumidor. Defina $U\left(x_{i}\right)$ como uma função que associa a cada vetor de alocação $x_{i}$ um valor real. A essa denomina-se Função Utilidade. Maximizando-se a Função Utilidade, sujeita a $\sum_{g} S_{g} \cdot x_{i, g} \leq w_{i}$ , determina-se o vetor ótimo de alocação a ser escolhido pelo indivíduo, $x_{i}^{*}$. Considerando a relação entre $x_{i}^{*}$ e $S$, é possível associar a demanda do consumidor aos preços relativos dos bens, denotada aqui por $d_{i}(S)=\left(d_{i, 1}(S), d_{i, 2}(S), \ldots, d_{i, n}(S)\right)$.

\footnotetext{
${ }^{3}$ A formalização apresentada na sequência está baseada em Ingrao e Israel (1990), capítulo 1.
} 
De modo análogo, a determinação da curva de oferta pode ser apresentada considerando o lado dos produtores. Seja “j” um produtor representativo e $y_{j}=\left(y_{j, 1}, y_{j, 2}, \ldots, y_{j, n}\right)$ um possível plano de produção dele. Defina $y_{j}=Q\left(b_{j}\right)$, na qual $Q$ é a Função de Produção, à qual estão associadas uma série de restrições tecnológicas que inibem que quaisquer quantias sejam produzidas. $\mathrm{O}$ produtor representativo busca maximizar os lucros associados com $\sum_{g} S_{g} \cdot y_{j, g}$, sujeito às restrições de tecnologia inerentes em $Q$. Assim estabelece a quantidade ótima a ser ofertada, $y_{j, g}^{*}$. No processo de otimização, os preços relativos são a variável chave, permitindo-se expressar a curva de oferta do produtor como função deste, $o_{j}(S)=\left(o_{j, 1}(S), o_{j, 2}(S), \ldots, o_{j, n}(S)\right)$.

Ao se agregar as curvas de demanda para todo "i" e as curvas de oferta para todo "j" obtém-se as curvas de demanda e oferta da economia para cada um dos "n" mercados, ou seja, $\quad d(S)=\left(d_{1}(S), d_{2}(S), \ldots, d_{n}(S)\right) \quad$ e $\quad o(S)=\left(o_{1}(S), o_{2}(S), \ldots, o_{n}(S)\right) \quad$. Definindo-se $e_{g}(S)=d_{g}(S)-o_{g}(S)-\omega_{g}$ como o excesso de demanda do mercado "g", é possível conceituar o equilíbrio geral dos mercados através do sistema de equações

$$
\begin{gathered}
e_{1}(S)=D_{1}(S)-O_{1}(S)-\omega_{1}=0 \\
e_{2}(S)=D_{2}(S)-O_{2}(S)-\omega_{2}=0 \\
\ldots \\
e_{n}(S)=D_{n}(S)-O_{n}(S)-\omega_{n}=0 .
\end{gathered}
$$

Em particular, o estado de equilíbrio da economia é condicionado à existência de um conjunto de preços $S=\left(S_{1}, S_{2}, \ldots, S_{n}\right)$ tal que não exista excesso de demanda em nenhum mercado.

Além da questão relacionada com a existência do equilíbrio, um outro aspecto relevante é a sua estabilidade, isto é, a ocorrência de forças naturais da economia que a fazem convergir para este estado. A esse processo de convergência Walras denominou tâtonnement. A ideia pode ser representada na figura de um leiloeiro central, o qual captura os dados de produção e consumo de todos, avalia os excessos de demanda e devolve informações para os agentes econômicos sobre o estado ou não de equilíbrio. Nesse processo, o leiloeiro conta com as forças naturais do mercado para que, em caso de não equilíbrio, a estrutura de preços relativos seja alterada, e um novo processo de verificação do equilíbrio da economia seja executado. A principal dessas forças é a lei da oferta e da demanda, a qual promoveria redução relativa de preços nos bens em que $e_{g}(S)<0$ e aumento no caso de $e_{g}(S)>0$.

Do exposto acima fica evidente o mecanicismo da caracterização da economia, desde o processo decisório dos agentes econômicos até a coordenação e respectivas correções 
promovidas pelo leiloeiro central. Embora de maneira não harmônica e sequencial na literatura econômica, sob essa abordagem a "mão invisível" de Adam Smith desaparece, sendo convertida em uma estrutura funcional bem definida para o comportamento dos agentes econômicos e a relação entres eles. O estado de equilíbrio de uma economia e sua estabilidade podem agora ser avaliados sob a ótica do rigor matemático que os definem.

Hicks (1939) e Samuelson (1947) são duas importantes referências não só para a continuidade das ideias de Walras e Pareto, mas também porque foi graças a eles que a formalização matemática e sistêmica das teorias do equilíbrio geral passam a ganhar espaço dentro dos trabalhos dos economistas. Nas palavras do próprio Hicks, argumentando a respeito de seu trabalho "Valor e Capital" de 1939,

In the first (static) half I had taken the general equilibrium system of Walras and Pareto, and had reformulated it so that it could be used for purposes of comparative statics. That is to say, having exhibited the pricesystem as determined by tastes, resources and technology, through the equations of demand and supply on the various markets, I supposed a change of data which upset some of these equations, and enquired what changes in prices would then be necessary to restore equilibrium. (Hicks, 1959, pág. 159).

Em particular, Hicks buscou, através de um refinamento das formulações de Walras e Pareto, relacionar a teoria do valor, ou dos preços relativos, com potenciais realizações dos estados da economia expressas pela teoria do equilíbrio geral.

Embora os objetivos de Samuelson (1947) fossem mais ambiciosos do que a simples reformulação da teoria do valor, a sinergia entre esta e a proposição de se definir as bases da economia em termos de modelos matemáticos formais parece ter sido relevante. A teoria do valor sempre ocupou um papel de destaque na literatura econômica, de modo que uma formalização de sucesso neste tema facilitaria o avanço para outras áreas. Sob a ótica da teoria do valor, o refinamento na caracterização da economia através de um sistema de equações permitia aprofundar as implicações sobre o estado de equilíbrio, conceito fundamental para a determinação dos preços relativos. Nessa acepção, é possível argumentar que as teorias de apreçamento de ativos que passam a surgir nas modernas Teorias de Finanças tiveram influência direta dos desenvolvimentos vivenciados na microeconomia entre as décadas de 1930 e 1940.

\subsection{Modernas TeOrias de FinanÇAS}

As teorias nascidas a partir da década de 1950 para explicar a alocação e utilização de recursos ao longo do tempo pelos agentes econômicos deram origem ao que hoje se denomina modernas Teorias de Finanças. De acordo com Merton (1998), prefácio, foi com a literatura desse período que finanças deixou de ser apenas uma disciplina descritiva com foco em assuntos institucionais e legais, passando ao posto de uma teoria econômica rigorosa sujeita à 
validação empírica. Dentre os principais contribuintes dessa nova proposta estão autores como Arrow, Debreu, Lintner, Markowitz, Miller, Modigliani, Sharpe e Tobin.

De um modo geral, pode-se sugerir que o deslocamento da literatura prévia de finanças foi acompanhado de uma certa aproximação com o tipo de modelagem feita nas ciências econômicas para explicar o comportamento dos indivíduos e das firmas, os quais já vinham se estruturando com os trabalhos de autores como Walras, Pareto, Hicks, Samuelson mencionados na seção anterior. Desse modo, assim como a modelagem microeconômica mencionada, também faziam parte dos estudos conduzidos nas modernas Teorias de Finanças a formalização do comportamento dos agentes econômicos. No entanto, um enfoque particular passou a ser dado a um terceiro tipo de agente, os intermediários financeiros e, respectivamente, ao mercado no qual estes transacionavam suas mercadorias, o mercado de capitais.

Embora de suma importância, o estudo e modelagem do comportamento de cada um desses agentes fogem ao escopo do presente trabalho. Em específico, para os fins propostos, o interesse recaí apenas sobre os indivíduos, e o respectivo entendimento de como a atuação destes no mercado de capitais acaba por determinar os preços dos ativos nele transacionados. De forma ilustrativa, mas não exaustiva, é nesse mercado que recursos dos indivíduos são direcionados para as firmas poderem financiar seus investimento, que estas últimas estimulam o consumo com o partilhamento dos ganhos com os consumidores, ou ainda que os intermediários financeiros se financiam para poderem prestar seus serviços.

No processo de transição da literatura de finanças os trabalhos de Debreu (1959) e Arrow (1964) merecem destaque, cujas bases foram estruturadas em Arrow e Debreu (1954). ${ }^{4}$ Sem abandonar os princípios da modelagem microeconômica, os autores introduzem no contexto a noção da incerteza, passando a caracterizar o estado de equilíbrio diante destas condições. Em outros termos, a formalização matemática da alocação ótima acontece no nível dos agentes econômicos, especialmente os indivíduos, os quais agora se deparam com a existência de um ativo primitivo que paga $\$ 1$ em um dado estado da economia e nada nos demais. A incerteza assume a forma de potenciais ocorrência de estados da natureza, com os quais os agentes interagem atribuindo diferentes medidas subjetivas de probabilidade para elas. Incerteza passa a ser o atributo necessário para caracterizar o risco no mercado de capitais.

Sharpe (1964) e Lintner (1965) propuseram estender os modelos microeconômicos de alocação ótima do portfolio dos indivíduos investidores, formulando teorias que

\footnotetext{
${ }^{4}$ Embora as ideias de Arrow se difundissem apenas com publicação de 1964, ele já havia formalizado suas proposta deste o início da década de 50 com "Le Role des Valeurs Boursieres pour la Repartition la Meilleure des Risques," International Colloquiumon Econometrics, 1952
} 
determinassem, a partir do comportamento destes agentes, implicações sobre o apreçamento dos ativos sob condições de existência de equilíbrio com risco. O primeiro passo nesse sentido foi a suposição de uma função utilidade, a partir da qual os agentes investidores baseassem suas atitudes. Essa dependeria do retorno esperado e desvio-padrão dos portfólios sujeitos à aplicação de recursos, $U=f\left(E_{R}, \sigma_{R}\right)$. Além disso, supõe-se que $d f / d E_{R}>0$ e $d f / d \sigma_{R}<0$, implicando que, para um dado valor da função utilidade, existe uma relação positiva entre $E_{R}$ e $\sigma_{R}$.

O uso da esperança matemática e o desvio-padrão como variáveis a serem observadas pelo investidor na decisão da alocação de seu portfólio não é uma inovação proposta pelos autores, mas já havia sido sugerida desde a publicação de "Portfolio Selection" por Markowitz em 1952. Em termos da história do pensamento econômico, é possível argumentar que o autor é o grande precursor das ideias presentes em Sharpe e Lintner de que o risco impacta o valor dos ativos. O elemento central do trabalho de Markowitz é o de que risco não se resume apenas a variância, mas também a covariância entre os ativos. Dessa maneira, não apenas o retorno esperado, como a própria diversificação de ativos devem ser atributos presentes na decisão do indivíduo, conforme detalhado na sequência.

Considerando complementarmente a hipótese de que todos os investidores podem emprestar e tomar emprestado a uma dada taxa livre de risco sem modificá-la e, além disto, de que os mesmos possuem expectativas homogêneas sobre $E_{R}$ e $\sigma_{R}$, Sharpe (1964) formula uma das primeiras teorias analíticas sobre equilíbrio no mercado de capitais. No entanto, seguindo a tradição das abordagens microeconômicas, utiliza-se das forças de mercado para a obtenção do equilíbrio. Em particular, a lei da oferta e demanda é aplicada a fim de garantir uma relação positiva de estabilidade entre $E_{R}$ e $\sigma_{R}$, implicando que ativos mais arriscados devem remunerar mais, em média. À formalização de tal relação denominou-se curva do mercado de capitais.

Sobre essa curva se localizariam os portfólios de menor volatilidade e, principalmente, o portfólio de mercado, aquele que, para qualquer modificação no processo de diversificação, resultaria em uma elevação no seu risco ou redução no seu retorno esperado. Nesse sentido, quaisquer potenciais alterações no seu retorno seriam provenientes apenas das realizações dos estados da natureza, não estando elas sujeitas à modificação via diversificação. Por essa razão, a esse tipo de risco não mitigável denomina-se risco sistêmico, enquanto que seu resíduo é conceituado como risco específico. 
Esses últimos aspectos engendram a ideia de que o risco de um portfólio não deve ser medido por si só, ou seja, por sua volatilidade, mas sim por sua dependência em relação às potenciais realizações de estados da natureza, isto é, o risco sistêmico. Em termos algébricos, com alguma modificação na notação dos autores, a relação entre retorno esperado de um portfólio e seu risco pode ser expressa como

$$
E_{R i}=R_{f}+\beta_{i}\left(E_{R m}-R_{f}\right)
$$

na qual $E_{R i}$ é a esperança do retorno do portfólio “i”, $R_{f}$ é o retorno do ativo livre de risco, $E_{R m}$ é a esperança do retorno do portfólio de mercado e $\beta_{i}=\operatorname{COV}(R i, R m) / V A R(R m)$. Dado a relação direta entre preço e retorno, as implicações sobre o último foram logo transformadas em propostas sobre o valor dos ativos, ficando o modelo conhecido contemporaneamente como Capital Asset Pricing Model (CAPM).

O modelo CAPM rapidamente ganhou espaço na literatura teórica e aplicada de finanças. A busca por generalizações e aprimoramentos das propostas impulsionou o desenvolvimento desta área do conhecimento. Dentre as abordagens, destaque para a modelagem do ICAPM, Intertemporal Capital Asset Pricing Model. Apresentada por Merton em 1973, o modelo busca superar a premissa de decisão estática do investidor inerente ao CAPM, adicionando no processo de escolha a dinâmica intertemporal. Por ação dessas novas bases, não apenas o lado da demanda do investidor precisa ser modelado, mas também a oferta dos ativos. Em outros termos, o indivíduo decide investir considerando a própria dinâmica de evolução do conjunto potencial de ativos. Outra inovação advinda do ICAPM é a incorporação do consumo no processo decisório do indivíduo, ainda que de modo introdutório. Contudo, supera a hipótese implícita do CAPM de que consumo é resíduo da alocação da riqueza.

Valendo-se da hipótese de negociação contínua no tempo, Merton utiliza-se dos desenvolvimentos contemporâneos ao seu trabalho e propõe que a taxa de retorno dos ativos segue um processo de Itô, $d S_{t} / S_{t}=\mu_{t} d t+\sigma_{t} d B_{t}$, no qual $\mu_{t}$ e $\sigma_{t}$ são denominados respectivamente drift e diffusion do processo, $B_{t}$ é um movimento Browniano padrão, cuja formalização estatística será apresentada na sequência do trabalho. Do ponto de vista da escolha do investidor, a evolução dos preços dos ativos é relevante, pois impacta diretamente o seu nível de riqueza $W$. Em termos específicos, $d W=\sum_{i} w_{i} \cdot W \cdot d S_{t} / S_{t}+(y-c) \cdot d t$, na qual $w_{i}$ é a parcela investida no ativo "i", "y" é o salário e "c" é o gasto com consumo.

Além das hipóteses sobre o padrão evolutivo dos preços dos ativos, Merton (1973a) também elenca uma série de outras premissas sobre a caracterização do mercado e do 
comportamento do investidor, assim como havia sido feito por Sharpe em 1964. Sob essas definem-se a estrutura de um mercado perfeito, assim como uma Função Utilidade coerente para determinação do consumo do indivíduo, inputs para a formalização do processo decisório do investidor. De modo preciso, com essas premissas, um indivíduo genérico " $\mathrm{k}$ " busca maximizar a esperança matemática do seu fluxo de consumo e de sua riqueza momentânea até o fim do seus dias,

$$
\max _{\{c, w\}} E\left[\int_{0}^{T^{k}} U^{k}\left(c^{k}(s), s\right) \cdot d s+R^{k}\left(W^{k}\left(T^{k}\right), T^{k}\right)\right]
$$

na qual $U^{k}$ é a Função Utilidade do Consumo estritamente côncava, $c^{k}(t)$ é o consumo instantâneo no período " $\mathrm{t}$ ", $R^{k}$ é a Função Utilidade da Riqueza estritamente côncava e $W^{k}\left(T^{k}\right)$ é o estado da riqueza no último período a ser considerado, $T^{k}$.

Resolvendo o processo de otimização, o autor consegue determinar a função demanda do ativo "i" para cada período de tempo considerada por um $k$-ésimo investidor genérico. Tal função é dada por $d_{i}^{k}=A^{k} \sum_{j} v_{i, j}\left(\mu_{j}-r\right)+H^{k} \sum_{j} v_{i, j} \cdot \sigma_{j, r}$, na qual $v_{i, j}$ é uma função da correlação entre o ativo "i” e o “j”, $\sigma_{j, r}$ está relacionada com a covariância entre o ativo “j” e o ativo livre de risco "r" e $A^{k}$ e $H^{k}$ são respectivamente parâmetros associados à aversão ao risco do investidor e à sensibilidade frente às oportunidades de investimento. De uma maneira genérica, o termo $A^{k} \sum_{j} v_{i, j}\left(\mu_{j}-r\right)$ indica que a demanda do ativo "i" depende de sua correlação com o excesso de retorno dos demais ativos, tal como apresentado em Sharpe (1964). Por outro lado, $H^{k} \sum_{j} v_{i, j} \cdot \sigma_{j, r}$ implica que a demanda do ativo "i”" varia de acordo com sua relação com as oportunidades de investimento, as quais dependem de "r".

Até o presente momento apresentou a formalização do lado da demanda de um investidor, a qual quando agregada perfaz a demanda da economia para um dado ativo "i", $D_{i}=\sum_{k} d_{i}^{k}$. No entanto, no modelo de equilíbrio desenvolvido por Merton é necessário avaliar-se o lado da oferta, a qual de forma resumida pode ser expressa como $d M_{i}=N_{i} \cdot d P_{i}+d N_{i}\left(P_{i}+d P_{i}\right)$, na qual $M_{i}=N_{i} \cdot P_{i}$ representa o valor total dos ativos do mercado "i", com preço $P_{i}$ e quantidade $N_{i}$. O primeiro termo da formulação indica que o valor ofertado dos ativos cresce com seu preço, enquanto que a segunda com o aumento em sua emissão.

Considerando a premissa de que em equilíbrio a oferta para um dado ativo "i" deve igualar a sua demanda, implicação válida para todos os mercados, o autor deriva a relação de equilíbrio entre o retorno esperado de um ativo "i” e o seu risco, dada por 


$$
\mu_{i}-r=\frac{\sigma_{i}\left[\rho_{i M}-\rho_{i n} \rho_{n M}\right]}{\sigma_{M}\left(1-\rho_{n M}^{2}\right)} \cdot\left(\mu_{M}-r\right)+\frac{\sigma_{i}\left[\rho_{i n}-\rho_{i M} \rho_{n M}\right]}{\sigma_{n}\left(1-\rho_{n M}^{2}\right)} \cdot\left(\mu_{n}-r\right),
$$

na qual $\mu_{i}$ é o retorno esperado instantâneo do ativo "i”, $\rho_{i M}$ é a correlação entre o retorno do ativo "i” e do portfólio $M$ e $\sigma_{i}$ é a volatilidade do ativo "i”. As demais variáveis seguem os mesmos padrões de definição do ativo "i”, com a conceituação que $M$ representa o portfólio de mercado e " $\mathrm{n}$ " um portfólio negativa e perfeitamente correlacionado com a taxa livre de risco " $r$ ". Assim como a função demanda do investidor, a relação de equilíbrio para o retorno esperado de um ativo e seu risco é uma composição de duas parcelas: uma primeira associada com o risco sistemático, expresso pelo portfólio de mercado $M$ e; uma segunda relativa às oportunidades potenciais de investimento, expressa pelo portfólio " $\mathrm{n}$ ".

O modelo ICAPM, ao introduzir a dinâmica temporal na decisão de consumo e poupança do investidor, lançou as bases para uma novo ramo da literatura de finanças sobre comportamento do agente econômico e a valoração de ativos, os Modelos de Equilíbrio Intertemporal. Esses modelos aparecem com a proposta de tornar mais real a caracterização da economia, trabalhando com múltiplos bens de consumo, com a determinação endógena da taxa livre de risco e, principalmente, com a capacidade de prever mudanças na relação entre o retorno de um ativo e seus riscos associados.

Dentre essas abordagens, uma apareceu na sequência do ICAPM, o Consumption Capital Asset Pricing Model, CCAPM. Fruto dos trabalhos de Rubinstein (1976), Lucas (1978), Breeden (1979) e Grossman e Shiller (1981), o CCAPM propõe a determinação de uma função demanda de consumo agregada, relacionando-a com o que na teoria se denomina fator estocástico de desconto. Outras abordagens também se observaram nas décadas seguintes, com destaque aos trabalhos de Weil (1989), Epistein e Zin (1991), Campbell (1993), Campbell e Cochrane (1999), Yogo (2006) entre muitos outros relevantes. Para uma visão evolutiva dessas abordagens vide Merton (1998).

\subsection{Teorias de ApreÇamento: Não Arbitragem}

A tentativa de formalização de uma equação para a determinação dos retornos dos ativos representa uma parcela importante dos esforços da literatura das modernas Teorias de Finanças, os quais, conforme apresentado na seção anterior, evoluíram dinamicamente desde suas propostas iniciais. Ao longo desse período, a busca por sanar as dificuldades empíricas dos modelos gerou um processo de caracterização dos mesmos cada vez mais próximo dos reais procedimentos de escolha intertemporal de um agente econômico investidor e consumidor. 
Amparados pela premissa de equilíbrio nos mercados e pela lei da oferta e da demanda, por ação desses modelos foi-se capaz de estabelecer uma série de proposições sobre a valorização dos ativos. O retorno esperado de um ativo é a taxa de desconto que deve ser aplicada ao seu valor final de modo a obter-se o seu valor presente. Nessa relação, diferentes caracterizações do processo decisório do agente econômico, através da função consumo e da função de alocação da riqueza, criam implicações distintas para o retorno esperado e, consequentemente, para a determinação dos preços dos ativos.

Uma classe diferente de literatura nas modernas Teorias de Finanças tem seus marcos nos trabalhos de Black e Scholes (1973) e Merton (1973b). Distintamente dos estudos anteriormente referenciados, a literatura que passa a se desenvolver por meio dessas bases tem na noção da arbitragem um dos seus conceitos fundamentais. Embora compatível com a literatura baseada na modelagem do processo de decisão do agente econômico, a noção de arbitragem, ou mais precisamente sua ausência ou não existência, é por si só suficiente para estruturar um sistema único de apreçamento de ativos, as vezes também denominado de lei de um preço só.

Sob tal classe de literatura, o elemento essencial reside no fato de que dos ativos que possuem a mesma estrutura de valor futuro não podem possuir diferentes preços no presente. Em outros termos, ativos que pagam o mesmo valor financeiro no futuro devem ter o mesmo preço hoje. Desse modo, independentemente da caracterização da estrutura do processo decisório do agente econômico, função consumo e investimento, é possível estabelecer o valor presente dos ativos. O retorno esperado de cada ativo exigido pelo investidor deixa ter relevância. Contudo, a lei da oferta e demanda e, consequentemente, a noção de equilíbrio nos mercados, não é abandonada uma vez que é através desta que os preços dos ativos convergem para um único valor.

Com o intuito de ilustrar as bases do conceito, considera-se a formulação da equação de apreçamento desenvolvida por Black e Scholes (1973) para a valorização de opções de compra europeias sobre ações. A opção é um produto financeiro que dá ao seu detentor um direito. Se é uma opção de compra, o direito é o de adquirir o objeto de negociação a um determinado preço. Se é uma opção de venda, esse direito é de venda. Diz-se que a opção é europeia se o direito só pode ser exercido em uma data acordada, a data de vencimento. As opções fazem parte de uma classe de produtos financeiros denominada derivativos, visto que seus preços podem ser derivados de um ativo subjacente ao qual o produto está vinculado, no presente caso uma ação.

Coerentemente com os estudos de Merton (1973a) e Merton (1973b), Black e Scholes (1973) estabelecem uma série de premissas de modo a criar condições ideais de 
funcionamento dos mercados. Diante da hipótese de contínua ocorrência dos negócios, os autores introduzem um caso complementar do processo de Itô para descrever o comportamento dos preços dos ativos, o modelo Geométrico Browniano, dado por $d S_{t}=S_{t} \mu d t+S_{t} \sigma d B_{t}$, no qual $\mu$ e $\sigma$ representam agora o drift e diffusion fixos do processo e $B_{t}$ é um movimento Browniano padrão.

Sejam $S, c$ e $c_{s}$ respectivamente o preço da ação, o preço da opção e a primeira derivada do preço da opção com relação ao preço da ação. Considere uma carteira formada por uma ação e $-1 / c_{s}$ opção, na qual o sinal negativo indica uma posição lançadora. Suponha um variação $\Delta S$, a qual para uma aproximação de primeira ordem implica $c_{s} \cdot \Delta S$ no valor da opção. ${ }^{5}$ Sob essa ótica, a carteira de valor $S-1 / c_{s} \cdot c$ possui variação nula para pequenas alterações $\Delta S$, podendo argumentar-se que é uma carteira sem risco. Desse modo, foi-se capaz de sintetizar um investimento em um ativo sem risco através de uma carteira de ação e opção.

A fim de se determinar a equação de apreçamento da opção torna-se necessário ser mais preciso em relação a sua potencial variação de preço, $\Delta c$, incorporando não apenas $\Delta S$, mas também a variação no tempo, $\Delta t$. Utilizando-se dos métodos do cálculo estocástico, é possível expandir $\Delta c=c(S+\Delta S, t+\Delta t)-c(S, t) \quad, \quad$ quando $\quad \Delta t \rightarrow 0 \quad, \quad$ como $\Delta c=c_{s} \cdot \Delta S+1 / 2 \cdot c_{s, s} \cdot S^{2} \cdot \sigma_{s}^{2} \cdot \Delta t+c_{t} \cdot \Delta t$, na qual os subescritos indicam as derivadas com relação as respectivas variáveis e $\sigma_{s}^{2}$ é a variância da taxa de retorno de $S$. Sob essa expansão, a variação no valor do portfólio da ação mais a opção é dada por

$$
\Delta S-\frac{1}{c_{s}} \cdot \Delta c=-\left(\frac{1}{2} c_{s, s} \cdot S^{2} \cdot \sigma_{s}^{2}+c_{t}\right) \frac{\Delta t}{c_{s}} .
$$

Valendo-se da constatação de que o portfólio é livre de risco para pequenas variações de $S$, torna-se possível estabelecer uma equivalência entre a variação no valor do portfólio e aquela inerente da aplicação em um ativo sem risco quando $\Delta t \rightarrow 0$. Em particular tem-se que

$$
-\left(\frac{1}{2} c_{s, s} \cdot S^{2} \cdot \sigma_{s}^{2}+c_{t}\right) \frac{\Delta t}{c_{s}}=\left(S-\frac{1}{c_{s}} c\right) \cdot r \Delta t
$$

a partir da qual simplificando $\Delta t$ e rearranjando os termos obtém-se a equação diferencial estocástica dada por

\footnotetext{
${ }^{5}$ Aqui, e na sequência, novamente o subescrito referente ao tempo será omitido de modo a facilitar o entendimento e permanecer o mais fiel a notação dos autores. Assim, $\Delta S=\left(S_{t+\Delta t}-S_{t}\right)$.
} 


$$
c_{t}=r \cdot c-r \cdot S \cdot c_{s}-\frac{1}{2} c_{s, s} \cdot S^{2} \cdot \sigma_{s}^{2}
$$

Na data de vencimento, $T$, uma opção de compra vale $c(S, T)=S-K$ se $S>K$ e $c(S, T)=0$ se $S \leq K$, na qual $K$ representa o valor acordado para a aquisição da ação. Com essas condições de contorno, ao se resolver a equação diferencial estocástica determina-se a fórmula de apreçamento de opções de Black e Scholes, dada por

$$
c(S, t)=S \cdot N(d 1)-K \cdot N(d 2) \cdot \exp (-r(T-t))
$$

com $N(\cdot)$ representando a densidade acumulada de uma distribuição Gaussiana com média 0 e variância 1 e

$$
d 1=\frac{\ln (S / K)+\left(r+\sigma_{s}^{2} / 2\right) \cdot(T-t)}{\sigma \cdot \sqrt{(T-t)}} \text { e } d 2=d 1-\sigma_{s}^{2} \cdot(T-t)
$$

Embora Black e Scholes (1973) e Merton (1973b) tenham utilizado a premissa da não arbitragem para valorização de opções, dado sua generalidade, o método foi rapidamente estendido para outros derivativos financeiros, tornando-se reconhecido não apenas no âmbito acadêmico, mas também na indústria financeira. No final da década de 1970 e início da 1980, com os trabalhos de Harrison e Kreps (1979) e Harrison e Pliska (1981), estabeleceram-se as diretrizes finais para a estruturação de toda uma teoria de apreçamento de ativos alicerçada na noção de não arbitragem e em movimentos de martingal para os preços, descrito em detalhes na sequência do trabalho.

Argumentos de importantes autores existem na literatura evidenciando que os pilares das modernas Teorias de Finanças foram estabelecidos nos 30 anos que se estendem do início de 1950 até final da década de 1970. Nas palavras de Darrel Duffie

The period since 1979, with relatively few exceptions, has been a mopping- up operation. On the theoretical side, assumptions have been weakened, there have been noteworthy extensions and illustrative models, and the various problems have become much more unified under the umbrella of the Harrison-Kreps model. On the applied side, markets have experienced an explosion of new valuation techniques, hedging applications, and security innovation, much of this based on the BlackScholes and related arbitrage models. (Duffie, 2001, prefácio).

Ao longo do período as proposições sobre a valoração ou apreçamento dos ativos financeiros, sejam baseadas nos modelos de decisão intertemporal dos agentes econômicos ou na premissa da não arbitragem, foram formuladas sob condições particulares de funcionamento dos mercados. A lei da oferta e da demanda surge como mecanismo auxiliar para dirimir desajustes dos mercados, garantindo que as condições se perpetuassem. Sob essa concepção, os preços dos ativos são realizações particulares de estados dos mercados, associados à validade de precisas hipóteses nas teorias econômicas. 


\title{
Capítulo 3
}

\section{Teorias de Apreçamento de Derivativos: Não Arbitragem}

\begin{abstract}
The pricing of options, warrants, and other derivative securities - financial securities whose payoffs depend on prices of other securities - is one of the great successes of modern financial economics. Based on the wellknown Law of One Price or no-arbitrage condition, the option pricing models of Black and Scholes (1973) and Merton (1973b) gained an almost immediate acceptance among academics and investment professionals that is unparalleled in the history of economic science. (Campbell et al., 1997, pág. 339)
\end{abstract}

O conceito de arbitragem, ou mais propriamente a sua não ocorrência, exerce uma papel fundamental dentro das teorias de finanças. Em linhas gerais, isso se deve pois em mercados sem arbitragem é possível garantir a existência de uma variável aleatória $\pi$ tal que quando aplicada à estrutura de payoff de um ativo fornece o preço atual do mesmo. Algebricamente, para um dado ativo "i” tem-se $S_{i}=E\left[\pi \delta_{i}\right]$, na qual $\delta_{i}$ representa a variável estocástica payoff do ativo “i” e $S_{i}$ o respectivo preço. Esse mecanismo é as vezes denominado de apreçamento pelo princípio da não arbitragem.

Do ponto de vista da aplicação prática o conceito da não arbitragem é atributo simples, e até certo ponto intuitivo quando pensado em relação ao comportamento subjacente do homo economicus. Afinal, uma definição informal de arbitragem é a possibilidade de obter um ganho financeiro sem incorrer em riscos e dispêndio líquido de capital. Não obstante, o conceito permeia as teorias econômicas desde seus primórdios.

O princípio da não arbitragem consiste essencialmente do fato de que ativos ou portfólios com a mesma estrutura de payoff não podem possuir diferentes valores no momento presente. Como um exemplo simplório, tome o mercado de futuro de moeda BRL. Se a cotação do BRL/USD negociada na BM\&FBovespa (Brasil) e na CME (USA) diferirem, eximindo-se dos custos de transação e barreira legais, os agentes econômicos seriam estimulados a comprar BRL no mercado com menor preço e revendê-lo no mercado com maior. Com esse processo, haveria um ajuste nos mercados e rapidamente a possibilidade de obtenção de uma vantagem econômica sem risco seria extinta. Como um segundo exemplo considere o caso de uma opção europeia sobre uma ação. Sua estrutura de payoff pode ser replicada por um portfólio contendo um título de renda fixa e a ação objeto de negociação da 
opção. Desse modo, pelo princípio da não arbitragem é esperado que o valor presente da opção seja idêntico ao valor do portfólio.

Tanto o futuro de moeda quanto a opção sobre ação fazem parte da classe de produtos financeiros denominada "derivativos". Conforme apontado acima, os derivativos são produtos cuja estrutura de payoff depende do preço dos ativos do qual ele é derivado. Dado essa característica e os exemplos motivacionais expostos anteriormente, torna-se possível argumentar que o princípio da não arbitragem também engendra as condições para a determinação do preço nessa classe de produtos financeiros. Assim, o princípio valeria para ativos e derivativos.

Cochrane (2001) destaca que, distintamente das demais teorias de apreçamento, um dos benefícios da hipótese de não arbitragem nos mercados é que não se faz necessário pressupostos complementares para se derivar as equações dos preços dos ativos. Em específico, não se precisa delinear conjecturas sobre a função utilidade dos agentes, a agregação e representatividade dos mesmos, sobre a completude dos mercados entre outros. O ponto central é que os agentes se comportem segundo as leis da não arbitragem nos mercados.

Nesse sentido, no caso do apreçamento baseado no princípio da não arbitragem, o interesse recaí sobre a avaliação das condições que garantem este fenômeno. Uma das condições necessárias é a existência de distribuições estatísticas que tornam o movimento dos preços processos de martingal. ${ }^{6}$ Para tanto, faz-se necessário que os parâmetros que governam o movimento dos preços, conhecidos, por exemplo, como drift e diffusion no caso dos processos de Itô, engendrem essa condição de martingalidade.

Essa relação entre não arbitragem e processos de martingal deu origem ao que nas finanças modernas se conhece como Teorema Fundamental do Apreçamento de Ativos. Conforme apontado em Delbaen e Shachermayer (2006), prefácio, o teorema estabelece que em um modelo matemático de finanças o princípio de não arbitragem vale se e somente se existe uma medida equivalente de probabilidade que tornem os preços processos de martingal. Segundo os autores essa relação abriu um vasto campo para a aplicação da matemática e da integração estocástica na teoria das finanças, cuja força motriz nas últimas décadas tem sido converter esses princípios gerais em teoremas precisos. ${ }^{7}$

\footnotetext{
${ }^{6}$ Como visto no primeiro parágrafo, e desenvolvido na sequência do capítulo, através da não arbitragem as equações de preços tornam-se esperanças estatísticas. Assim, para essas teorias inexiste o termo de erro das equações de apreçamento tais como do modelo CAPM ou APT.

${ }^{7}$ A linha mestra de desenvolvimento do capítulo está baseada em Harrison e Pliska (1981) e Duffie (2001). Para uma abordagem matemática mais geral vide Delbaen e Shachermayer (2006).
} 


\subsection{Incerteza, Preços e Estratégias}

A construção de uma teoria de apreçamento de ativos, seja esta baseada nos princípios da não arbitragem ou em outras hipóteses complementares, exige de maneira mais ou menos explícita a introdução da incerteza nas suas formulações. No que tangem aquelas baseadas no princípio da não arbitragem, essa incorporação da incerteza toma a forma da definição de um espaço de probabilidade filtrado $\left(\Omega, \mathfrak{I},\left(\mathfrak{I}_{t}\right)_{t \in \mathbf{T}}, P\right)$.

Nesse espaço $\Omega$ representa o conjunto de todos os possíveis estados da natureza $\omega_{s}$ ao longo do tempo. $\Im$ expressa a sigma-álgebra desses estados. Por sua vez, $\left(\Im_{t}\right)_{t \in \mathbf{T}}$ é uma filtração formada por sigma-álgebras crescentes de $\mathfrak{I}$ para todo $t \in \mathbf{T}$, no qual $\mathbf{T}$ representa o conjunto das datas dos negócios. A filtração expressa o conjunto da informação disponível na data " $\mathrm{t}$ ", gerada não apenas pelo estado atual dos preços, mas por todo os insumos necessários para a tomada de decisão dos agentes.

Um ativo negociado nessa estrutura tem seus preços definidos a partir de um processo estocástico, $S: \mathbf{T} \times \Omega \rightarrow \Re$. Como exemplo, tome o preço $S$ como seguindo um processo de Itô, em cuja forma algébrica assume

$$
S_{t}=x_{0}+\int_{s=0}^{t} \mu_{s} d s+\int_{s=0}^{t} \sigma_{s} d B_{s}
$$

na qual $t \in \mathbf{T}, x_{0}$ é um número real, $\int_{s=0}^{t} \sigma_{s}^{2} d s<\infty, \int_{s=0}^{t}\left|\mu_{s}\right| d s<\infty$ e $B_{t}$ é um movimento Browniano padrão também caracterizado no espaço $\left(\Omega, \mathfrak{I}_{,}\left(\mathfrak{\Im}_{t}\right)_{t \in \mathbf{T}}, P\right)$. Em alguns casos é possível encontrar o processo de Itô expresso como $d S_{t}=\mu_{t} d t+\sigma_{t} d B_{t}$, no qual $\mu_{t}$ e $\sigma_{t}$ são denominados respectivamente drift e diffusion do processo, estando os termos respectivamente relacionados com a expectativa de variação de $S_{t}$ e sua variância.

Outra variável definida no espaço de probabilidade acima apresentado é a estratégia de negócio $\theta$, a qual também é uma função do tempo e do estado da natureza em questão, $\theta: \mathbf{T} \times \Omega \rightarrow \Re$ ou resumidamente $\theta_{t}$. Distintamente dos preços dos ativos, $\theta$ é um processo previsível, no sentido de que no tempo "t" já é conhecido. ${ }^{8}$ Em termos econômicos, uma estratégia de negócio é a quantia, de um ou mais ativos, demandada pelo agente em um dado período de tempo e estado da natureza. No presente caso, assim como $S, \theta$ é um processo univariado.

\footnotetext{
${ }^{8}$ Formalmente diz-se que um processo $\theta$ é previsível se para cada $t_{n}$, $\theta_{t_{n}}$ é mensurável em $\mathfrak{\Im}_{t_{m}}$, para $t_{m}<t_{n}$. Para mais detalhes vide Willians (1991), capítulo 10.
} 
A combinação da estratégia de negócio com o preço, mais especificadamente sua variação, resulta no ganho do negócio, expresso por $\theta_{t} \cdot\left(S_{t+1}-S_{t}\right)$ quando $\theta$ é uma variável aleatória simples previsível. Sob essa ótica, o ganho acumulado do negócio ao longo de sua vida até o momento $t_{n}$ assume a forma $(\theta \cdot S)_{t_{n}}=\sum_{t=0}^{t_{n}-1} \theta_{t} \cdot\left(S_{t+1}-S_{t}\right)$, em alguns casos também expresso por $\int \theta_{s} d S_{s}$. Esse processo $(\theta \cdot S)_{t}$ é também conhecido como a integral estocástica de $\theta$ em relação a $S$.

Ao se considerar que a estratégia $\theta$ assume valores em um número infinito de tempos "t", isto é, esta deixa de poder ser expressa como uma variável aleatória simples. Nesse caso, a definição da integral estocástica se torna mais complexa, e outras técnicas se tornam necessárias garantir que o processo está bem definido. Para um dado $\theta$ previsível tal que $\int_{s=0}^{t} \theta_{s}^{2} d s<\infty,(\theta \cdot S)_{t}$ pode ser interpretado como o limite de uma série de integrais definidas sobre integrandos simples. Isso pois para um $\theta$ com essas propriedades, existe uma seqüência de $\left\{\theta_{n}\right\}_{n=1}^{\infty}$ simples tais que $\left\|\theta-\theta_{n}\right\|_{L^{2}} \rightarrow 0 .{ }^{9}$

Por fim, com o intuito de simplificar as análises, vai-se considerar um tipo especial de estratégia de negócio, aquelas denominadas de autofinanciadas. Uma estratégia autofinanciada é estratégia que não paga nem recebe dividendos durante seu tempo de existência, não requerendo influxos de dinheiro e não permitindo saques ao longo deste período. Em termos notacionais tem-se

$$
\theta_{t} \cdot S_{t}=\theta_{0} \cdot S_{0}+\int_{s=0}^{t} \theta_{s} \cdot d S_{s}
$$

\subsection{ARbitragem}

Delineadas as principais formalizações matemáticas para caracterização de um mercado financeiro, está-se apto para apresentar a noção de arbitragem. Primeiramente, de um modo intuitivo, define-se uma estratégia de negócio autofinanciada como arbitrada se $\theta_{0} \cdot S_{0} \leq 0$ e $\theta_{T} \cdot S_{T}>0$. A ideia contida nessas expressões é a de que se existe uma estratégia que no seu momento inicial não possui valor econômico, mas na sua maturidade oferece ao investidor ganhos, então diz-se que esta é uma estratégia arbitrada. Nos termos de Duffie (2000), arbitragem é um portfólio que oferece alguma coisa por nada.

\footnotetext{
${ }^{9}$ Para uma definição formal de integral estocástica vide Ǿksendal (2003). Para uma descrição da evolução da aplicabilidade da técnica vide Delbaen e Shachermayer (2006), capítulo 7.
} 
Ao se buscar a formalização do fenômeno da arbitragem tornar-se necessário especificar os elementos acima apresentados, tais como $\Omega, S_{t}, \theta_{t}$ e $\mathbf{T}$. Desse modo, considere inicialmente $\Omega$ finito, que $S_{t}$ é um processo adaptado à filtração $\left(\mathfrak{\Im}_{t}\right)_{t \in \mathbf{T}}$ e que $\theta_{t}$

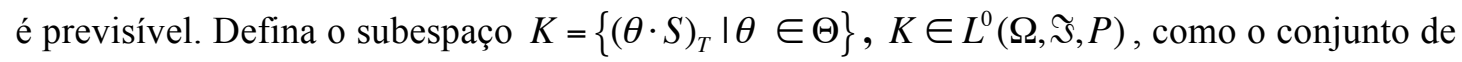
todos os ganhos acumulados do negócio cujo valor inicial é zero, e mudam de valor ao longo

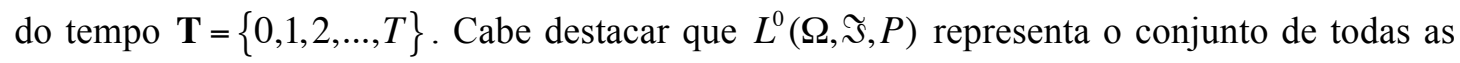
funções reais mensuráveis em $\mathfrak{\Im}$, isto é, $[\omega: f(\omega) \in H] \in \mathfrak{I}$ para todo $H \in \Re$.

Considere $L_{+}^{0}(\Omega, \Im, P)$ como o conjunto formado apenas pelas funções positivas de $L^{0}(\Omega, \Im, P)$. Nesse sentido, define-se como uma situação de arbitragem no mercado formado pelo processo estocástico dos preços $S$ se

$$
K \cap L_{+}^{0}(\Omega, \Im, P) \neq\{0\}, \text { ou antagonicamente, }
$$

$$
K \cap L_{+}^{0}(\Omega, \mathfrak{I}, P)=\{0\} \text { para uma situação de não arbitragem. }
$$

Ao se generalizar as definições acima para $\Omega$ não-finitos, outras hipóteses precisam ser feitas. Em particular, considere que o processo estocástico $\left(S_{t}\right)_{t \in \mathbf{T}}$, definido no espaço filtrado $\left(\Omega, \mathfrak{I},\left(\mathfrak{I}_{t}\right)_{t \in \mathbf{T}}, P\right)$, é localmente limitado. Isto é, para uma sequência de Tempos de Parada, $\left(\tau_{n}\right)_{n=1}^{\infty}$, o processo $S_{t \wedge \tau_{n}}$ é uniformemente limitado. ${ }^{10}$ Além disso, distintamente do caso anterior, $\mathbf{T}=[0, T]$. $^{11}$

No que tange a estratégia de negócio $\theta$, suponha inicialmente que trata-se de uma estratégia simples. Diz-se que $\theta$ é uma Estratégia de Negócio Simples se pode ser expressa da seguinte forma $\theta=\sum_{k=1}^{n} h_{k} \cdot 1_{\left.\left.\|] \tau_{k-1}, \tau_{k}\right]\right]}$, na qual $0=\tau_{0} \leq \tau_{1} \leq \ldots \leq \tau_{n}<\infty$ são Tempos de Parada finitos e $h_{k}$ são funções reais mensuráveis em $\mathfrak{\Im}_{\tau_{k-1}}$. Se as $h_{k}$ são também localmente limitadas, denominam-se essas estratégias como admissíveis.

Nessa nova caracterização do mercado, pode-se reespecificar a expressão da não arbitragem. Seja $K^{s}=\left\{(\theta \cdot S)_{T} \mid \theta\right.$ simples e admissível $\}$, tal que $K^{s} \subset L^{\infty}(\Omega, \mathfrak{\Im}, P)$, isto é, $K^{s}$

\footnotetext{
${ }^{10}$ Diz-se que um mapeamento $\tau: \Omega \rightarrow\{0,1,2, \ldots, \infty\}$ é um Tempo de Parada se $\{\omega: \tau(\omega) \leq n\} \in \mathfrak{\Im}_{n}$ para $\forall n \leq \infty$. Em termos econômicos, o Tempo de Parada está associado ao período em que o agente reavalia sua estratégia de investimento.

${ }^{11}$ A preferência por $\mathbf{T}=[0, T]$ em detrimento de $\mathbf{T}=\Re_{+}=[0, \infty[$ está relacionada com a simplicidade de tratamento. Para uma abordagem mais completa sem essa e outras hipóteses simplificadoras assumidas ao longo do capítulo vide Delbaen e Shachermayer (2006).
} 
é um subespaço do conjunto de ganhos acumulados gerados pelas estratégias simples. ${ }^{12}$ Considere agora um segundo conjunto $C^{s}$ formado por ganhos acumulados que podem ser obtidos através de estratégias que resultem em $f, f \in K^{s}$, e descartando-se uma parcela " $\mathrm{k}$ " destes ganhos. Em outros termos, diz-se que $C^{s}$ é o conjunto dos ganhos acumulados do negócio dominados por um dado $f \in K^{s}$. Especificamente

$$
C^{s}=\left\{f-k \mid f \in K^{s}, f \in L^{\infty}, k \geq 0\right\} .
$$

Sob essas condições, define-se como uma situação de não arbitragem se $C^{s} \cap L_{+}^{\infty}(\Omega, \mathfrak{I}, P)=\{0\} \cdot{ }^{13}$

A passagem de um espaço de probabilidade discreto para outro gerado a partir de um $\Omega$ não-finito representa uma generalização na caracterização dos mercados financeiros. Contudo, ao se trabalhar apenas com as estratégias de negócio simples está-se em uma classe restrita de integrandos, quando pensada em termos da integral estocástica definida por $(\theta \cdot S)_{T}$ . Nesse sentido, para se proceder com a caracterização da não arbitragem em seu mais elevado nível de generalização é preciso expandir os tipo de integrandos considerados.

Seja a estratégia de negócio caracterizada pelo processo estocástico previsível $\left(\theta_{t}\right)_{t \in \mathbf{T}}$, $\mathbf{T}=[0, T]$. Assim como no caso das estratégias simples, é importante delimitar o tipo de processo a ser considerado definindo-se o conceito de admissibilidade. Diz-se que, para esse tipo de processo estocástico contínuo, que a estratégia é admissível se: i) a integral $\left((\theta \cdot S)_{t}\right)_{t \in \mathbf{T}}$ está bem definida; ii) se existe uma constante que limita inferiormente a integral estocástica, $(\theta \cdot S)_{t} \geq-k$ quase certamente para $t \in \mathbf{T}$.

A segunda condição visa excluir do rol das estratégias de negócio aquelas em que o investidor busca a aferição de um ganho certo através de uma alavancagem contínua e sem limite, também conhecida como doubling strategy. Em contrapartida, a primeira condição trata do comportamento da integral à medida que $|\theta|$ cresce. Em termos técnicos, $\left(\left(\theta \cdot \mathbf{1}_{\{|\theta| \leq n\}} \cdot S\right)_{\mathrm{T}}\right)_{n=1}^{\infty}$ deve-se comportar como uma sequência de Cauchy.

A última etapa na formalização de um conceito mais geral de não arbitragem consiste na escolha de um processo estocástico para o movimento dos preços dos ativos tais que a

$12 L^{\infty}(\Omega, \mathfrak{I}, P)$ representa a classe de funções reais $f$ mensuráveis em $\mathfrak{I}$ tais que $\inf [\alpha: P(\omega:|f(\omega)|>\alpha)=0]$ é finito.

${ }^{13} \mathrm{O}$ termo não-arbitragem é uma convenção adotada pelo autor. Na literatura, sob essas condições dizse que o mercado está em uma situação de No Free Lunch. 
integral $\left((\theta \cdot S)_{t}\right)_{t \in \mathbf{T}}$ esteja bem definida, conforme apontado acima. Dessa maneira, vai-se considerar que $\left(S_{t}\right)_{t \in \mathbf{T}}$ assuma a forma de um semi-martingal. Essa classe de processo está entre as mais genéricas dentre aquelas para as quais a teoria da integral estocástica é capaz de tratar.

A noção de semi-martigalidade está engendrada na relação entre o tipo de convergência de uma sequência de integrandos simples e aquela presente na integral $\left((\theta \cdot S)_{t}\right)_{t \in \mathbf{T}}$. No entanto, uma consequência dessa relação é que o processo estocástico $S=\left(S_{t}\right)_{t \in \mathbf{T}}$ é um semi-martingal se, e somente se, ele pode ser decomposto em dois termos, $S=M+A$, no qual $M$ é um martingal local e $A$ é um processo de variância localmente limitada, isto é, $\sup _{0<t_{1}, \ldots, t_{n}<t} \sum_{i=0}^{n-1}\left|S_{t_{i}}-S_{t_{i-1}}\right|<\infty$ para $t_{n} \in \mathbf{T}$. Desse modo, caracteriza-se a semimartingalidade pela possibilidade de decomposição do processo estocástico nos termos acima mencionados.

Por ação dessa formalização do mercado, seja $K=\left\{(\theta \cdot S)_{T} \mid \theta\right.$ admissível e $\lim _{t \rightarrow T}(\theta \cdot S)_{t} \exists$ a.s. $\}$, e assim como anteriormente, defina $C=\left\{g \in L^{\infty} \mid g \leq f, f \in K\right\}$. Desse modo, não existe uma situação de arbitragem quando $\bar{C} \cap L_{+}^{\infty}(\Omega, \Im, P)=\{0\}$, na qual $\bar{C}$ representa o fecho de $C .{ }^{14}$

De um modo geral, definida conforme acima a noção de arbitragem está intimamente relacionada às propriedades das funções $\theta$ e $S$. Assim, para se avaliar o fenômeno da arbitragem poder-se-ia focar nas medidas de probabilidade dessas funções, ou mais propriamente, do processo $\left((\theta \cdot S)_{t}\right)_{t \in \mathbf{T}}$. Contudo, as complexidades enfrentadas nessa abordagem inibem seu desenvolvimento. A fim de diminuí-las, ao invés de se trabalhar diretamente com o fenômeno, o presente trabalho buscou estudá-la a partir das condições que garantem e são garantidas pela mesma, conforme estruturadas no Teorema Fundamental do Apreçamento de Ativos.

\subsection{Teorema Fundamental do ApreÇamento de Ativos (TFAA)}

A partir da caracterização do mercado financeiro mais geral apresentada acima, isto é, $\Omega$ não finito, $S=\left(S_{t}\right)_{t \in \mathbf{T}}$ um semi-martingal, $\theta=\left(\theta_{t}\right)_{t \in \mathbf{T}}$ admissível e $\mathbf{T}=[0, T]$, pode-se expressar o teorema como a equivalência das afirmações

\footnotetext{
${ }^{14} \mathrm{O}$ termo não-arbitragem é aqui novamente utilizado como uma convenção adotada pelo autor. $\mathrm{Na}$ literatura, sob essas condições diz-se que o mercado está em uma situação de No Free Lunch with Vanishing Risk.
} 
i. (EMM) existe uma medida de probabilidade $\boldsymbol{Q}$, equivalente a $\boldsymbol{P}$, tal que o processo $S$ é um martingal local sob $\boldsymbol{Q}$;

ii. (NAR) o processo $S$ satisfaz a noção de não arbitragem.

Conforme argumento de Delbaen e Shachermayer (2006), capítulo 8, a condição $(E M M)=>(N A R)$ decorre basicamente do fato de que em média um agente nunca pode ganhar apostando em um martingal. Se o portfólio vale nada no início dos tempos, então se comporta-se como um martingal não deve possuir valor ao final da estratégia de negociação. De um modo um pouco mais específico, se S é uma martingal local sob $\boldsymbol{Q}$, então $(\theta \cdot S)_{t}$ também o é. Assim, se $\theta_{0} \cdot S_{0}=0$ e as estratégias são autofinanciadas, $E_{Q}\left[(\theta \cdot S)_{t} \mid \mathfrak{\Im}_{0}\right]=0$, $\forall t$.

No que tange a implicação $(\mathrm{NAR})=>(\mathrm{EMM})$, a ideia contida na mesma é a de que se existe uma situação de não arbitragem vigente em um mercado, então para os preços vigentes no mesmo é possível encontrar um medida de probabilidade $\boldsymbol{Q}$ tal que sob esta passem a se comportar como processos de martingal. De maneira inversa a condição anterior, embora a implicação possa até parecer intuitiva como enunciada, a complexidade matemática para prová-la no caso geral em questão é extremamente elevada. Em linhas gerais, sob a hipótese

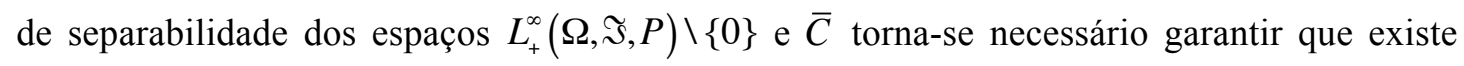
uma medida $\boldsymbol{Q}$ tal que $E_{Q}\left[(\theta \cdot S)_{t} \mid \mathfrak{\Im}_{0}\right] \leq 0, \forall t$.

Independentemente sob qual prisma se olhe o teorema, suas proposições lançam luz sobre um aspecto que há séculos desperta o interesse dos pesquisadores, a saber, a determinação dos preços. Implicitamente o TFAA propõem que em mercados nos quais não existem condições para ganhos sem risco, isto é, a arbitragem, o preço de um ativo pode ser expresso pelo valor presente esperado das suas potencias realizações no futuro, $E_{Q}\left[S_{t} \mid \mathfrak{S}_{0}\right]=S_{0}$. Concomitantemente, se g(.) é uma função real de uma variável real tal que $g \in L^{1}(\Omega, \mathfrak{\Im}, P)$, então o conceito pode ser estendido para $E_{Q}\left[g\left(S_{t}\right) \mid \mathfrak{I}_{0}\right]=c\left(S_{0}\right)$.

Em termos econômicos, enquanto a primeira expressão está associada ao apreçamento de ativos, a segunda faz referência aos derivativos financeiros. Como um derivativo financeiro tem suas potenciais realizações futuras determinadas por seu ativo subjacente, isto é, por uma função do tipo $g($.), então a formulação acima indica que seu preço também pode ser expresso por uma esperança matemática. Desse modo, se sabe-se calcular essa esperança, então implicitamente torna-se possível apreçar um derivativo financeiro, seja qual for sua dependência do seu ativo subjacente. 
Uma das implicações mais importantes dessas equações de apreçamento para o presente estudo está na sua capacidade de ser utilizada como mecanismo de obtenção das Medidas Martingal Equivalentes $\boldsymbol{Q}$. Ao se observar os preços dos derivativos negociados no mercado e considerar que podem ser determinados segundo as formulações apresentadas acima, está implicitamente tratando como adequado as implicações do Teorema Fundamental do Apreçamento de Ativos, segundo o qual sob essas condições é válido nesses mercados o princípio da não arbitragem. É sob esse referencial que argumenta-se que uma maneira de se verificar a não arbitragem é através das medidas estatísticas subjacentes aos modelos de apreçamento de derivativos.

No que se segue vai-se explicitar em mais detalhes as implicações do TFAA, evidenciando como a partir das Medidas Martingal Equivalentes chega-se a condição de Não Arbitragem e vice-versa. Desse modo, apresenta-se o instrumental necessário para a compreensão da análise do fenômeno da não arbitragem desenvolvida na sequência do estudo. A título de ilustração, no que se segue considerará novamente que $S=\left(S_{t}\right)_{t \in \mathbf{T}}$ se comporta como um processo de Itô, tal como definido acima.

\subsection{Deflatores Estado-Preço}

Um deflator é uma variável aleatória estritamente positiva, que segue algum processo estocástico bem definido. A função econômica dos deflatores é a de normalizar os preços em relação a um dado numerário. Na maior parte dos casos o preço de um outro ativo é utilizado. Mais especificamente, o preço $\beta_{t}$ de um título de valor inicial $\beta_{0}$ e reinvestido continuamente à taxa livre "r" é um potencial deflator, uma vez que $\beta_{t}=\beta_{0} \cdot \exp \left(\int_{s=0}^{t} r_{s} \cdot d s\right)>0$ pois $\beta_{0}>0$ e $r_{s} \geq 0$.

Dessa maneira, o processo $S^{\beta}=S / \beta$ é o preço normalizado do ativo $S$ pelo deflator $\beta$. No presente caso, no qual o $S$ segue um processo de Itô e que $d \beta_{t}=\beta_{t} \cdot r_{t} d t$, a expressão em termos de equação diferencial de $S^{\beta}$ é dada por $d S_{t}^{\beta}=\left(\mu_{t} \cdot \beta_{t}^{-1}-S_{t}^{\beta} \cdot r_{t}\right) d t+\sigma_{t} \cdot \beta_{t}^{-1} d B_{t}$ ou $d S_{t}^{\beta}=\mu_{t}^{\beta} d t+\sigma_{t}^{\beta} d B_{t}, \quad$ com $\mu_{t}^{\beta}=\left(\mu_{t} \cdot \beta_{t}^{-1}-S_{t}^{\beta} \cdot r_{t}\right)$ e $\sigma_{t}^{\beta}=\sigma_{t} \cdot \beta_{t}^{-1}$. Isso se deve pois $d S_{t}^{\beta}=S_{t} d \beta_{t}^{-1}+\beta_{t}^{-1} d S_{t}+\sigma_{t} \cdot \sigma_{t}^{\beta^{-1}}$, na qual $\sigma_{t}^{\beta^{-1}}$ é a volatilidade do deflator.

Cabe destacar que o uso dos deflatores não causa modificações nas definições feitas até o momento, e em linhas gerais nas análises econômicas. Uma estratégia de negócio autofinanciada em relação a $S$ continua sendo autofinanciada quando avaliada com $S^{\beta}$. Do 
mesmo modo, se uma estratégia de negócio é arbitrada em relação a $S$, esta também será sob a ótica de $S^{\beta}$.

Um tipo particular de deflatores é aquele que quando aplicado a um preço transforma o processo estocástico do mesmo em um martingal. Esses deflatores são conhecidos como Deflatores Estado-Preço, expressos aqui como $\pi$. Uma primeira implicação relevante desses deflatores é que se $S^{\pi}$ é um martingal, então o processo de ganho acumulado dado por $\int_{s=0}^{t} \theta_{s} d S_{s}^{\pi}$ também é um martingal, se $\int_{s=0}^{t} \theta_{s}^{2} d s<\infty$ para $0 \leq t \leq T .^{15}$

Tal como mencionado anteriormente, um primeiro passo para relacionar processos de martingal com não arbitragem é mostrar que as integrais de Itô sobre estes processos também se comportam como martingais. Dessa forma, uma consequência direta dos Deflatores Estado-Preço é sua implicação sobre o fenômeno da arbitragem. Sejam $\mu_{t}^{\pi}$ e $\sigma_{t}^{\pi}$ respectivamente o drift e diffusion do processo deflacionado por $\pi$. Assim se $\int_{s=0}^{t}\left(\theta_{s}^{2} \cdot\left(\sigma_{s}^{\pi}\right)^{2}\right) d s<\infty$ e $E\left(\left[\int_{s=0}^{t}\left(\theta_{s} \cdot \mu_{s}^{\pi}\right) d s\right]^{2}\right)<\infty$ para $t \geq 0$, então é possível garantir que não existe arbitragem no processo autofinanciado $\theta \cdot S^{\pi}$. Em outros termos, se o processo estocástico dos preços aceita um Deflator Estado-Preço e as demais condições de integrabilidade são respeitadas, então se tem uma primeira condição para a não ocorrência de arbitragem.

Equivalentemente, além dos Deflatores Estado-Preço, existem outros modos de expressar a conversão dos processos $\theta$ e $S$ em martingais. Portanto, existem outras formas de se apresentar condições que implicam na não arbitragem, como a seção abaixo apresenta.

\subsection{Medida Martingal Equivalente}

Seja $Q$ também uma medida de probabilidade definida no espaço $(\Omega, \Im)$, as vezes denominada de medida induzida. Diz-se que $Q$ é absolutamente contínua em relação a $P$ se para todo evento $A \in \mathfrak{I} P(A)=0 \Rightarrow Q(A)=0$, expressa por $Q \ll P$. Se $Q \ll P$ e, além disso $P \ll Q$, então definem-se as medidas como equivalentes, $Q=P$. Concomitantemente, se o processo estocástico de $S$ for um processo de martingal sob a medida $Q$, então diz-se que $Q$ é uma Medida Martingal Equivalente. ${ }^{16}$

A existência de Medidas Martingal Equivalentes desempenha um papel relevante dentro das teorias de apreçamento de derivativos. Do mesmo modo que os Deflatores Estado-

\footnotetext{
${ }^{15}$ Para detalhes da prova vide Protter (1990).

${ }^{16}$ Para detalhes de medidas equivalentes vide Billingsley (1995), capítulo 6.
} 
Preço, a ocorrência dessas medidas tem uma implicação direta sobre a não existência da arbitragem em estratégias autofinanciadas. Contudo, as mesmas condições de contorno são exigidas, as quais são dadas por $\int_{s=0}^{t}\left(\theta_{s}^{2} \cdot\left(\sigma_{s}\right)^{2}\right) d s<\infty$ e $E^{Q}\left(\left[\int_{s=0}^{t}\left(\theta_{s} \cdot \mu_{s}\right) d s\right]^{2}\right)<\infty$ para $t \geq 0$, ou então se $\theta_{t} \cdot S_{t} \geq k$ para $k \in \Re$ e $t \geq 0$.

A relação entre as Medidas Martingal Equivalentes e a não arbitragem está alicerçada no fato de que se $S$ é um martingal sob $Q$, então o processo $\theta \cdot S$ também é. Como visto anteriormente, sob essa hipótese e adicionando-se o fato de que $\int_{s=0}^{t} \theta_{s}^{2} d s<\infty$ para $t \geq 0$, o processo de ganho acumulado dado por $\int_{s=0}^{t} \theta_{s} d S_{s}$ também é um martingal. Se $S_{0}=0$, então $E\left[\int_{s=0}^{T} \theta_{s} d S_{s} \mid \mathfrak{I}_{0}\right]=\theta_{0} S_{0}=0$ e consequentemente $E\left[\int_{s=0}^{T} \theta_{s} d S_{s}\right]=0$. Portanto, a expectativa de ganhos acumulados de qualquer estratégia é sempre nula.

Em algumas situações, ao invés de se buscar a existência de Medidas Martingal Equivalentes diretamente nos preços, é um facilitador trabalhar com os preços deflacionados. Conforme argumentado acima os deflatores não modificam as proposições relacionadas ao processo $\theta \cdot S$, e desta forma se $S^{\beta}$ admite uma Medida Martingal Equivalente, então sob as condições apresentadas esta também resulta em não arbitragem.

Uma consequência adicional das Medidas Martingal Equivalentes para as teorias de apreçamento de derivativos aventa sobre o modo como o padrão das preferências dos agentes econômicos é incorporado nas mesmas. Em particular, sob a condição de martingalidade de $S$ ou $S^{\beta}$ a tipologia da estrutura das expectativas dos agentes frente ao risco não é determinante para as equações dos preços. Os resultados são idênticos para agentes sob preferências aversas ao risco, neutras ao risco ou atraídas por risco.

Nas palavras de Campbell et al. (1997)

Therefore, the pricing formula for any derivative security that can be priced in this fashion must be identical for all preferences that do not admit arbitrage. In particular, the pricing formula must be the same regardless the agents' risk tolerance (...). (pág. 354)

Umas das razões para a não dependência das equações de preços em relação ao padrão de preferência dos agentes reside no fato de que sob Medidas Martingal Equivalentes todos os agentes têm expectativas de retorno idênticas e iguais a zero ou à taxa livre de risco, a depender como se está considerando o comportamento de $S$. No caso do processo do preço 
deflacionado $S^{\beta}$, ao se definir $\mu_{t}^{Q, \beta}, \sigma_{t}^{Q, \beta}$ e $B_{t}^{Q}$ respectivamente como drift, diffusion e o Browniano sob a medida $Q, \operatorname{com} d S_{t}^{\beta}=\mu_{t}^{Q, \beta} d t+\sigma_{t}^{Q, \beta} d B_{t}^{Q}$, o argumento acima decorre do fato que $\mu_{t}^{Q, \beta}=0$. Por essas razões as Medidas Martingal Equivalentes são às vezes denominadas de medidas risco-neutras.

\subsection{Preço de Mercado do Risco}

Até o momento apresentou-se como as Medidas Martingal Equivalentes, ou equivalentemente os Deflatores Estado-Preço, engendram condições que implicam na impossibilidade de se obter ganhos sem risco, ou seja, na não arbitragem. Contudo, no sentido inverso dessa relação reside a questão de quais condições levam à existência destas medidas, ou similarmente, asseguram que os processos do preços se comportam como martingais. Argumentou-se, por exemplo, que $B_{t}^{Q}$ era o movimento Browniano sob a medida $Q$, mas nada foi dito sobre as propriedades que garantem a existência.

Uma ferramenta importante nesse sentido é o Teorema de Girsanov, o qual versa sobre a troca de medidas nos processos de difusão. Para se explicitar o teorema defina $\zeta$ como um processo adaptado à Filtração $\left\{\mathfrak{I}_{t}\right\}_{t=0}^{T}$. Diz-se que $\varsigma$ satisfaz a Condição de Novikov se

$$
E\left[\exp \left(\frac{1}{2} \int_{s=0}^{T} \varsigma_{s}^{2} \cdot d s\right)\right]<\infty
$$

Considere a densidade de Radon-Nikodym dada por $\xi_{t}$, isto é $d Q_{t} / d P_{t}=\xi_{t}$. Suponha que esta assume a forma

$$
\xi_{t}=E\left[\exp \left(-\int_{s=0}^{t} \varsigma_{s} \cdot d B_{s}\right) \cdot \exp \left(-\frac{1}{2} \int_{s=0}^{t}\left(\varsigma_{s} \cdot \varsigma_{s}\right) d s\right)\right], \quad t \leq T
$$

Então, o Teorema de Girsanov propõem que sob essas condições, um novo processo Browniano para a medida $\boldsymbol{Q}$ seria dado por $B_{t}^{Q}=\int_{s=0}^{t} \varsigma_{s} d s_{s}+B_{t}$, para $t \leq T .{ }^{17}$

Uma consequência direta do teorema é que se pode reescrever o processo de Itô do preço deflacionado, dado por $d S_{t}^{\beta}=\mu_{t}^{\beta} d t+\sigma_{t}^{\beta} d B_{t}$, como $d S_{t}^{\beta}=\left(\mu_{t}^{\beta}-\sigma_{t}^{\beta} \varsigma_{t}\right) d t+\sigma_{t}^{\beta} d B_{t}^{Q}$, isto pois $d B_{t}^{Q}=\varsigma_{s} d s_{s}+d B_{t}$. Reescrevendo a expressão como base nas definições de $\mu_{t}^{\beta}$ e $\sigma_{t}^{\beta}$

\footnotetext{
${ }^{17}$ Para a formalização do teorema vide Ǿksendal (2003), capítulo 8. Para uma exemplificação mais intuitiva vide Steele (2001), capítulo 13.
} 
dadas acima, obtém-se a forma final do processo como $d S_{t}^{\beta}=\frac{1}{\beta_{t}}\left[\left(\mu_{t}-r_{t} \cdot S_{t}\right)-\sigma_{t} \varsigma_{t}\right] d t+\frac{\sigma_{t}}{\beta_{t}} d B_{t}^{Q}$.

O termo $\varsigma$ é também denominado Preço de Mercado do Risco, uma vez que define a relação entre a variação média do preço e o risco $\sigma$. Mais especificamente, o termo relaciona o excesso da variação do preço sobre o ativo aplicado à taxa livre de risco, $\left(\mu_{t}-r_{t} \cdot S_{t}\right)$, com o risco do ativo $\sigma_{t}$ em um determinado período " $\mathrm{t}$ ".

A expressão acima permite vislumbrar que a condição necessária para a existência das Medidas Martingal Equivalentes é que $\left(\mu_{t}-r_{t} \cdot S_{t}\right)=\sigma_{t} \varsigma_{t}$, visto que neste caso $d S_{t}^{\beta}=\frac{\sigma_{t}}{\beta_{t}} d B_{t}^{Q}$ ou $S_{t}^{\beta}=\int_{s=0}^{t} \sigma_{s} / \beta_{s} \cdot d B_{s}^{Q}$, com a hipótese no presente caso de que $x_{0}=0$. No entanto, para que $\boldsymbol{Q}$ seja uma Medida Martingal Equivalente é preciso que $S^{\beta}$ seja um processo de martingal, condição que ocorrerá quando $\int_{s=0}^{t} \sigma_{s} / \beta_{s} \cdot d s<\infty$ para $0 \leq t \leq T$. Assim as condições necessária e suficiente para as Medidas Martingal Equivalentes são a existência do Preço de Mercado do Risco e a integrabilidade de $\sigma_{t} / \beta_{t}$ em $0 \leq t \leq T$.

\subsection{ApreÇamento de Derivativos}

Sob a ótica do Teorema Fundamental de Apreçamento de Ativos, por um lado, a ocorrência de não arbitragem nos mercados financeiros está intimamente relacionada com a existência dos Deflatores Estado-Preço ou das Medidas Martingal Equivalentes. Na contrapartida, mercados não arbitrados, sob as condições de aplicabilidade do Teorema de Girsanov, geram a possibilidade de uma caracterização dos preços como processos de martingal. Do ponto de vista econômico, essa última implicação surge como uma caracterização bastante plausível, uma vez que a não ocorrência da arbitragem aparenta ser uma condição natural dos mercados financeiros sem fricções, principalmente no que tange a assimetria de informações.

De um modo ou de outro, conforme argumentado acima, o Teorema Fundamental é um importante instrumento na formalização e generalização das equações de apreçamento, sejam estas de ativos ou derivativos. Em particular, sendo os preços ou os preços deflacionados processos de martingal, a equação do preço de um derivativo pode ser definida como a esperança matemática da estrutura de payoff do mesmo, condicionada ao conjunto de informação disponível na presente data. 
Com o intuito de ilustrar o conceito, suponha que sobre o ativo de preço $S$ é definido um derivativo de preço $D$, cuja estrutura de payoff é dada pelo processo $\delta=g(S)$. Para simplificar, considere ainda que os potencias payoffs do Derivativo acontecem somente no período $\mathrm{T}, \delta=\delta_{T}$, e que o valor do derivativo neste momento é igual ao próprio payoff realizado, $D_{T}=\delta_{T}$.

Ao considerar que se está trabalhando com os preços deflacionados por $\beta$, $D_{t}^{\beta}=D_{t} / \beta_{t}$ em $0 \leq t \leq T$, os argumentos acima implicam que, sob uma Medida Martingal Equivalente, o processo $D_{t}^{\beta}$ é um martingal. Desse modo, algebricamente tem-se

$$
D_{t} / \beta_{t}=E^{Q}\left[D_{T} / \beta_{T} \mid \mathfrak{\Im}_{t}\right]=E^{Q}\left[\frac{D_{T}}{\beta_{0} \cdot \exp \left(\int_{s=0}^{T} r_{s} \cdot d s\right)} \mid \mathfrak{\Im}_{t}\right] .
$$

Reorganizando a fórmula e utilizando-se do valor do derivativo no período T obtém-se a equação de apreçamento do derivativo

$$
D_{t}=E^{Q}\left[\frac{\delta_{T}}{\exp \left(\int_{s=t}^{T} r_{s} \cdot d s\right)} \mid \mathfrak{\Im}_{t}\right]=E^{Q}\left[\pi_{t} \cdot \delta_{T} \mid \mathfrak{\Im}_{t}\right] .
$$




\title{
Capítulo 4
}

\section{Instrumental para Hipóteses Precisas}

\begin{abstract}
The revolutionary character of the majority of revolutions in the history of science is not due to their introducing entirely new ideas into the debate but rather to their offering surprising solutions to problems that have been the object of discussion over a long period (Krohn et al., 1990, pág. 1).
\end{abstract}

Hipóteses precisas, às vezes também denominadas de simples ou pontuais, se referem a caracterizações do tipo $H: \theta=\theta_{0}$. Essa classe de hipóteses engendra dificuldades tanto do ponto de vista da sua conceituação epistemológica quanto do instrumental estatístico necessário para testá-la. Para algumas abordagens, as hipótese precisas são consideradas implausíveis, muitas vezes não expressando corretamente a tentativa de geração de conhecimento científico. Do ponto de vista analítico, a necessidade de considerá-las exige uma série de ajustes nos métodos tradicionais de teste, sejam esses baseados no Fator de Bayes ou no p-valor. Para belas discussões sobre o tema vide Berger e Delampady (1987), Casella e Berger (1987) e Stern (2008).

Maturana e Varela (1980), ao definir a existência de organismos vivos, propõem o conceito de sistemas autopoiéticos. Trata-se de estruturas auto-referenciadas e cuja autoorganização promove sua manutenção e reprodução. Estando presente em organismos vivos, a caracterização de autopoiesis aplica-se ao processo de cognição dos seres humanos. O avanço desse processo deu origem ao que atualmente se conceitua como Epistemologia Construtivista, sob qual abordagem as hipóteses precisas surgem como condição inerente do sistema. A fim de ilustrar os principais conceitos da abordagem, apresenta-se na sequência sua concepção de geração de conhecimento científico.

\subsection{OPERACIONALIZAÇÃo DO CONHECIMENTO}

De acordo com Krohn e Küppers (1990), toda pesquisa desenvolvida pelos diferentes ramos das ciências empíricas é formada por dois componentes independentes, a saber, um teórico e outro experimental. Essa independência estaria relacionada à dinâmica interna de funcionamento de cada componente, conforme apresentado na sequência, uma vez que, de um ponto de vista mais global, a estrutura de produção do conhecimento seria recursiva, ou seja, o output de um entraria como input do outro.

No lado teórico aconteceria a interpretação dos estudos empíricos e seus resultados, a confrontação destes com padrões já estabelecidos e, finalmente, a dedução de novas 
hipóteses. Inerente a essa dinâmica haveria uma espécie de mecanismo de validação, a partir do qual os padrões teóricos existentes seriam avaliados comparativamente aos resultados empíricos obtidos.

Por sua vez, na contraparte, haveria o componente operacional da produção do conhecimento, também expresso por experimental. Nesse haveria o planejamento, execução e obtenção dos resultados dos estudos empíricos, cuja dinâmica interna de funcionamento também seria regulada por critérios de sucesso e falha, de acordo com o cumprimento ou não do processo desenhado. Essas primeiras ideias são sumarizadas na Figura 4.1, a qual segundo os autores apresenta a estrutura ideal de produção do conhecimento científico.

Figura 4.1: Estrutura de Produção do Conhecimento

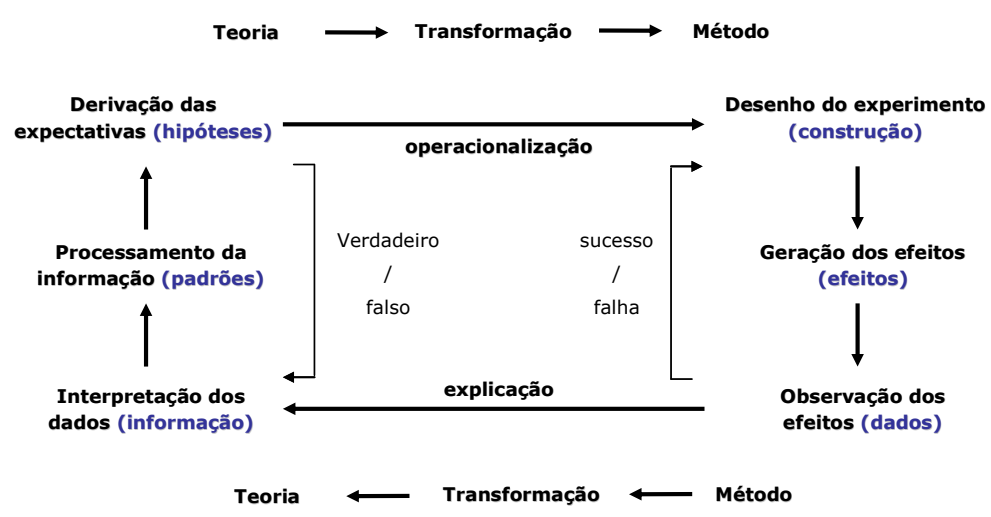

O inter-relacionamento recursivo entre os dois componentes da estrutura de produção de conhecimento se daria pelo que Krohn e Küppers (1990) denominam "Transformações”. A primeira, definida como Operacionalização, trata do modo como ideias se transformam em ações, isto é, as hipóteses teóricas em procedimentos operacionais de experimentação. Concomitantemente haveria a contraparte Explicação, sob qual denominação se agrupariam as distintas maneiras de interpretação dos resultados empíricos.

Expressa dessa maneira, a operacionalização do conhecimento é uma combinação complexa e sinérgica de uma base estrutural e de procedimentos de ação, cujos elementos formadores são dos tipos teóricos, metodológicos, empíricos e interpretativos. É por meio da interação desses elementos, e do funcionamento recursivo dessa estrutura, que o conhecimento é gerado. Em específico, a consecução de um novo conhecimento acontece quando existe coerência interna entre os seus elementos formadores, implicando estabilidade na estrutura de produção de conhecimento.

De acordo com os autores, quando o processo de pesquisa está na sua etapa inicial, as interações que se formam na estrutura de produção do conhecimento são "frouxas", no 
sentido de que não existem procedimentos únicos e específicos para gerar as interações. Exemplificando para as interações entre o componente teórico e o experimental, definida como a Transformação de Operacionalização, é como se no começo existissem diversas formas de converter as hipóteses teóricas em layout de experimentação, ou seja, no planejamento e efetivação do experimento.

No entanto, na medida em que o processo de pesquisa ganha maturidade, e as expectativas, atitudes e ideologias adquirem uniformidade, os mecanismos de interação entre os elementos deixam de ser "frouxos" e passam a ser caracterizados pela padronização. A gama de possibilidades dos mecanismos de interação se restringe a convenções préestabelecidas, advindas do consenso inerente ao grupo de pesquisa.

Nesse momento, em que o funcionamento recursivo da estrutura de produção do conhecimento se torna circular, e que as interações se tornam fixas, a aplicação de um método de investigação a dois elementos distintos de um conjunto de objetos geram resultados similares em suporte a alguma hipótese sobre este conjunto. A coerência e estabilidade obtidas nesse ponto são os elementos centrais para a consecução do novo conhecimento. Para utilizar a terminologia dos autores, diz-se que a estrutura encontrou sua auto-solução, isto é, novo conhecimento. ${ }^{18}$

\subsection{Auto-SOLUÇões}

De modo a esclarecer o conceito de auto-solução utiliza-se o exemplo de Foerster (2003). Dentre os diversos contextos passíveis de registro das auto-soluções, no exemplo em questão o autor recorre às interações senso-motoras, ou seja, ao processo que se dá na interação repetida de um sujeito e um objeto. Nesse caso específico, as auto-soluções são denominada de Eigen-Behaviors, pois o domínio de existência do objeto é o comportamento humano.

Utilizando a terminologia apresentada, defina "obs" como a variável que representa tudo aquilo que é observado pelo indivíduo, e "COORD” como toda e qualquer ação ou operação executada pelo mesmo. A relação entre essa variável e o operador COORD seria do tipo

$$
o b s_{1}=\operatorname{COORD}\left(o b s_{0}\right)
$$

na qual COORD transforma o objeto inicialmente concebido pelo indivíduo.

\footnotetext{
${ }^{18}$ Auto-solução é a tradução do presente autor para Eigensolution.
} 
Além disso, suponha uma estrutura recursiva para o operador COORD, de acordo com a qual pode-se escrever $o b s_{2}$ em função de $o b s_{0}$ simplesmente substituindo a definição de $o b s_{1}$ na expressão de $o b s_{2}$, conforme

$$
o b s_{2}=\operatorname{COORD}\left(o b s_{1}\right)=\operatorname{COORD}\left(\operatorname{COORD}\left(\mathrm{obs}_{0}\right)\right) .
$$

Generalizando o procedimento para um $n$ qualquer obtém-se $o b s_{n}=\operatorname{COORD}^{(n)}\left(o b s_{0}\right)$, na qual COORD $^{(n)}$ representa a aplicação do operador em $n$ passos consecutivos. Fazendo o processo de interação tender ao infinito conclui-se que

$$
o b s_{\infty}=\lim _{n \rightarrow \infty} \operatorname{COORD}^{(n)}\left(o b s_{0}\right) .
$$

A fim de se expressar a definição formal de auto-solução, considere o fato de que como o objeto $o b s_{\infty}$ representa um processo recursivo indefinido de operadores COORD em função de operadores COORD, pode-se escrever

$$
\begin{array}{ll}
\text { i) } & o b s_{\infty}=o b s_{\infty} \\
\text { ii) } & o b s_{\infty}=\operatorname{COORD}\left(o b s_{\infty}\right) \\
\text { iii) } & o b s_{\infty}=\operatorname{COORD}\left(\operatorname{COORD}\left(o b s_{\infty}\right)\right) \ldots
\end{array}
$$

Assim, qualquer procedimento recursivo indefinido escrito em termos de COORD pode ser substituído por $o b s_{\infty}$. Os valores dos $o b s$ que satisfazem as expressões i), ii), iii) e etc. acima são denominados de auto-soluções, ou especificamente Eigen-Behaviors. Em termos mais concretos, nesse campo das interações senso-motoras, isso implica em dizer que os objetos concebidos pelas pessoas são a representação de seus Eigen-Behaviors.

Uma outra exemplificação do conceito de auto-soluções pode ser pensada a partir de um exemplo matemático simples, apresentado em Segal (2001). Nesse caso, por se tratar de números estar-se-á no domínio dos autovalores. Para aproveitar a estrutura acima apresentada, defina como operador a raiz quadrada matemática, e como variável sobre a qual será aplicado o operador os números Reais positivos maiores ou iguais a 1 . Fazendo a analogia, é como se $C O O R D \approx \sqrt{ }$ e $o b s_{i} \in \Re_{+}^{*}$, tal que se $x \in \Re_{+}^{*}$, então $x \geq 1$.

A ideia do exemplo é que para qualquer número escolhido, após uma sequência grande de aplicações do operador raiz quadrada, o processo convergirá para um valor específico, isto é, o valor 1 . Nesse sentido, após a incidência desse processo recursivo indefinidas vezes, o valor inicial escolhido desaparece, permanecendo apenas o valor de equilíbrio, definido como autovalor. 
De acordo com Foerster (2003), os autovalores, ou Eigen-Values ou Eigen-Behavior e etc., podem ser caracterizados por certas propriedades. Em específico, são manifestações exteriores discretas, ao mesmo tempo em que apresentam circularidade, isto é, fecho topológico. A ideia da não continuidade está relacionada com o fato de que qualquer perturbação infinitesimal no autovalor desaparecerá com as interações dos operadores, permanecendo apenas o estado de equilíbrio original, no caso de um sistema estável. Caso o sistema seja instável, haverá a convergência para um novo autovalor, o qual, porém, será único novamente.

Esse estado de equilíbrio é único, seja o autovalor original ou aquele novo obtido após a perturbação na relação entre operador e variável. Em outros termos, de uma quantidade infinita de possíveis soluções, o processo de operação recursiva estabelece somente uma como estado de equilíbrio. De acordo com Segal (2001), esse aspecto é de extrema relevância na medida em que é só devido a essa unicidade que é possível nomear os "objetos" em análise.

Segal (2001) também aborda a noção da circularidade ou fecho das auto-soluções. Como visto, as auto-soluções produzem a si mesmas. Nesse sentido, elas ocorrem em ambientes organizados de maneira circular, ou em novos termos, em um ambiente no qual operações sobre suas variáveis sempre resultam em variáveis contidas na mesma classe daquelas originárias. É sobre a análise desses ambientes que se destina a próxima seção.

\subsection{AUTOPOIESIS}

Os ambientes organizados de modo circular denotam-se por Sistemas Fechados. Essa característica de fecho pode ser objetivamente apresentada como "An entity is systemically closed when the interactions of the elements comprising the entity are precisely those operations that produce the elements of the entity" (Segal , 2001, pág. 113). Em suma, nesses sistemas as interações produzem as suas próprias variáveis, ou elementos.

Transpondo-se a noção de sistemas fechados para entidades vivas dá-se origem ao termo autopoiesis. De acordo com Maturana e Varela (1980), autopoiesis é a condição necessária e suficiente para a caracterização da "organização" das entidades vivas, na qual por organização subentende-se as relações entre os elementos presentes na entidade. No entanto, não se trata das interações entre quaisquer elementos, mas sim entre aqueles que definem a entidade. Assim, autopoiesis está relacionada com as interações entre os elementos definidores da entidade, as quais são caracterizadas pelo fato de gerarem os insumos necessários para a manutenção e desenvolvimento da própria entidade.

Nessa breve conceituação de autopoiesis, enfatizou-se a definição da entidade a partir de seus elementos. A ideia inerente no argumento é a de que só se pode distinguir uma 
entidade a partir das propriedades de seus elementos. De acordo com os autores, a operação básica de cognição delineada pelas pessoas é a distinção. Uma entidade, ou unidade na terminologia dos autores, é concebida na medida em que esta se distingue do meio no qual está presente. Quando essa entidade é composta por elementos, são as propriedades destes que a caracterizam, pois é somente através destas que se distingue a entidade.

Além da noção de entidade e de organização apresentadas anteriormente, para Maturana e Varela (1980) um outro conceito é importante no entendimento da autopoiesis, a saber, a estrutura. Essa concatena os elementos definidores da entidade e as interações entre eles. O ponto relevante se encontra no fato de que em alguns casos a estrutura pode se alterar, mas não sua organização. Assim, mesmo sujeita às modificações na sua estrutura, uma entidade pode manter sua identidade de classe, desde que sua organização permaneça inalterada, visto que é essa que a caracteriza.

Uma fonte de alteração na estrutura advém da interação da entidade com o meio no qual se insere, isto é, o domínio das interações. Se a entidade não estiver preparada para se adaptar aos estímulos provenientes do meio, a organização sofrerá modificações e, com isso, o resultado natural será a desintegração da entidade. Contrariamente, entidade e meio podem iniciar um processo de structural coupling. Nesse, modificações na estrutura da entidade levam a estímulos ao meio que, por sua vez, devolvem novos estímulos para a entidade, sem que a organização seja transformada.

O processo de adaptação ao meio, structural coupling, não é particular de entidades vivas, conforme observam os autores. No entanto, nessas entidades a organização invariante é a autopoiesis. Desse modo, entidades ou sistemas vivos que são caracterizados pela autopoiesis são autônomos, visto que, para sua manutenção, o que se faz necessário é que as interações entre seus elementos continuem gerando as condições para a invariância delas mesmas. Se essa condição for rompida, a resultante é a desintegração da entidade ou sistema.

A possibilidade de realização do structural coupling não é a única resultante proveniente da característica fechada, autopoiética ou circular da entidade. Esse aspecto, ao estabelecer o domínio das possíveis interações da entidade, também a torna um sistema inferencial. A ideia subjacente é a de que a circularidade da entidade faz com que uma interação que ocorreu em um dado instante ocorrerá novamente se as condições do meio se repetirem. Em outros termos, a entidade está continuamente revisitando estados internos anteriormente assumidos.

Nesse sentido, ao existir a possibilidade de recorrência de estados internos da entidade, torna-se factível a realização de previsões sobre essa e, portanto, sua caracterização como um sistema inferencial. No entanto, cabe destacar, que não se trata de previsões sobre 
eventos em particular, mas sobre o conjunto de interações. Nos termos dos autores "Every interaction is a particular interaction, but every prediction is a predicition of a class of interactions that is defined by those features of its elements [...]" (Maturana e Varela, 1980, pág. 10).

Se essa previsibilidade não se confirmar, isto é, se as classes de interações deixarem de ser recorrentes, a resultante do sistema é a desintegração, visto que sua organização foi modificada. Contudo, se as previsões se confirmarem, então a entidade mantém sua integridade, e se abre a possibilidade de novas previsões, as quais estarão mais uma vez condicionadas aos estímulos do meio.

\subsection{Autopoiesis E Sistemas Sociais}

A noção de entidade ou sistemas autopoiéticos tem sido utilizada na tentativa de se elevar a compreensão sobre a manutenção e desenvolvimento dos sistemas sociais. De acordo com Luhmann (1990), os sistemas sociais podem ser interpretados como sistemas autoreferenciados, tendo como base a comunicação. Em particular, para fazer analogia com os conceitos tratados até então, nos sistemas sociais os elementos se tornam as ações ou eventos, e a comunicação faz o papel das interações entre os elementos. Trata-se de sistemas autopoiéticos pois "They exist only by reproducing the events that serve as components of the system” (Luhmann, 1990, pág. 176).

Uma consequência dessa visão de sistema é a conceituação de sociedade. Pensada nesses termos a sociedade passa a ser vista com um grande sistema, o qual abrange todos os sistemas sociais. Nas sociedades modernas esses demais sistemas ou subsistemas sociais seriam: a entidade política, a entidade econômica, a entidade científica, a entidade educacional, entre outras. Além de conter os inúmeros subsistemas sociais, é por meio da sociedade que se criam os mecanismos para que exista comunicação entre eles. Assim, a sociedade abrange toda a comunicação possível.

Do ponto de vista de cada subsistema presente na sociedade, os demais subsistemas constituem o ambiente ou meio com o qual interagem. Como visto acima, embora cada subsistema seja um sistema autopoiético autônomo, o meio exerce um papel relevante na conformação do próprio sistema. Nesse sentido, a maneira como cada sociedade gera seus subsistemas e seus meios recebe uma atenção especial. Esse processo de segregação é denominado de "diferenciação interna", ou seja, como cada sistema reproduz a divisão entre sistema e meio dentro de si mesmo.

Uma característica importante desse processo de diferenciação reside no fato de que as sociedades podem ser melhor entendidas avaliando-se o modo como procedem com a geração dos subsistemas. De acordo com Luhmann (1990) nas sociedades medievais o que se 
observava era um processo de diferenciação baseado na estratificação da hierarquia de classe. Distintamente, nas sociedades modernas o lastro da diferenciação acontece baseando-se em funções, conforme argumenta o autor

Modern society has realized a quite different pattern of system differentiation, using specific, functions as the focus for the differentiation of subsystems. Starting from special conditions in medieval Europe, where there existed a relatively high degree of differentiation of religion, politics, and economy, European society has evolved into a functionally differentiated system. This means that function, not rank, is the dominant principle of system building (Luhmann, 1990, pág. 177).

Desse modo, como argumenta o autor, parece existir uma relação direta entre o grau de complexidade presente em uma sociedade e a forma como acontece o processo de diferenciação. A sociedade moderna, baseando-se na diferenciação por funções, apresenta um elevado nível de complexidade. Com seus diversos subsistemas, tais como o científico, o político, o legal, o econômico, entre outros, e seus respectivos meios, a todo instante existem inúmeras interações acontecendo, seja entre os elementos de cada subsistema, seja entre subsistemas.

Sob essa ótica, é um exercício perigoso tentar entender a dinâmica evolutiva da sociedade a partir da observação da estrutura de um único subsistema. Por exemplo, em alguns casos é comum argumentos como o de que a dinâmica social é a dinâmica capitalista. No entanto, "Capitalism in itself is nothing other than the differentiation of the economic system out societal bonds, and it is by no means the only instance of functional differentiation" argumenta Luhmann (1990, pág. 182).

O processo de evolução da sociedade, visto como alterações em suas estruturas, conforme definida acima, na realidade advém da junção da evolução de cada um dos seus subsistemas. Em cada uma dessas entidades, vistas como sistemas autopoiéticos autônomos, o processo de diferenciação funcional continuará, dando origem a sub-subsistemas e meios, consequentemente, em elementos e inter-relações. É nesse âmbito que residem os responsáveis pela dinâmica evolutiva da estrutura do subsistema primário.

A transposição direta dos conceitos acima apresentados para as teorias econômicas, embora plausível e em andamento na literatura, pode ser delicada e árdua. Mesmo as próprias tentativas de Luhmann de fazê-la para os sistemas sociais têm sido objeto de críticas, conforme apontado em Baxter (1998). ${ }^{19}$ Concomitantemente, foge ao escopo do presente trabalho tentar fazer uma interpretação de seu objeto de estudo, as teorias de determinação do valor relativo dos bens de uma economia, como sistemas autopoiéticos. Relevante é o fato de que do ponto de vista epistemológico, a abordagem construtivista e seus conceitos de sistemas

\footnotetext{
${ }^{19}$ Para exemplo de aplicação vide Carvalho e Deakin (2009) e Lourenço (2010).
} 
autopoiéticos e auto-soluções fornecem o respaldo teórico necessário para interpretação e tratamento hipóteses relacionadas a pontos de equilíbrio, discretos e circulares.

Fazendo novamente alusão ao processo de geração do conhecimento de Krohn e Küppers (1990), se a Epistemologia Construtivista auxilia na sustentação do lado da Teoria, no que tange o lado do Método o tratamento de hipóteses precisas exige um instrumental analítico particular. Desse modo, as novas abordagens Bayesianas para verificação de hipóteses de teste surgem como uma alternativa relevante frente às técnicas tradicionais. É por meio dessa ótica que as próximas seções devem ser lidas.

\subsection{Testes de Hipóteses Bayesianos}

O paradigma Bayesiano de análise estatística tem na distribuição a posteriori do parâmetro avaliado o seu objeto chave de investigação. Para os pesquisadores Bayesianos essa distribuição incorpora toda a informação disponível sobre o parâmetro, a qual advém da combinação da informação inicial sobre o mesmo, a distribuição a priori, juntamente com a informação contida nos dados, materializada na verossimilhança.

Nesse paradigma as avaliações sobre o parâmetro são realizadas por meio de cálculos sobre a distribuição a posteriori, sendo através desta realizadas todas as estimativas do processo inferencial. A informação contida nessa distribuição pode ser sumarizada graficamente ou por medidas quantitativas de localização, dispersão e de forma funcional. Especificamente, pode-se trabalhar com medidas de estimação pontual, de estimação por intervalo, testes de hipóteses ou com medidas de predição.

No que se refere aos testes de hipóteses, a avaliação destas é realizada simplesmente através do cálculo de suas respectivas probabilidades, isto é, $\operatorname{Pr}\left(H_{0}\right), H_{0}: \theta \in \Theta_{0}$, e $\operatorname{Pr}\left(H_{1}\right), \quad H_{1}: \theta \in \Theta_{1}=\Theta-\Theta_{0}$, no qual $\Theta$ é o espaço paramétrico. A escolha por uma das hipóteses em confronto está baseada na construção de uma grandeza relativa, a qual é representada pelo Fator de Bayes. A medida visa quantificar o peso relativo da evidência contida nos dados a favor de uma das hipóteses avaliadas, sendo expressa matematicamente por

$$
B(x)=\frac{\operatorname{Pr}\left(H_{0} \mid x\right) / \operatorname{Pr}\left(H_{1} \mid x\right)}{\operatorname{Pr}\left(H_{0}\right) / \operatorname{Pr}\left(H_{1}\right)},
$$

na qual $\operatorname{Pr}\left(H_{i} \mid x\right)$ e $\operatorname{Pr}\left(H_{i}\right), \mathrm{i}=\{1,2\}$, representam, respectivamente, a probabilidade $a$ posteriori e a priori das hipóteses consideradas. 
O processo de escolha de uma das hipóteses em confronto a partir do Fator de Bayes é complementado com a implementação dos fatores analíticos da teoria da decisão, tais como a função de perda natural, a função crítica do teste e o cálculo dos riscos a posteriori da decisão. Para um dado vetor de observações da variável aleatória $X$, a melhor escolha dentre as hipóteses em questão é aquela que minimiza o risco a posteriori.

Os procedimentos inferenciais dos testes de hipóteses Bayesianos acima descritos podem ser facilmente generalizados para serem utilizados na comparação e seleção de modelos. Em termos similares, o próprio teste de hipóteses paramétrico expresso anteriormente pode ser encarado como uma avaliação de dois grupos de modelos distintos, os quais se matizam devido à diferença nos parâmetros indexadores das famílias de distribuições amostrais. Com o intuito de ilustrar a aplicação suponha a existência de "n" modelos concorrentes, $M=\left\{M_{i}, i=1,2, \ldots, n\right\}$, originando as seguintes distribuições preditivas $a$ priori

$$
P\left(x \mid M_{i}\right)=\int_{\Theta} f_{i}\left(x \mid \theta_{i}\right) h\left(\theta_{i}\right) d \theta_{i}, i=1,2, \ldots, n,
$$

nas quais $f_{i}\left(x \mid \theta_{i}\right)$ e $h\left(\theta_{i}\right)$ são, respectivamente, a densidade de x e a priori de $\theta$ sob a ótica do modelo $M_{i}$. Com base nessas e na distribuição a priori para os modelos, $P\left(M_{i}\right), i=1,2, \ldots, n$, é possível se definir a densidade preditiva global de $\mathrm{x}$, expressa por

$$
P(x)=\sum_{i=1}^{n} P\left(M_{i}\right) P\left(x \mid M_{i}\right)
$$

As distribuições acima expressas servem de base para a configuração da Fórmula de Bayes, na qual a probabilidade dos modelos é atualizada a partir da informação contida nos dados. Em termos matemáticos tem-se

$$
P\left(M_{i} \mid x\right)=\frac{P\left(M_{i}\right) P\left(x \mid M_{i}\right)}{P(x)}, i=1,2, \ldots, n
$$

Do mesmo modo que os procedimentos ordinários de teste de hipóteses Bayesianos, pode-se utilizar as distribuições a priori e a posteriori dos modelos para se construir o Fator de Bayes, permitindo desta forma criar a medida de grandeza relativa necessária para a comparação entre eles. Em termos concretos, no caso de dois modelos distintos, o Fator de Bayes é dado por

$$
B_{i j}(x)=\frac{P\left(M_{i} \mid x\right) / P\left(M_{j} \mid x\right)}{P\left(M_{i}\right) / P\left(M_{j}\right)},
$$


sendo a escolha de um deles determinada a partir da incorporação do cenário de decisão e seus respectivos atributos.

Até o momento considerou-se que as hipóteses avaliadas possuíam probabilidade $a$ priori positiva, tanto no caso mais geral, $H_{0}: \theta \in \Theta_{0}$ e $H_{1}: \theta \in \Theta_{1}$, quanto no caso da seleção de modelos, $H_{0}: M=M_{i}$ e $H_{1}: M \neq M_{i}$. Contudo, se estiver utilizando uma priori contínua, a definição de uma hipótese simples do tipo $H_{0}: \theta=\theta_{0}$ versus $H_{1}: \theta \neq \theta_{0}$ pode inviabilizar os procedimentos inferenciais abordados. Esse aspecto decorre do fato de que a Fórmula de Bayes não permite atualizar uma probabilidade nula a priori.

Uma primeira maneira de se contornar o problema reside na incorporação de uma distribuição a priori mista, na qual uma massa de probabilidade pontual é dada a $H_{0}$, e o restante da probabilidade distribuída de forma contínua nos demais valores de $\theta$. Esse procedimento é fundamentado na noção de que a própria hipótese $H_{0}: \theta=\theta_{0}$ enseja informação relevante sobre o parâmetro. Especificamente, definida como tal, a hipótese atribui um grau de importância maior a $\theta_{0}$ do que aos demais valores de $\theta$, justificando assim a massa concentrada de probabilidade.

Uma maneira distinta de se pensar sobre o problema das hipóteses categóricas é tratar $H_{0}: \theta=\theta_{0}$ como irrealista. Na verdade, ao se formular uma hipótese como tal não se está considerando somente o $\theta_{0}$, mas toda uma gama de valores de $\theta$ próximos a este. Em outros termos, tanto $\theta_{0}$ quanto os seus vizinhos mais próximos possuem crenças a prioristicas relativamente homogêneas. Nesse sentido, a hipótese $H_{0}: \theta=\theta_{0}$ deve no fundo ser interpretada como $H_{0}: \theta=V_{\varepsilon}\left(\theta_{0}\right)$, no qual $V_{\varepsilon}($.$) representa uma esfera centrada em \theta_{0}$ com raio $\varepsilon \cdot^{20}$

Um terceiro modo de se avaliar as hipóteses simples, dado distribuições a priori contínuas para os parâmetros, é construir uma região de credibilidade $\gamma$ para $\theta$, aceitando a hipótese nula se $\theta_{0}$ estiver contido na região. Ao se proceder dessa maneira está se alterando a forma de analisar as hipóteses, de um cálculo inicial do peso relativo dos dados a favor de $H_{0}$, medido pelo Fator de Bayes, para uma mensuração da plausibilidade de $\theta_{0}$ frente aos demais valores do parâmetro.

A construção da região de credibilidade $\gamma$ para $\theta$ pode estar alicerçada em um conhecimento a priori sobre o parâmetro, assim como no desejo de um determinado nível de confiança para o intervalo. A fim de se mitigar o inconveniente de se possuir nesse intervalo

\footnotetext{
${ }^{20}$ Para maiores detalhes vide Casella e Berger (1987).
} 
valores de $\theta$ que tenham menor credibilidade do que os valores não contidos no mesmo, os pesquisadores têm se utilizado dos intervalos HPD (Highest Posterior Density), nos quais, para um nível dado de credibilidade do intervalo, os valores de $\theta$ apresentam as maiores densidades.

Assim como a construção de intervalos de credibilidade para $\theta$, a plausibilidade de $\theta_{0}$ também pode ser analisada calculando-se a probabilidade dos valores de $\theta$ com densidade maior ou igual à densidade de $\theta_{0}$, expresso da seguinte maneira:

$$
R(x)=\left\{\theta: h(\theta \mid x) \geq h\left(\theta_{0} \mid x\right)\right\} .
$$

A probabilidade de que $\theta \in R(x)$ pode ser encarada como uma medida da não pertinência da hipótese $H_{0}: \theta=\theta_{0}$, no sentido de que se está for muito grande, elevado também é o volume de valores de $\theta$ mais plausíveis do que $\theta_{0}$.

Consoante com Murteira et al. (2003), este último método tem sido utilizado no caso de estudo multiparamétricos, nos quais os procedimentos de teste de hipóteses ordinários não são pertinentes, e o cálculo das probabilidades pode ser bastante trabalhoso. O Full Bayesian Significance Test (FBST) busca avançar com estas técnicas no caso de vários parâmetros e hipóteses precisas, $\operatorname{dim}\left(\Theta_{0}\right)<\operatorname{dim}(\Theta)$. Devido a sua relevância para o presente trabalho, o teste será estudado em detalhes nas próximas seções.

\subsection{FBST: FormulaÇÃo MetodolóGiCA}

Nos parágrafos anteriores procurou-se evidenciar que o tratamento e a mensuração do suporte estatístico de hipóteses precisas coloca uma série de dificuldades metodológicas para a abordagem Bayesiana tradicional, a qual procura responder às questões relacionadas com os testes de hipóteses através do Fator de Bayes e da utilização de procedimentos conceituais da teoria da decisão. A introdução de densidades a priori com massa de probabilidade positiva na hipótese precisa foi uma das soluções encontradas por essa abordagem para contornar o problema. ${ }^{21}$

A mudança no modo de se avaliar a hipótese nula, partindo do cálculo de uma grandeza relativa baseada nas probabilidades das hipóteses em direção à mensuração da plausibilidade da hipótese nula em relação aos demais valores do parâmetro, tem se apresentado como uma alternativa de sucesso no tratamento das hipóteses precisas. Dentre as abordagens Bayesianas, distintas daquelas voltadas ao Fator de Bayes e à teoria da decisão,

\footnotetext{
${ }^{21}$ A Estatística frequentista clássica também se depara com dificuldades metodológicas ao tratar das hipóteses precisas ou categóricas.
} 
está o FBST. O teste foi inicialmente proposto por Pereira e Stern (1999) como uma forma de se avaliar hipóteses precisas através do cálculo de medidas de evidência.

Embora o FBST tenha alterado a maneira de como se extrair informação dos dados sobre a hipótese a ser testada, cabe observar que o teste não se mostra incompatível com a teoria da decisão, a qual segundo Stern (2004) se apresenta como alicerce da abordagem Bayesiana tradicional. Tanto o FBST quanto a teoria da decisão provisionam um sistema coerente para utilização dos conceitos da Probabilidade. Além disso, Madruga et al. (2001), ao definir uma função perda para as decisões feitas a partir da implementação do FBST, garante a coerência do teste com a teoria.

De acordo com Stern (2004), o FBST também apresenta atributos positivos em relação aos procedimentos tradicionais Bayesianos no que se refere à metodologia estatística e a consistência lógica. Esses serão introduzidos ao longo da seção, à medida que forem sendo apresentandos os conceitos do teste. Do ponto de vista epistemológico e ontológico, o autor argumenta que o teste está alinhado com a perspectiva construtivista da geração do conhecimento científico, visto que trata de modo coerente as hipóteses precisas, experimentalmente e teoricamente.

O FBST é metodologicamente considerado um teste "Bayesiano Completo" (Full Bayesian), visto que a elaboração de uma medida de evidência para a hipótese precisa depende somente da distribuição a posteriori. Especificamente, o teste não necessita de hipóteses adicionais, como uma priori positiva para a hipótese precisa. Além disso, o FBST é coerente com o princípio da Verossimilhança Bayesiano, segundo o qual a informação obtida dos dados observados está toda representada na função de verossimilhança.

A caracterização do FBST fica facilitada se se pensa no teste como sendo composto por duas partes: a primeira definida pela determinação de uma região tangente a hipótese nula, denominada Highest Posterior Density Set (HPDS) e, a segunda, pelo cálculo da credibilidade do conjunto HPDS. Embora as definições propostas nessas duas partes do teste tratem de procedimentos gerais, merece ser destacado que o teste foi concebido para se avaliar hipóteses precisas, nas quais a dimensão da hipótese nula é inferior à dimensão do espaço paramétrico.

Com o intuito de apresentar metodologicamente o teste, considere inicialmente a hipótese nula precisa, $H_{0}: \theta \in \Theta_{0}$, na qual $\Theta_{0} \subset \Theta \subseteq R^{n}$ e $\Theta$ é o espaço paramétrico. Seja $\theta^{*}$ o argumento máximo da posteriori $h(\theta \mid x)$ sob a hipótese nula, $\theta^{*}=\operatorname{argmax}_{\theta \in \Theta_{0}} h(\theta \mid x)$. Assim, pode-se definir o intervalo HPDS como

$$
H P D S=\left\{\theta \in \Theta \mid h(\theta \mid x)>h\left(\theta^{*} \mid x\right)\right\} .
$$


O intervalo contém todos os valores do parâmetro $\theta$ para os quais a densidade $a$ posteriori assume valores superiores ao maior ponto dentro do intervalo definido pela hipótese nula.

Para se calcular a credibilidade do conjunto HPDS integra-se a densidade a posteriori neste intervalo, sendo matematicamente expressa por

$$
k=\int_{\theta \in H P D S} h(\theta \mid x) d \theta
$$

O complemento da probabilidade do conjunto HPDS, as vezes denominada de $\boldsymbol{e}$-valor, é a medida de evidência da hipótese nula proposta por Pereira e Stern (1999),

$$
E v\left(H_{0}\right)=1-k .
$$

Como uma medida de probabilidade do HPDS, a evidência a favor da hipótese nula varia no intervalo $[0,1]$, sendo a hipótese sob avaliação tanto mais plausível quanto mais o valor da evidência se aproximar da unidade. A lógica inerente à medida de evidência considerada é a de que se a credibilidade do HPDS é relativamente elevada, então o conjunto de valores dos parâmetros pertencentes a $\Theta_{0}$ ocupa uma região de baixa probabilidade na posteriori. Inversamente, quanto menor for a probabilidade do HPDS, mais plausível se torna a hipótese nula, visto que os valores dos parâmetros sob esta possuem densidades relativas elevadas.

A implementação dos cálculos para a obtenção da evidência a favor da hipótese nula é realizada em duas etapas: a primeira de otimização e a segunda de integração. Essas etapas descrevem respectivamente os procedimentos para consecução das partes do teste acima expostas. Através do processo de otimização se obtém o argumento $\theta^{*}$ que maximiza a posteriori sob $H_{0}$, permitindo a definição do intervalo HPDS. No caso da integração, esta serve para a consecução da credibilidade do conjunto HPDS, e consequentemente da $E v\left(H_{0}\right)$

Conforme será apresentado na sequência, quando exposto à implementação do teste, a não trivialidade analítica da distribuição a posteriori implica que essas etapas sejam realizadas, de modo geral, numericamente. No que tange a primeira etapa, a de definição do intervalo HPDS, esta pode ser realizada recorrendo-se a algoritmos numéricos gerais de otimização. ${ }^{22}$ Distintamente, a etapa de integração deve ser especificamente formatada para cada problema em específico. Para tal pode-se utilizar as ferramentas padrões dos

\footnotetext{
${ }^{22}$ Para exemplos desses algoritmos vide Birgin e Martinez (2002) e Birgin et al. (2005).
} 
procedimentos inferenciais Bayesianos, como o método de Monte Carlo e a técnica de Cadeias de Markov com Monte Carlo, MCMC. ${ }^{23}$

No caso dos procedimentos de Monte Carlo com amostragem de importância, técnica aplicada quando se tem dificuldade para simular diretamente da distribuição a posteriori de interesse, Zacks e Stern (2003) expõem mecanismos para reduzir a variabilidade do estimador, tornando o procedimento de aproximação de integrais mais eficiente. Dessa forma, nos casos em que esse instrumental é necessário, a determinação da medida de evidência a favor da hipótese nula se torna mais precisa.

Além das melhorias nos procedimentos de implementação do FBST, tais como as apresentadas por Zacks e Stern (2003), após a divulgação do teste, outros estudos buscaram elevar o seu potencial de aplicabilidade. Madruga et al. (2003) apresentaram uma distinta formulação do FBST, a qual permite tornar a medida de evidência invariante para transformações de coordenadas gerais do espaço paramétrico. Seja $\omega=\phi(\theta)$ uma reparametrização, na qual $\phi$ é uma função mensurável e integrável. Os autores demonstram que sob certas condições a medida de evidência da $H_{0}: \theta \in \Theta_{0}$ é a mesma da $H_{0}: \omega \in \Omega_{0}$, na qual $\Omega_{0}=\phi\left(\Theta_{0}\right)$.

A fim de caracterizar o teste com essa propriedade, ao invés de se trabalhar diretamente com a posteriori, a proposta é utilizar a função relative surprise, definida por $s(\theta)=h(\theta \mid x) / r(\theta)$, na qual $r(\theta)$ representa uma densidade de referência com domínio também em $\Theta$. Sob essa nova caracterização, seja $\dot{\theta}^{*}$ o argumento máximo da relative surprise sob a hipótese nula, $\dot{\theta}^{*}=\operatorname{argmax}_{\theta \in \Theta_{0}} s(\theta)$. Assim, pode-se redefinir o HPDS como o intervalo HRSS, Highest Relative Surprise Set, dado por

$$
H R S S=\left\{\theta \in \Theta \mid s(\theta)>s\left(\dot{\theta}^{*}\right)\right\} .
$$

A medida de evidência da hipótese nula é então dada pelo complemento da credibilidade do conjunto HRSS, sendo matematicamente expressa por

$$
E v\left(H_{0}\right)=1-k, \text { na qual } k=\int_{\theta \in H R S S} h(\theta \mid x) d \theta .
$$

Resta apenas observar, assim como fazem os autores, que se $r(\theta) \propto 1$ os conjuntos HPDS e HRSS coincidem, e também a formulação da medida $E v($ ).

\footnotetext{
${ }^{23}$ Murteira et al. (2003) discutem as técnicas de implementação do algoritmo de Monte Carlo ordinário e por amostragem de importância. Gelman et al. (1998) avançam com essas técnicas tratando de Monte Carlo com Cadeias de Markov. Gilks et al. (1996) apresentam as especificidades dessa última técnica.
} 


\subsection{Avaliação dos Procedimentos de Teste}

Tradicionalmente, na literatura de inferência estatística, caracteriza-se o processo de teste de hipóteses estando sujeito a dois tipos de erro. Em um primeiro caso, denominado de Erro do Tipo I, o pesquisador rejeita a hipótese nula quando na realidade esta é verdadeira. Uma segunda possibilidade de erro, decorrente da decisão do pesquisador, acontece quando ele aceita a hipótese nula, sendo a hipótese alternativa a verdadeira. Esse erro é tratado como Erro do Tipo II.

Em linhas gerais, um procedimento de teste eficiente deve reduzir ao máximo esses dois tipos de erro, ou seja, no limite torná-los nulos. No entanto, de acordo com DeGroot e Schervish (2000), a possibilidade de erro existe virtualmente em todo problema de teste de hipóteses, sendo improvável reduzi-los a zero. Nesse sentido, uma vez determinado os dois tipos de erro para os procedimentos de teste a serem adotados, cabe ao pesquisador escolher o procedimento que minimize o valor total do erro a ser incorrido.

O exposto acima remete ao pressuposto conhecido entre os estatísticos de que todo procedimento de teste pode ser caracterizado pelas chances de aceitação e rejeição da hipótese nula, ou em termos pragmáticos, pela determinação dos erros dos Tipos I e II. A fim de auxiliar na caracterização dos testes, a teoria estatística se utiliza do conceito da função poder. Essa função especifica, para cada valor do parâmetro a ser tratado, a probabilidade de que um dado procedimento de teste rejeite a hipótese nula.

Em termos matemáticos, suponha $H_{0}: \theta \in \Theta_{0}$ como a hipótese nula e $H_{1}: \theta \in \Theta_{1}$ como hipótese alternativa, na qual $\Theta_{0}$ e $\Theta_{1}$ é uma partição disjunta do espaço paramétrico $\Theta$ . Seja $\mathrm{C}$ a região crítica, isto é, o conjunto de valores de variável aleatória $\mathrm{X}$ analisada para os quais se rejeita $H_{0}$. Nesses termos, a função que satisfaz a seguinte definição é denominada de função poder:

$$
\pi(\theta \mid \zeta)=\operatorname{Pr}(X \in C \mid \theta) \text { para todo } \theta \in \Theta
$$

na qual $\zeta$ é um dado procedimento de teste.

Utilizando-se da definição da função poder, o cenário desejado, de se minimizar a possibilidade de erro nos testes de hipóteses, poderia ser expresso em termos de baixos valores de $\pi(\theta \mid \xi)$ para $\theta \in \Theta_{0}$, probabilidade do Erro do Tipo I, e elevados valores de $\pi(\theta \mid \xi)$ quando $\theta \in \Theta_{1}$, o complementar da probabilidade do Erro Tipo II. No entanto, novamente esse não é um objetivo de um todo factível, dado que ao se tentar reduzir o valor de $\pi(\theta \mid \xi)$ para $\theta \in \Theta_{0}$, incorre-se também na baixa do valor da função poder na hipótese 
alternativa. Assim sendo, torna-se central para um procedimento de teste achar um equilíbrio entre os valores de $\pi(\theta \mid \zeta)$ na hipótese nula e na alternativa.

A utilização do FBST para a realização dos testes de hipóteses também está sujeita à ocorrência dos erros Tipo I e II. Em linhas gerais, para o teste a origem dos erros reside no fato de que as observações da variável em análise possuídas pelo pesquisador representam apenas uma das suas inúmeras realizações possíveis. Especificamente, a constatação acima implica que para cada diferente elemento do espaço amostral tem uma nova função de verossimilhança, alterando o valor da evidência. Dessa maneira, no FBST a avaliação dos erros é uma forma de quantificar o impacto de outras funções de verossimilhança sobre a evidência.

De maneira diferente de outros testes de hipóteses, para análise dos quais é possível a construção da função poder objetiva, no caso do FBST o cálculo das chances dos erros Tipo I e II não é trivial. Uma primeira proposta é a utilização de simulação estocástica. Basicamente, ambos os erros são obtidos com a determinação de novas evidências contrárias à hipótese nula a partir da simulação de conjuntos de amostras para a variável em questão. Inicialmente, simulam-se novos dados para a variável através da função verossimilhança parametrizada pelo estimador de máxima verossimilhança (EMV) calculado na hipótese nula. O próximo passo é repetir a simulação, substituindo o valor dos parâmetros pelo EMV obtido no espaço paramétrico completo. Após determinar-se a evidência para cada novo conjunto amostral, estipula-se a região crítica, avaliando as chances da evidência contrária a hipótese nula pertencer a esta.

Essa abordagem é apresentada em Lauretto et al. (2003), os quais avançam na proposição de propriedades para a medida de evidência gerada através do FBST quando abordam o erro total decorrente da aceitação ou rejeição da hipótese nula incorretamente. Contudo, diferentemente da medida de evidência inicialmente proposta por Pereira e Stern (1999), os autores trabalham diretamente com a credibilidade do intervalo de valores do parâmetro com densidade superior ao máximo obtido sob a hipótese nula. Nesse sentido, estão medindo a evidência contrária à hipótese em consideração, e não a seu favor, como até então se vinha tratando.

No caso de se procurar estimar as chances de rejeição de $H_{0}$ quando esta for verdadeira, Erro Tipo I, pode-se optar pela determinação de um nível crítico para a evidência contrária à hipótese nula a partir do qual se decide pela sua não aceitação. A definição desse nível é feita por meio do cálculo de quantis. Utilizando os valores de $\theta^{*}$ como parâmetros da função de verossimilhança $L(x \mid \theta)$, simulam-se novos conjuntos de valores para a variável $\mathrm{X}$, ou seja, $\dot{x}_{i j}, i=1,2, \ldots, n$ e $j=1,2, \ldots, m$, sendo "n" o tamanho de cada amostra e "m" o 
número de amostras simuladas. Para cada nova amostra de $\dot{x}_{\bullet_{j}}$ calcula-se a medida de evidência $e_{j}^{*}=E v c_{\theta^{*}}\left(H_{0}\right)_{j}$. Com todas as medidas determinadas, estabelece-se o quantil $\lambda=q_{\alpha ; n}\left(\theta^{*}\right)$, no qual $(1-\alpha)$ é o nível de credibilidade desejado.

A estimativa do poder do teste e, consequentemente, das chances de aceitação indevida de $H_{0}$, Erro Tipo II, pode ser feita de modo semelhante à determinação do nível de credibilidade. Inicialmente simulam-se conjuntos de valores $\hat{x}_{i j}, i=1,2, \ldots, n$ e $j=1,2, \ldots, m$, a partir da verossimilhança parametrizada por $\hat{\theta}$, o valor do parâmetro que maximiza $a$ posteriori sem restrições. Para cada conjunto $\hat{x}_{\bullet j}$, determina-se a evidência contrária à hipótese testada, $\hat{e}_{j}=E v c_{\hat{\theta}}\left(H_{0}\right)_{j}$. A estimativa do poder do teste, $(1-\beta)$, é dada pela fração das medidas de evidência $\hat{e}_{j}$ que são superiores ao nível $\lambda$. Nesse caso, $\beta$ é uma estimativa da chance de se incorrer no Erro Tipo II.

Diferentemente de Lauretto et al. (2003), que utilizam a simulação como forma de se avaliar as chances de erro ao se optar pela rejeição ou aceitação da hipótese nula, Stern (2006) desenvolve uma formulação analítica para determinar intervalos de credibilidade para a medida de evidência contrária a $H_{0}$. De acordo com o autor, para um conjunto inicial de valores de $\mathrm{X}$ crescente, $x_{l}, l \rightarrow \infty$, somada a condições de regularidades apropriadas e a um valor verdadeiro do parâmetro dado por $\theta^{0}$, a distribuição cumulativa da evidência contrária, $\bar{V}(c)=\operatorname{Pr}\left(E v c\left(H_{0}\right) \leq c\right)$, tem as seguintes características:

- Se $H_{0}$ é falsa, $\theta^{0} \notin H_{0}$, então $\operatorname{Evc}\left(H_{0}\right)$ converge em probabilidade para 1 , e $\bar{V}(1) \rightarrow 0$;

- Se $H_{0}$ é verdadeira, $\theta^{0} \in H_{0}$, então $\bar{V}(c)$ converge em distribuição para

$$
\begin{aligned}
& Q Q\left(d_{1}, d_{0}, c\right)=Q\left(d_{1}-d_{0}, Q^{-1}\left(d_{1}, c\right)\right), \text { na qual } \\
& Q(k, x)=\frac{\Gamma(k / 2, x / 2)}{\Gamma(k / 2, \infty)}, \quad \Gamma(k, x)=\int_{0}^{x} y^{k-1} e^{-y} d y,
\end{aligned}
$$

$d_{1}=\operatorname{dim}(\Theta), d_{0}=\operatorname{dim}\left(H_{0}\right)$ e $Q(k, x)$ é a distribuição cumulativa Qui-quadrado com "k" graus de liberdade.

\subsection{FBST: SELEÇão DE MODELOS}

$\mathrm{O}$ argumento de que os mecanismos de teste de hipóteses Bayesianos podem ser facilmente estendidos para o processo de seleção de modelos, conforme descrito no início do 
capítulo com o Fator de Bayes, também é válido no caso do FBST. Pereira e Stern (2001) expandem o escopo da aplicabilidade do teste, utilizando-o para comparar e selecionar modelos concorrentes de regressão linear múltipla.

Um aspecto positivo da utilização do FBST na seleção de modelos é a sua capacidade de penalizar a parametrização excessiva dos modelos. De acordo com Pereira e Stern (2001), sob condições gerais, o critério de avaliação do FBST possui um mecanismo de regularização intrínseco. Esse mecanismo de penalização está alicerçado no tratamento de distribuições a posteriori completas, ou seja, na permanência na dimensão original do vetor de parâmetros. Diversamente do sugerido por Basu (1988), os parâmetros perturbadores não precisam ser eliminados dos cálculos estatísticos para a implementação do FBST. ${ }^{24}$

Pereira e Stern (2001) tratam no artigo da comparação e seleção de modelos aninhados, isto é, caso em que a partir de restrições no modelo mais geral obtém-se um modelo mais reduzido, denominado de aninhado. A fim de se ilustrar a técnica do FBST para esses tipos de modelos, suponha inicialmente que se tem um Modelo Geral dado por

$$
y_{i}=X_{i} \beta+\varepsilon_{i},
$$

no qual $y_{i}$ é a variável dependente, $X_{i}$ é um vetor de variáveis exógenas, $\boldsymbol{\beta}$ é vetor dos parâmetros a serem estimados de tamanho "k" , $\varepsilon_{i}$ é o termo de erro, suposto ser independente e normalmente distribuído com média zero e variância $\sigma_{0}^{2}$ para todo i , $\varepsilon_{o i} \sim N\left(0, \sigma_{0}^{2}\right), \mathrm{i}=1,2, \ldots, \mathrm{n}$. Imagine que se deseja comparar o Modelo Geral com um Modelo Aninhado, entre os quais a única diferença reside no vetor de parâmetros. Seja $\beta$ esse vetor para o Modelo Aninhado. Especificamente, considere que $\beta_{k}=0$ no vetor $\beta^{\prime}$.

No caso de se possuir uma informação inicial vaga ou difusa sobre os parâmetros em questão, $\beta$ e $\sigma$, pode-se atribuir uma distribuição $a$ priori não informativa, do tipo

$$
h(\boldsymbol{\beta}, \sigma) \propto \frac{1}{\sigma}, \quad-\infty<\beta_{j}<\infty, j=1,2, \ldots, k \quad \text { e } \quad 0<\sigma<\infty .
$$

Considerando-se essa distribuição com a função de verossimilhança do Modelo Geral, e aplicando a fórmula de Bayes, obtém-se a seguinte densidade a posteriori, conforme descrito em Zellner (1971),

$$
h(\boldsymbol{\beta}, \sigma \mid y, x) \propto \frac{1}{\sigma^{n+1}} \exp \left\{-\frac{1}{2 \sigma^{2}}\left[v s^{2}+(\boldsymbol{\beta}-\hat{\boldsymbol{\beta}})^{\prime} X^{\prime} X(\boldsymbol{\beta}-\hat{\boldsymbol{\beta}})\right]\right\},
$$

\footnotetext{
${ }^{24}$ Denomina-se parâmetro perturbador, ou nuisance parameter no inglês, o parâmetro que não faz parte do interesse do pesquisador para uma dada análise estatística.
} 
na qual $v=n-k$

$$
\begin{gathered}
\hat{\boldsymbol{\beta}}=\left(X^{\prime} X\right)^{-1} X Y, \\
s^{2}=\frac{(Y-X \hat{\boldsymbol{\beta}})^{\prime}(Y-X \hat{\boldsymbol{\beta}})}{v} .
\end{gathered}
$$

A posteriori pode ser fatorada em uma parte com distribuição normal multivariada em $\boldsymbol{\beta}$ dado $\sigma$, com média $\hat{\boldsymbol{\beta}}$ e matriz de covariância $\left(X^{\prime} X\right)^{-1} \sigma^{2}$, e uma distribuição marginal gama inversa para $\sigma$, na qual os parâmetros são dados por $v$ e $s^{2}$.

A implementação do FBST para a comparação e seleção de modelos é feita de maneira semelhante à aplicação do teste para avaliação de hipóteses precisas, descrito na seção anterior. A primeira etapa consiste na maximização da distribuição a posteriori sob a hipótese nula $H_{0}: \beta_{k}=0$, resultando no vetor de parâmetros ótimos $\theta^{*}=\left[\beta_{0}^{*}, \beta_{1}^{*}, \ldots, \beta_{k-1}^{*} ; \sigma^{*}\right]$ e concomitantemente na determinação do intervalo HPDS.

A etapa subsequente é dada pela integração da posteriori completa no intervalo HPDS, obtendo-se a credibilidade do conjunto de valores do parâmetro, ou seja, a evidência contrária à hipótese nula. Em casos multidimensionais como o apresentado, a aplicação do algoritmo de Monte Carlo com amostragem por importância é uma boa opção para se poder estimar a integral em questão.

A medida de evidência contrária a $H_{0}$, gerada pela implementação do FBST, é um indicador da falta de plausibilidade do Modelo Aninhado. Valores elevados, isto é, próximos à unidade, sugerem que o modelo reduzido não se ajusta bem ao conjunto de dados analisados, evidenciando que a variável $X_{k}$ agrega pouca informação para a modelagem de $Y$. Em termos da densidade, uma medida elevada para a evidência representa o fato de que a hipótese nula permeia uma região de baixa densidade. O inverso das constatações é válido quando a evidência contrária se aproxima de zero.

As técnicas de implementação do FBST para avaliação e seleção de modelos aninhados servem de base para a análise comparativa de modelos não aninhados. Modelos não aninhados são aqueles em que um modelo não é subconjunto do outro, não podendo obter um por meio da imposição de restrições ao outro. Seguindo a linha da ilustração apresentada até o momento, suponha o Modelo Não Aninhado expresso segundo

$$
y_{i}=Z_{i} \gamma+\tau_{i}
$$


no qual $y_{i}$ é a variável dependente, $Z_{i}$ é um vetor de variáveis exógenas, $\gamma$ é vetor dos parâmetros a serem estimados de tamanho $l, \tau_{i}$ é o termo de erro, suposto ser independente e normalmente distribuído com média zero e variância $\sigma_{1}^{2}$ para todo “i” , $\tau_{i} \sim N\left(0, \sigma_{1}^{2}\right)$, $\mathrm{i}=1,2, \ldots, \mathrm{n}$. Esse modelo não está aninhado no Modelo Geral dado que a matriz de valores $\mathbf{Z}_{n \times l}$ não é um subconjunto de $\mathbf{X}_{n \times k}$.

Considere que se deseja comparar o Modelo Geral, apresentado acima, com o Modelo Não Aninhado através da utilização do FBST, avaliando qual dos modelos melhor se ajusta a um determinado conjunto de dados. Nesse caso, o primeiro procedimento a ser executado é a definição de um modelo conjunto para os dados, denominado em diante de Modelo Expandido. Esse modelo será formado pela junção de todas as variáveis explicativas singulares do Modelo Geral com as variáveis singulares do Modelo Não Aninhado, mais as variáveis comuns em ambos os modelos. Estatisticamente esse processo é denominado de aninhamento mecânico. Algebricamente, para um cenário no qual a única variável em comum entre os modelos é a constante, tem-se

$$
y_{i}=\omega_{0}+X_{i}^{[c]} \boldsymbol{\omega}_{X}+Z_{i}^{[c]} \boldsymbol{\omega}_{Z}+\mu_{i}
$$

no qual $Z_{i}^{[c]}$ é o vetor de variáveis independentes presentes somente no Modelo Não Aninhado, com exceção da constante, $X_{i}^{[c]}$ é o vetor de variáveis explicativas do Modelo Geral sem a constante, $\omega_{X}$ e $\omega_{Z}$ são vetores de parâmetros, e $\mu_{i} \sim N\left(0, \sigma_{E}^{2}\right)$, para $\mathrm{i}=1,2, \ldots, \mathrm{n}$.

Com a utilização de uma distribuição a priori não informativa nos parâmetros $\omega=\left[\omega_{0}, \omega_{X}, \omega_{Z}\right]$ e $\sigma_{E}$ do tipo apresentada anteriormente, a densidade a posteriori do Modelo Expandido tem a mesma forma da distribuição do Modelo Geral, alterando apenas o número de parâmetros a serem estimados. Em outros termos, a densidade do Modelo Expandido pode ser fatorada em uma parte com distribuição normal multivariada em $\omega$, condicionada ao valor de $\sigma_{E}$, e uma distribuição marginal gama invertida para $\sigma_{E}$.

A implementação do FBST para a obtenção das evidências contrárias a cada um dos modelos considerados é realizada nos mesmos moldes daquela exposta para a comparação de modelos aninhados. Primeiramente se maximiza a posteriori sob a hipótese nula, determinando os parâmetros ótimos e o intervalo HPDS. Na sequência integra-se essa densidade no intervalo descrito, resultando no cálculo da credibilidade do HPDS e, consequentemente, na medida de evidência desejada. 
Se o intuito é avaliar a plausibilidade do Modelo Geral, pode-se utilizar o FBST para testar se a hipótese de que todas as variáveis singulares a este modelo não agregam informação ao Modelo Expandido, ou seja, $H_{0}: \boldsymbol{\omega}_{X}=\mathbf{0}$. Por intermédio da implementação do FBST calcula-se a evidência que os dados observados dão a essa hipótese, apontando para adequação ou não do modelo a estes. Identicamente se procede no caso da avaliação do Modelo Não Aninhado, testando-se $H_{0}: \omega_{Z}=\mathbf{0}$.

No caso da avaliação da plausibilidade do Modelo Geral através da hipótese $H_{0}: \omega_{X}=\mathbf{0}$, a obtenção de uma evidência contrária à hipótese próxima a zero é um indicativo de que o modelo pode estar mal especificado, dado que a área correspondente a nulidade dos parâmetros singulares ao Modelo Geral permeia uma região de alta densidade na posteriori. Nessa acepção matemática, a obtenção de um resultado como o acima descrito sugere que os dados provenientes do Modelo Geral agregam pouco poder explicativo frente às variáveis do Modelo Não Aninhado. Por fim, cabe destacar o fato de que a implausibilidade do Modelo Geral não remete a adequação do Modelo Não Aninhado. Caso se deseje avaliar o Modelo Não Aninhado, é necessário calcular a evidência da hipótese $H_{0}: \omega_{Z}=\mathbf{0}$.

A comparação e seleção de modelos utilizando a aplicação do FBST não se restringe aos exemplos lineares apresentados anteriormente, sejam estes aninhados ou não-aninhados. No que tangem especificamente aqueles nesse último grupo, merece destaque que o processo de aninhamento mecânico é apenas uma das formas de se obter o modelo expandido. Certo é que, para modelos não aninhados, não só lineares, torna-se necessário a construção de uma forma híbrida de espaço paramétrico, a qual deve conter tanto o suporte da posteriori sob $H_{0}: \theta \in \Theta_{0}$ quanto sob $H_{1}: \theta \in \Theta_{1}$, isto é, $\Theta=\Theta_{0} \times \Theta_{1}$.

Embora para alguns casos trivial, é na concepção do modelo expandido que reside o sucesso da implementação do teste. Se de um lado nesse processo a coerência semântica com o objeto de estudo deve ser mantida, por outro deve-se respeitar o rigor estatístico na construção de densidades a posteriori híbridas. De um modo geral, distintas caracterizações da densidade expandida engendram diferentes condições de contorno para o escopo dos testes a serem realizados. De um modo particular, no estudo em questão a hipótese da independência dos erros, presente na econometria financeira, serviu de pilar para construção do modelo expandido, enquanto que a hipótese de teste caracterizou-se pela unicidade do distribuição geradora dos resíduos. As especificidades dessa formulação são apresentadas nas próximas seções. 


\title{
Capítulo 5
}

\section{Arbitragem nos Mercados Financeiros: uma proposta de teste}

\begin{abstract}
ONE OF THE CENTRAL IDEAS of economic thought is that, in properly functioning markets, prices contain valuable information that can be used to make a wide variety of economic decisions. [...] In financial economics, for example, it has been argued that future spot interest rates, predictions of inflation, or even anticipation of turns in the business cycle, can be inferred from current bond prices. (Rubinstein, 1994, pág. 771)
\end{abstract}

Nas seções anteriores abordou-se o pressuposto da não arbitragem nos mercados, destacando-se a sua importância para a elaboração de uma formulação geral de apreçamento de derivativos financeiros. Naquelas seções sugeriu-se maneiras de, lastreadas nas implicações das formulações, avaliar efetivamente a existência ou não do fenômeno da não arbitragem. Nas presentes seções o objetivo é apresentar uma implementação empírica das propostas de verificação, utilizando-se para tanto do instrumental recente de apreçamento de opções.

\subsection{Modelagem do Processo Estocástico}

Ao se referir ao apreçamento de opções, há consenso entre os especialistas de que o trabalho de Black e Scholes (1973) e Merton (1973b) são os pilares. As equações de preços apresentadas por esses autores ainda influenciam os profissionais e acadêmicos na área de finanças em todo o globo. Apesar desse fato, é também bem documentado na literatura de que algumas das suposições feitas por eles não têm contrapartida empírica. Em particular, em relação aos processos estocásticos considerados, a hipótese de normalidade para os retornos compostos tem sido seriamente questionada.

Conforme apresentado em Carr et al. (2007), a necessidade de superar a falta de suporte empírico da distribuição normal em finanças tem levado muitos autores a propor modelos diferentes para os retornos. Madan et al. (1998) sugerem que as perdas são mais possíveis do que os ganhos, dando origem ao que se denomina de prêmio de assimetria. Concomitante, esforços foram dedicados a tentar explicar variações em relação ao nível, inclinação e curvatura do smile de volatilidade, assim como a modificação do smile ao longo dos prazos. Rubinstein (1994) propõe uma volatilidade local em detrimento a uma global para minimizar os efeitos de um smile de volatilidade. O resultado deste processo foi que os novos 
modelos estavam usando outros parâmetros além da volatilidade, como inicialmente proposto por Black e Scholes (1973) e Merton (1973b).

Entre esses novos modelos um tem ganhado importância considerável nos últimos anos, o modelo Variância Gama (VG), inicialmente apresentado em Madan e Seneta (1990) e Madan e Milne (1991), e generalizada em Madan et al. (1998). Segundo os autores, o modelo VG ajusta corretamente o smile da volatilidade, porque incorpora um parâmetro relacionado com a curtose. Em contraste, o prêmio de assimetria é tratado com a inserção no modelo de parâmetro associado com a mesma. Além disso, os testes apresentados pelos autores mostram que os erros relativos de preços teóricos versus os de mercado tendem a ser minimizados com a abordagem.

Especificamente, o modelo VG é uma extensão do processo de Itô apresentado anteriormente, tendo os tempos como variáveis aleatórias determinadas por uma distribuição estocástica Gama. Com pequenas alterações na terminologia dos autores

$$
X(T-t ; \sigma, v, \mu)=\mu \cdot \gamma(T-t ; 1, v)+\sigma \cdot B(\gamma(T-t ; 1, v)),
$$

na qual $X(T-t ; \sigma, v, \mu)$ é o processo $\mathrm{VG}, \mu$ é o drift associado com a assimetria, $\sigma$ é a volatilidade, $B(\cdot)$ é um processo Browniano Padrão e $\gamma(T-t ; 1, v)$ é um processo Gama com média igual a $T-t$ e variância $v \cdot(T-t)$, na qual $v$ está associado com a curtose. A ideia é a de que o tempo aqui representa a atividade econômica relevante, possuindo tanto mais saltos quanto maior for o nível de atividade. Desse modo, o tempo $T-t$ representa o tamanho do salto esperado, isto é, o intervalo médio entre os negócios considerados.

Uma característica atrativa do modelo VG é a de que contém o processo de Itô e o modelo Black e Scholes como um caso especial paramétrico. Em particular, condicionada à realização de um tempo aleatório $g$, o processo $X(T-t ; \sigma, v, \mu)$ é normalmente distribuído. Assim, a densidade não condicional para o processo de $\mathrm{X}$ pode ser obtida integrando fora $g$, com base em uma distribuição Gama,

$$
f(X)=\int_{0}^{\infty} \frac{1}{\sigma \sqrt{2 \pi g}} \cdot \exp \left(\frac{(X-\mu g)^{2}}{2 \sigma^{2} g}\right) \cdot \frac{g^{(T-t) / v^{-1}} \cdot \exp (-g / v)}{v^{(T-t) / v} \cdot \Gamma((T-t) / v)} \cdot d g,
$$

A partir do movimento estocástico VG é possível determinar o comportamento dos preços, aqui expresso por

$$
S_{T}=S_{t} \cdot \exp (r \cdot(T-t)+X(T-t ; \sigma, v, \mu)+\omega \cdot(T-t)),
$$

na qual $\omega=v^{-1} \cdot \ln \left(1-\mu \cdot v-\sigma^{2} \cdot v \cdot 2^{-1}\right)$, sendo determinado de modo que $E\left[S_{T}\right]=S_{t} \cdot \exp (r \cdot(T-t))$. Sob essa configuração de processo estocástico é possível 
visualizar que $\ln \left(E\left[S_{T}\right] / S_{t}\right)=r \cdot(T-t)$, implicando que se está trabalhando com uma medida de probabilidade risco-neutra. Além disso, evidencia-se que sob essa medida o valor presente dos preços é um processo de martingal, $E\left[S_{T} \cdot \exp (-r \cdot(T-t))\right]=S_{t}$.

Baseando-se nessa caracterização, é possível estender o conceito e se definir o preço de uma opção de compra para um ativo que segue um processo VG, com strike $K$ e vencimento em $T$. Sob a hipótese de neutralidade de risco, essa equação é dada pela condição de martingalidade como $c\left(S_{t} ; K, T\right)=\exp (-r \cdot(T-t)) \cdot E\left[\max \left[S_{T}-K ; 0\right]\right]$. Madan et al. (1998) demonstram que essa esperança pode ser expressa analiticamente por

$$
\begin{aligned}
c\left(S_{t} ; K, T\right)=S_{t} \cdot \Psi\left(d \cdot \sqrt{\frac{1-c_{1}}{v}},(\alpha+s) \cdot \sqrt{\frac{v}{1-c_{1}}}, \frac{(T-t)}{v}\right) \\
-K \cdot \exp (-r \cdot(T-t)) \cdot \Psi\left(d \cdot \sqrt{\frac{1-c_{2}}{v}},(\alpha \cdot s) \cdot \sqrt{\frac{v}{1-c_{2}}}, \frac{(T-t)}{v}\right)
\end{aligned}
$$

$\operatorname{com} d=\frac{1}{s} \cdot\left[\ln \left(\frac{S_{t}}{K}\right)+r \cdot(T-t)+\frac{(T-t)}{v} \cdot \ln \left(\frac{1-c_{1}}{1-c_{2}}\right)\right]$,

$\alpha=\zeta \cdot s, \zeta=-\mu / \sigma^{2}$ e $s=\frac{\sigma}{\sqrt{1+(\mu / \sigma)^{2} \cdot v / 2}}$,

$c_{1}=v \cdot(\alpha+s)^{2} / 2, c_{2}=v \cdot \alpha^{2} / 2$

$\Psi$ é uma função definida em termos de Funções Bessel Modificadas de Segunda Ordem e Funções Hipergeométricas Degeneradas de duas variáveis, conforme apresentado no apêndice do trabalho dos autores.

\subsection{Verossimilhança e Densidade a Posteriori}

Não somente o modelo VG, mas também aqueles inicialmente apresentados por Black e Scholes (1973) e Merton (1973b), definem expressões matemáticas diretas para o apreçamento de derivativos, em específico opções. Embora amplamente utilizadas nos mercados financeiros, há situações em que a simples aplicação dessas formulações para a valorização de opções não encontra contrapartida do ponto de vista empírico. Elliott et al. (1997) apresentam um série de estudos em que essa distinção é ressaltada, resumindo em três aspectos a origem da divergência, a saber: erros de observação, erros de modelagem e mau apreçamento do mercado.

O primeiro aspecto se refere à coleta não eficiente das informações necessárias para utilização das fórmulas de apreçamento, sejam elas devido à falta de sincronia ou mesmo a 
qualidade da fonte do dado capturado. O segundo aspecto é direto e trata da dificuldade de escrever a realidade a partir de equações matemáticas, tal como as dos processos aleatórios em questão. Esses assumem distintos comportamentos para os preços, a depender do modelo trabalhado. Por fim, o mau apreçamento do mercado faz referência à demora para os agentes se ajustarem dada uma alteração nos fundamentos da economia.

Em particular, os autores argumentam que os preços teóricos dos ativos e derivativos, isto é, proposto pelos modelos, nunca são observados. As informações coletadas no mercado são tratadas como ruídos, cujas divergências em relação ao preço teórico por ser explicada pelos aspectos acima apontados. Baseando-se nessas ideias os autores propõem a seguinte equação do ruído

$$
w_{i}=\hat{w}_{i} \cdot \exp \left(\eta \cdot \varepsilon-\eta^{2} / 2\right)
$$

na qual $w_{i}$ é o preço da $i$-ésima opção observada no mercado, $\hat{w}_{i}$ é o preço da $i$-ésima opção calculada pelo modelo de VG, $\eta$ é a volatilidade do erro, $\varepsilon \sim N(0,1)$. Assim, pode-se observar que $w_{i} \sim \ln N\left(\ln \hat{w}_{i}-\eta^{2} / 2, \eta^{2}\right)$, tendo para uma sequência de $M$ observações independentes à verossimilhança dada por

$$
\ell=\prod_{i=1}^{M} \frac{1}{w_{i} \sqrt{2 \pi \eta^{2}}} \cdot \exp \left(-\frac{1}{2} \frac{\left(\ln \left(w_{i}\right)-\ln \left(\hat{w}_{i}\right)+\eta^{2} / 2\right)^{2}}{\eta^{2}}\right) .
$$

A fim de obter a densidade a posteriori, pode-se reescrever $\hat{w}_{i}$ pela sua formulação analítica dada na seção anterior, sutilmente modificada para evidenciar sua dependência dos parâmetros em questão, $\hat{w}_{i}=c(\sigma, v, \mu, W)$. Nessa, $W$ indica as demais variáveis de mercado necessárias para determinação do valor da opção, $W=\left\{S_{t} ; K, T\right\}$, as quais não possuem interpretação estatística, isto é, não são aleatórias. Com essa alteração e alguma álgebra para simplificar os fatores que não dependem dos parâmetros de interesse tem-se

$$
\begin{aligned}
\ell(\eta, \sigma, v, \mu \mid w) \propto & \left(\prod_{i=1}^{M} w_{i}^{-1}\right) \cdot \eta^{-n} \cdot \exp \left(-\frac{1}{2 \eta^{2}} \sum_{i=1}^{M}\left(\ln \left(w_{i}\right)-\ln \left(\bar{w}_{i}\right)\right)^{2}\right) \\
& \cdot \exp \left(-\frac{1}{2 \eta^{2}} M \cdot\left(\ln (c(\sigma, v, \mu, W))-\ln \left(\bar{w}_{i}\right)+\eta^{2} / 2\right)^{2}\right)^{\prime}
\end{aligned}
$$

na qual $w=\left\{w_{1}, w_{2}, \ldots, w_{M}\right\}$ e $\ln \left(\bar{w}_{i}\right)=\frac{1}{M} \cdot \sum_{i=1}^{M} \ln \left(w_{i}\right)$. A partir dessa é possível constatar que para um dado valor de $\eta$ tem-se $\ln (c(\sigma, v, \mu \mid W)) \sim N\left(\ln \left(\bar{w}_{i}\right)+\eta^{2} / 2, \eta^{2} / M\right)$.

Madan et al. (1998), baseando-se em propriedades assintóticas dos estimadores, consideraram que o valor da volatilidade do erro, $\eta$, poderia ser obtido diretamente da 
verossimilhança, não o considerando como um parâmetro a ser estimado. Em particular, $\eta=\sqrt{2 \cdot\left(\sqrt{1+k^{2}}-1\right)}, \quad$ com $k^{2}=1 / M \cdot \sum_{i=1}^{M}\left(\ln \left(w_{i}\right)-\ln \left(\hat{w}_{i}\right)\right)^{2}$. Sob essa formulação a verossimilhança ficaria simplificada, tendo apenas $(\sigma, v, \mu)$ como parâmetros, isto é, $\ell(\sigma, v, \mu \mid w)$. De acordo com os autores, para esse caso, os estimadores de máxima verossimilhança dos parâmetros podem ser obtidos pelo método equivalente assintótico de mínimos quadrados, dado especificamente pela minimização de $k$.

No presente estudo trabalhar-se-á com a versão completa da verossimilhança, $\ell(\eta, \sigma, v, \mu \mid w)$. A fim de se obter a densidade a posteriori dos parâmetros considerou-se uma priori não informativa, dada por $h(\eta, \sigma, v, \mu)=h(\eta) \propto 1 / \eta$. Desse modo,

$$
h(\eta, \sigma, v, \mu \mid w) \propto h(\eta, \sigma, v, \mu) \cdot \ell(\eta, \sigma, v, \mu \mid w) .
$$

\subsection{Não Arbitragem, Hipótese de Teste e InformaÇões de MerCado}

A equação de precificação de opções proposta por Madan et al. (1998), bem como aquelas originalmente apresentadas por Black e Scholes (1973) e Merton (1973b), baseiam-se na proposição de não arbitragem. Conforme apresentado anteriormente, a ideia é encontrar uma estratégia de um portfólio sem custo que replica o payoff do derivativo em análise, e depois impor a condição de não arbitragem entre seus retornos.

Uma consequência da abordagem é que todos os ativos negociados na economia devem ter a mesma taxa de retorno esperada, dado pela taxa de juros livre de risco. Por esta razão, o método é também conhecido como avaliação neutra de risco. Especificamente, sob a abordagem neutra ao risco, o valor presente de todos os ativos deve ser igual a seu valor futuro esperado descontado à taxa livre de risco, como visto acima, $E\left[S_{T} \cdot \exp (-r \cdot(T-t))\right]=S_{t}$. Implícito nesta expressão está o fato de que os ativos se comportam como processos martingal quando deflacionadas pela taxa de juros livre de risco.

No que diz respeito especificamente ao apreçamento de opções, a implicação da abordagem é que seu valor presente pode também ser expresso em termos da expectativa da sua estrutura de payoff futuro, $\delta_{T}$. Para uma opção de compra europeia com vencimento em $T$ e strike $K$, seu valor presente é dado por $c\left(S_{t} ; K, T\right)=\exp (-r \cdot(T-t)) \cdot E\left[\delta_{T}\right]$, em que $\delta_{T}=\max \left[S_{T}-K ; 0\right]$. Assim, fica evidente a estreita relação entre a distribuição estatística dos preços dos ativos, as formulações das equações de apreçamento e a arbitragem.

Caracterizada de tal forma, uma maneira simples de avaliar o fenómeno de arbitragem é estudar os parâmetros das distribuições estatísticas que governam o comportamento de 
preços dos ativos. Em particular, dois mercados distintos que negociam a mesma estrutura de payoff deveriam, ceteris paribus, ser regidos pela mesma medida de probabilidade. Em caso contrário, ter-se-ia preços diferentes para o mesmo derivativo, criando condições para que os agentes arbitrassem entre os mercados. Expresso em outros termos, uma diferença estatisticamente significativa entre as medidas de probabilidade pode ser um indicativo de oportunidades de arbitragem.

A fim de se verificar a existência de diferentes condições de mercado que permitam algum tipo vantagem econômica sem risco, isto é, a arbitragem, conforme apontado acima, selecionou-se dois ambientes de negociação distintos, mas que em última instância operam o mesmo ativo-objeto. Em particular, vai-se trabalhar com as opções de Ibovespa transacionadas no Segmento de Ações da BM\&FBovespa, mercado (a), e com as opções sobre Futuro de Ibovespa operadas no Segmento de Derivativos da mesma instituição, mercado (b).

Desse modo, para o modelo VG e a estrutura de erros log-normal independentes, a hipótese de teste de um mercado não arbitrado é dada por

$$
H:\left[\sigma_{a}, v_{a}, \mu_{a}\right]=\left[\sigma_{b}, v_{b}, \mu_{b}\right]
$$

a ser avaliada sob uma posteriori do tipo $h\left(\eta, \sigma_{a}, v_{a}, \mu_{a}, \sigma_{b}, v_{b}, \mu_{b} \mid w_{a}, w_{b}\right) \propto h(\eta) \cdot \ell\left(\eta, \sigma_{a}, v_{a}, \mu_{a} \mid w_{a}\right) \cdot \ell\left(\eta, \sigma_{b}, v_{b}, \mu_{b} \mid w_{b}\right)$, na qual $w_{a} \mathrm{e}$ $w_{b}$ representam o vetor de preços das opções observadas no mercado (a) e (b) respectivamente. Além desses, $\ell\left(\eta, \sigma_{a}, v_{a}, \mu_{a} \mid w_{a}\right)$ e $\ell\left(\eta, \sigma_{b}, v_{b}, \mu_{b} \mid w_{b}\right)$ são equações do tipo Eq. $(5.6) .^{25}$

Embora contratualmente haja uma distinção dos ativos subjacentes em cada uma dos tipos de opções, ao se considerar o processo de liquidação no vencimento das posições, ambos os mercados dependem da mesma variável econômica, a saber, o valor do Ibovespa Liquidação. ${ }^{26}$ No vencimento, as Opções sobre Ibovespa do segmento de Ações são liquidadas financeiramente pela diferença entre o Ibovespa Liquidação e o strike da opção.

No caso das Opções sobre Futuro de Ibovespa do Segmento Derivativos, no exercício as partes envolvidas assumem posições no Futuro do Índice, passando a valer as regras deste mercado. No entanto, no dia do vencimento, esses futuros liquidam financeiramente pelo Ibovespa Liquidação. Deste modo, ao se promover o exercício no dia do vencimento, as

\footnotetext{
${ }^{25}$ Uma proposta distinta de teste foi apresentada em Cerezetti e Stern (2012), cujos principais resultados são apresentados no Apêndice.

${ }^{26} \mathrm{O}$ Ibovespa Liquidação é a média aritmética dos Índices BOVESPA verificados nas três últimas horas de negociação até o final do call de fechamento, inclusive, do pregão do dia do exercício, conforme definido pela BM\&FBovespa.
} 
partes estão implicitamente assumindo a liquidação pela diferença entre o Ibovespa Liquidação e o strike da opção, que será considerado como o valor operado para fins das regras do mercado de Futuro de Índice.

Ademais dessa sutil distinção no ativo-objeto, no que tange aos demais aspectos contratuais das opções em ambos segmentos existem importantes similaridades. Em específico, para o presente estudo essa semelhança se torna relevante na medida em que os meses de vencimento são os mesmos, assim como também o é o último dia de negociação, a data de vencimento, os preços de exercício, a cotação e os estilos das opções, que podem ser tanto europeias quanto americanas.

Diante desse cenário, para fins das análises estatísticas, trabalhou-se com as informações dos negócios de opções de compra europeias e americanas sobre o Ibovespa para os vencimentos Fev./2012, Abr./2012 e Jun./2012. A estrutura do ciclo dos negócios imprimiu a restrição de se considerar apenas os dois meses de negociação anteriores ao vencimento em questão. Desse modo, por exemplo, para o vencimento de Fev./2012, utilizouse os dados de transações para o prazo iniciando em 15/12/2011 e finalizando em 14/02/2012. No total trabalhou-se com 1.080 observações, agrupadas em blocos semanais, perfazendo uma gama de 25 semanas tratadas.

As informações foram capturadas para os segmentos de Ações e para o Segmento Derivativos para strikes que variavam de 50.000 a 76.000 , com faixas a cada 1.000 pontos. A escolha dos strikes trabalhados a cada vencimento em questão pode variar, a depender dos contratos em aberto no período considerado. A fim de se evitar não sincronia dos dados, buscou capturar os negócios próximos ao call de marcação dos mercados. Os valores do Índice Ibovespa foram obtidos próximos do instante de cada negócio.

Como proxy do valor da Taxa de Juros Referencial da economia utilizou-se a taxa pré-fixada implícita nos contratos de Futuro de DI transacionados na BM\&FBovespa. No caso em que as maturidades dos Futuros de DI diferiam das maturidades das opções, aplicouse a interpolação exponencial base 252 para estimar-se as taxas de juros referenciais das opções. $^{27}$

\subsection{Teste de Hipótese e Resultados}

A fim de se investigar a hipótese de não arbitragem o teste FBST pode ser aplicado. O objetivo do procedimento é o de apresentar uma medida estatística desta hipótese, o $\boldsymbol{e}$ valor. Conforme discutido acima, a implantação dos cálculos para se obter o e-valor é realizado em duas etapas, uma primeira de otimização e uma segunda de integração, a qual

\footnotetext{
${ }^{27}$ Fonte dos dados de opções, Futuros de DI e Índice Ibovespa é BM\&FBovespa.
} 
por vezes é feita de forma não analítica, por meio dos procedimentos de integração numérica ou Monte Carlo. Através do processo de optimização é obtido o argumento de que maximiza a distribuição a posteriori irrestritamente $\left(\eta, \sigma_{a}, v_{a}, \mu_{a}, \sigma_{b}, v_{b}, \mu_{b}\right)$, isto é, considerando todos os valores dos parâmetros livremente. Além disso, são também mensurados os valores dos parâmetros sob a hipótese de teste $H$, permitindo a determinação dos HPDS. Aqui cabe destacar que só são reestimados os parâmetros $(\sigma, v, \mu)$, utilizando-se para $\eta$ o valor obtido no passo anterior.

De um modo geral, a estimação dos conjuntos de parâmetros desejados, via o processo de otimização, pode ser realizado de dois modos. Uma primeira possibilidade seria considerar a equivalência assintótica entre a estimação por máxima verossimilhança e a de mínimo quadrados não linear para o logaritmo dos preços, dada pela variável $k$ apresentada acima. Para a formalização da equivalência vide Madan et al. (1998). Dentre os algoritmos disponíveis para tratar quadrados de funções não lineares tem-se Levenberg-Marquardt, cujos detalhes podem ser vistos em Levenberg (1944), Marquardt (1963) e Moré (1977).

Uma segunda maneira de se obter estimativas dos parâmetros é otimizar diretamente a densidade a posteriori. Especificamente, o processo de otimização pode ser realizado sobre a log-posteriori, de um modo genérico dada por

$$
\begin{gathered}
\ln h=-\frac{1}{2} \sum_{i=1}^{M}\left(\frac{\ln \left(w_{i}\right)-\ln (c(\sigma, v, \mu, W))}{\eta}+\frac{\eta}{2}\right)^{2}-(M+1) \cdot \ln (\eta) \\
-\frac{M \cdot \ln (2 \pi)}{2}-\sum_{i=1}^{M} \ln \left(w_{i}\right)
\end{gathered}
$$

na qual os dois últimos termos podem ser abandonados por não impactarem os resultados. Algoritmos computacionais eficientes estão disponíveis para esse tipo de otimização, podendo ser implementados em ambientes de programação amigáveis ao usuário. Os métodos de busca direta, direct search methods, muitas vezes aparecem como uma solução robusta para problemas de otimização não linear. De fácil implementação, esses algoritmos dispensam o uso de derivadas para percorrer a função objetivo. Dentre essa classe de algoritmos, um dos mais conhecidos é o método Nelder-Mead. Sob esse método um simplex variante a cada iteração é utilizado para direcionar a busca até o ponto ótimo. Embora amplamente utilizado, Dennis e Torczon (1991) e McKinnon (1999) demostram que em algumas situações o algoritmo pode convergir para pontos não estacionários, visto que o simplex se torna arbitrariamente estreito.

No presente estudo ambos procedimentos de otimização foram avaliados. Considerando-se o valor final da densidade a posteriori, convergência e velocidade de processamento, optou-se pelo método Nelder-Meid para realizar o processo de estimação. Os 
resultados dos estimadores dos parâmetros, seja sob a hipótese de teste seja para a posteriori irrestrita, são apresentados na Tabela 5.1, Tabela 5.2 e Tabela 5.3, respectivamente para os vencimentos Fev./2012, Abr./2012 e Jun./2012. As semanas estão numeradas de acordo com sua ocorrência no ano. Para cada uma das semanas apresentadas, a primeira linha apresenta os parâmetros estimados irrestritamente e a segunda os mesmos valores apurados sob a hipótese de teste.

\section{Tabela 5.1}

Parâmetros Risco-Neutros do Modelo VG:

a cada semana a linhal representa a estimação irrestrita e a linha 2 a estimação sob a hipótese de teste; a $3^{a}$ coluna apresenta a estatística de teste da razão de verossimilhança e seu p-valor entre parênteses. Dados Semanais: Venc. Fev./2012.

\begin{tabular}{|c|c|c|c|c|c|c|c|c|c|}
\hline Semana & Observações & Log-LR & $\eta$ & $\sigma_{a}$ & $v_{a}$ & $\mu_{a}$ & $\sigma_{b}$ & $v_{b}$ & $\mu_{b}$ \\
\hline 51 & 51 & $\begin{array}{c}4,28 \\
(0,369)\end{array}$ & $\begin{array}{l}0,0701 \\
0,0701\end{array}$ & $\begin{array}{l}0,5360 \\
0,5346\end{array}$ & $\begin{array}{l}0,0019 \\
0,0017\end{array}$ & $\begin{array}{l}0,3263 \\
0,3208\end{array}$ & $\begin{array}{l}0,4549 \\
0,5346\end{array}$ & $\begin{array}{l}0,0017 \\
0,0017\end{array}$ & $\begin{array}{l}0,1721 \\
0,3208\end{array}$ \\
\hline 52 & 83 & $\begin{array}{c}5,21 \\
(0,266)\end{array}$ & $\begin{array}{l}0,1056 \\
0,1056\end{array}$ & $\begin{array}{l}0,3978 \\
0,3801\end{array}$ & $\begin{array}{l}0,0020 \\
0,0014\end{array}$ & $\begin{array}{l}0,1046 \\
0,0874\end{array}$ & $\begin{array}{l}0,3091 \\
0,3801\end{array}$ & $\begin{array}{l}0,0060 \\
0,0014\end{array}$ & $\begin{array}{l}0,0363 \\
0,0874\end{array}$ \\
\hline 53 & 21 & $\begin{array}{c}0,29 \\
(0,991)\end{array}$ & $\begin{array}{l}0,0852 \\
0,0852\end{array}$ & $\begin{array}{l}0,3193 \\
0,3232\end{array}$ & $\begin{array}{l}0,0012 \\
0,0012\end{array}$ & $\begin{array}{l}0,0507 \\
0,0530\end{array}$ & $\begin{array}{l}0,3313 \\
0,3232\end{array}$ & $\begin{array}{l}0,0030 \\
0,0012\end{array}$ & $\begin{array}{l}0,0581 \\
0,0530\end{array}$ \\
\hline 1 & 60 & $\begin{array}{c}0,15 \\
(0,997)\end{array}$ & $\begin{array}{l}0,1023 \\
0,1023\end{array}$ & $\begin{array}{l}0,3166 \\
0,3184\end{array}$ & $\begin{array}{l}0,0012 \\
0,0012\end{array}$ & $\begin{array}{l}0,0511 \\
0,0522\end{array}$ & $\begin{array}{l}0,3244 \\
0,3184\end{array}$ & $\begin{array}{l}0,0028 \\
0,0012\end{array}$ & $\begin{array}{l}0,0575 \\
0,0522\end{array}$ \\
\hline 2 & 38 & $\begin{array}{c}4,13 \\
(0,389)\end{array}$ & $\begin{array}{l}0,0937 \\
0,0937\end{array}$ & $\begin{array}{l}0,2911 \\
0,2715\end{array}$ & $\begin{array}{l}0,0008 \\
0,0008\end{array}$ & $\begin{array}{l}0,0379 \\
0,0280\end{array}$ & $\begin{array}{l}0,2279 \\
0,2715\end{array}$ & $\begin{array}{l}0,0040 \\
0,0008\end{array}$ & $\begin{array}{l}0,0127 \\
0,0280\end{array}$ \\
\hline 3 & 69 & $\begin{array}{c}1,68 \\
(0,794)\end{array}$ & $\begin{array}{l}0,1257 \\
0,1257\end{array}$ & $\begin{array}{l}0,2535 \\
0,2535\end{array}$ & $\begin{array}{l}0,0007 \\
0,0007\end{array}$ & $\begin{array}{l}0,0261 \\
0,0261\end{array}$ & $\begin{array}{l}0,2629 \\
0,2535\end{array}$ & $\begin{array}{l}0,0005 \\
0,0007\end{array}$ & $\begin{array}{l}0,0292 \\
0,0261\end{array}$ \\
\hline 4 & 49 & $\begin{array}{c}1,45 \\
(0,836)\end{array}$ & $\begin{array}{l}0,1306 \\
0,1306\end{array}$ & $\begin{array}{l}0,2521 \\
0,2773\end{array}$ & $\begin{array}{l}0,0005 \\
0,0005\end{array}$ & $\begin{array}{l}0,0307 \\
0,0441\end{array}$ & $\begin{array}{l}0,2729 \\
0,2773\end{array}$ & $\begin{array}{l}0,0004 \\
0,0005\end{array}$ & $\begin{array}{l}0,0420 \\
0,0441\end{array}$ \\
\hline 5 & 96 & $\begin{array}{c}0,48 \\
(0,975)\end{array}$ & $\begin{array}{l}0,3208 \\
0,3208\end{array}$ & $\begin{array}{l}0,1723 \\
0,1748\end{array}$ & $\begin{array}{l}0,0003 \\
0,0003\end{array}$ & $\begin{array}{l}0,0008 \\
0,0008\end{array}$ & $\begin{array}{l}0,1849 \\
0,1748\end{array}$ & $\begin{array}{l}0,0003 \\
0,0003\end{array}$ & $\begin{array}{l}0,0010 \\
0,0008\end{array}$ \\
\hline 6 & 34 & $\begin{array}{c}1,69 \\
(0,793)\end{array}$ & $\begin{array}{l}0,1710 \\
0,1710\end{array}$ & $\begin{array}{l}0,1862 \\
0,1955\end{array}$ & $\begin{array}{l}0,0002 \\
0,0002\end{array}$ & $\begin{array}{l}0,0011 \\
0,0047\end{array}$ & $\begin{array}{l}0,2178 \\
0,1955\end{array}$ & $\begin{array}{l}0,0004 \\
0,0002\end{array}$ & $\begin{array}{l}0,0123 \\
0,0047\end{array}$ \\
\hline 7 & 11 & $\begin{array}{c}0,57 \\
(0,966)\end{array}$ & $\begin{array}{l}0,1216 \\
0,1216\end{array}$ & $\begin{array}{l}0,2312 \\
0,2337\end{array}$ & $\begin{array}{l}0,0001 \\
0,0001\end{array}$ & $\begin{array}{l}0,0232 \\
0,0244\end{array}$ & $\begin{array}{l}0,2345 \\
0,2337\end{array}$ & $\begin{array}{l}0,0001 \\
0,0001\end{array}$ & $\begin{array}{l}0,0262 \\
0,0244 \\
\end{array}$ \\
\hline
\end{tabular}

Fonte de Dados: BM\&FBovespa

A partir desses valores estimados, através da utilização do teste da razão de verossimilhança, torna-se possível tecer as primeiras inferências sobre o processo de verificação em análise. Em particular, na $3^{\text {a }}$ coluna das tabelas são apresentadas as estatísticas do teste da razão de verossimilhança e seus respectivos p-valores entre parênteses, mensurados considerando a proposição de que sob a hipótese de teste as estatísticas seguem uma distribuição Qui-Quadrado com 4 graus de liberdade. Com bases nos resultados, pode-se argumentar que até a semana 11 de 2012 existem, para a maioria dos casos, evidências que sugerem a equivalência dos parâmetros. Contudo, a partir de então, os baixos valores da verossimilhança sob a hipótese de teste indicam uma potencial diferença entre eles. 
Na consecução do $\boldsymbol{e}$-valor para a hipótese de teste $\mathrm{H}$, o passo da integração serve para medir a probabilidade do conjunto HPDS. Especificamente, na presente análise, o processo de integração será necessário para determinar a probabilidade

$$
\operatorname{Pr}\left[\left(\sigma_{a}, v_{a}, \mu_{a}, \sigma_{b}, v_{b}, \mu_{b}\right) \in \Theta \mid h\left(\sigma_{a}, v_{a}, \mu_{a}, \sigma_{b}, v_{b}, \mu_{b} \mid w_{a}, w_{b}, \hat{\eta}\right) \geq h\left(\hat{\sigma}, \hat{v}, \hat{\mu} \mid w_{a}, w_{b}, \hat{\eta}\right)\right],
$$

na qual $h\left(\hat{\sigma}, \hat{v}, \hat{\mu} \mid w_{a}, w_{b}, \hat{\eta}\right)$ é a densidade a posteriori mensurada sob a hipótese de teste $\mathrm{H}$, tendo o valor do parâmetro $\eta$ fixo no estimador que maximiza a posteriori irrestrita, $\hat{\eta}$.

Como a maioria dos procedimentos inferenciais Bayesianos, a integração desempenha um papel importante no FBST. No entanto, em muitos casos, o cálculo analítico das integrais para a obtenção da probabilidade especificada acima pode ser problemático. Nesses casos, existem alternativas como a integração numérica e os métodos de Monte Carlo. Em cenários multidimensionais mais complexos, até mesmo a solução numérica não é viável, deixando apenas as aproximações obtidas por meio de simulação estocástica usando o procedimento de Monte Carlo. Para detalhes vide Evans e Swartz (1995, 2000), Gelman et al. (1998) e Murteira et al. (2003).

Tabela 5.2

Parâmetros Risco-Neutros do Modelo VG: a cada semana a linhal representa a estimação irrestrita e a linha 2 a estimação sob a hipótese de teste; a $3^{a}$ coluna apresenta a estatística de teste da razão de verossimilhança e seu p-valor entre parênteses. Dados Semanais: Venc. Abr./2012.

\begin{tabular}{|c|c|c|c|c|c|c|c|c|c|}
\hline Semana & Observações & Log-LR & $\eta$ & $\sigma_{a}$ & $v_{a}$ & $\mu_{a}$ & $\sigma_{b}$ & $v_{b}$ & $\mu_{b}$ \\
\hline 8 & 24 & $\begin{array}{c}3,49 \\
(0,479)\end{array}$ & $\begin{array}{l}0,2659 \\
0,2659\end{array}$ & $\begin{array}{l}0,4917 \\
0,4954\end{array}$ & $\begin{array}{l}0,3236 \\
0,2701\end{array}$ & $\begin{array}{l}0,2372 \\
0,2561\end{array}$ & $\begin{array}{l}0,1596 \\
0,4954\end{array}$ & $\begin{array}{l}0,0010 \\
0,2701\end{array}$ & $\begin{array}{c}-0,0019 \\
0,2561\end{array}$ \\
\hline 9 & 41 & $\begin{array}{c}27,08 \\
(0,000)\end{array}$ & $\begin{array}{l}0,6062 \\
0,6062\end{array}$ & $\begin{array}{l}0,2886 \\
0,7012\end{array}$ & $\begin{array}{l}0,4928 \\
0,0019\end{array}$ & $\begin{array}{l}0,0008 \\
1,0387\end{array}$ & $\begin{array}{l}0,1591 \\
0,7012\end{array}$ & $\begin{array}{l}0,0012 \\
0,0019\end{array}$ & $\begin{array}{c}-0,0038 \\
1,0387\end{array}$ \\
\hline 10 & 44 & $\begin{array}{c}27,57 \\
(0,000)\end{array}$ & $\begin{array}{l}0,5419 \\
0,4186\end{array}$ & $\begin{array}{l}0,2557 \\
1,2948\end{array}$ & $\begin{array}{l}0,8085 \\
0,0012\end{array}$ & $\begin{array}{l}-0,2710 \\
-0,4730\end{array}$ & $\begin{array}{l}0,2131 \\
0,4186\end{array}$ & $\begin{array}{l}0,0019 \\
1,2948\end{array}$ & $\begin{array}{l}-0,0004 \\
-0,4730\end{array}$ \\
\hline 11 & 24 & $\begin{array}{c}0,65 \\
(0,958)\end{array}$ & $\begin{array}{l}0,6253 \\
0,6253\end{array}$ & $\begin{array}{l}0,3414 \\
0,3352\end{array}$ & $\begin{array}{l}0,0024 \\
0,0021\end{array}$ & $\begin{array}{l}0,0694 \\
0,0655\end{array}$ & $\begin{array}{l}0,2964 \\
0,3352\end{array}$ & $\begin{array}{l}0,0006 \\
0,0021\end{array}$ & $\begin{array}{l}0,0468 \\
0,0655\end{array}$ \\
\hline 12 & 37 & $\begin{array}{c}28,47 \\
(0,000)\end{array}$ & $\begin{array}{l}0,1932 \\
0,1932\end{array}$ & $\begin{array}{l}0,1434 \\
0,1317\end{array}$ & $\begin{array}{l}0,1020 \\
0,0574\end{array}$ & $\begin{array}{r}0,0000 \\
-0,0013\end{array}$ & $\begin{array}{l}0,1662 \\
0,1317\end{array}$ & $\begin{array}{l}0,0009 \\
0,0574\end{array}$ & $\begin{array}{l}-0,0009 \\
-0,0013\end{array}$ \\
\hline 13 & 42 & $\begin{array}{c}25,34 \\
(0,000)\end{array}$ & $\begin{array}{l}0,7127 \\
0,7127\end{array}$ & $\begin{array}{l}0,3801 \\
0,3722\end{array}$ & $\begin{array}{l}0,0177 \\
0,0094\end{array}$ & $\begin{array}{r}0,0000 \\
-0,0001\end{array}$ & $\begin{array}{l}0,1818 \\
0,3722\end{array}$ & $\begin{array}{l}0,0005 \\
0,0094\end{array}$ & $\begin{array}{l}-0,0006 \\
-0,0001\end{array}$ \\
\hline 14 & 70 & $\begin{array}{l}411,78 \\
(0,000)\end{array}$ & $\begin{array}{l}0,2957 \\
0,2957\end{array}$ & $\begin{array}{l}0,2239 \\
0,4556\end{array}$ & $\begin{array}{l}0,0066 \\
0,0169\end{array}$ & $\begin{array}{c}-0,0793 \\
0,0738\end{array}$ & $\begin{array}{l}0,1939 \\
0,4556\end{array}$ & $\begin{array}{l}0,0012 \\
0,0169\end{array}$ & $\begin{array}{l}0,0054 \\
0,0738\end{array}$ \\
\hline 15 & 25 & $\begin{array}{c}21,73 \\
(0,000)\end{array}$ & $\begin{array}{l}0,2428 \\
0,2428\end{array}$ & $\begin{array}{l}0,9440 \\
0,9539\end{array}$ & $\begin{array}{l}0,0279 \\
0,0304\end{array}$ & $\begin{array}{l}3,0247 \\
3,1409\end{array}$ & $\begin{array}{l}0,2052 \\
0,9539\end{array}$ & $\begin{array}{l}0,0035 \\
0,0304\end{array}$ & $\begin{array}{l}0,0089 \\
3,1409\end{array}$ \\
\hline
\end{tabular}

$\mathrm{Na}$ seleção dos métodos de aproximação de integrais um aspecto relevante é a determinação do nível de acurácia desejada. Diferentes problemas suportam distintos erros de 
aproximação, demandando diferentes algoritmos de cálculo. Em particular, nos problemas estatísticos, os autores argumentam que a aleatoriedade dos dados engendra um nível de aceitação maior para a não precisão da aproximação. Desse modo, mesmo sob as críticas relativas à acurácia do algoritmo de Monte Carlo, o método tem sido crescentemente utilizado na estatística, às vezes sendo a única solução disponível. Outra característica do método que favorece sua aplicabilidade é a menor sensibilidade ao peso da dimensionalidade, curse of dimensionality, isto é, a deterioração da aproximação com o aumento das variáveis do processo de integração.

A dificuldade de obtenção de uma formulação analítica para as integrais da distribuição a posteriori $h\left(\sigma_{a}, v_{a}, \mu_{a}, \sigma_{b}, v_{b}, \mu_{b} \mid w_{a}, w_{b}, \hat{\eta}\right)$ engendrou a necessidade de recorrer a técnicas de integração via Monte Carlo para determinar o e-valor. Para se proceder com esta metodologia, o primeiro passo foi simular uma amostra aleatória dos valores dos parâmetros $\left(\sigma_{a}, v_{a}, \mu_{a}, \sigma_{b}, v_{b}, \mu_{b}\right)^{i_{1}},\left(\sigma_{a}, v_{a}, \mu_{a}, \sigma_{b}, v_{b}, \mu_{b}\right)^{i_{2}}, \ldots,\left(\sigma_{a}, v_{a}, \mu_{a}, \sigma_{b}, v_{b}, \mu_{b}\right)^{i_{m}}$, a partir da densidade a posteriori, a qual foi obtida combinando a técnica de Gibbs Sampling e MetropolisHastings. Para abordagens diretas e intuitivas dessas técnicas veja Casella e George (1992) e Chib e Greenberg (1995) respectivamente.

Tabela 5.3

Parâmetros Risco-Neutros do Modelo VG: a cada semana a linhal representa a estimação irrestrita e a linha 2 a estimação sob a hipótese de teste; a $3^{a}$ coluna apresenta a estatística de teste da razão de verossimilhança e seu p-valor entre parênteses. Dados Semanais: Venc. Jun./2012.

\begin{tabular}{|c|c|c|c|c|c|c|c|c|c|}
\hline Semana & Observações & Log-LR & $\eta$ & $\sigma_{a}$ & $v_{a}$ & $\mu_{a}$ & $\sigma_{b}$ & $v_{b}$ & $\mu_{b}$ \\
\hline 16 & 21 & $\begin{array}{c}24,31 \\
(0,000)\end{array}$ & $\begin{array}{l}0,7014 \\
0,7014\end{array}$ & $\begin{array}{l}0,5300 \\
0,5458\end{array}$ & $\begin{array}{l}0,6253 \\
0,4049\end{array}$ & $\begin{array}{l}0,0625 \\
0,1704\end{array}$ & $\begin{array}{l}0,3373 \\
0,5458\end{array}$ & $\begin{array}{l}0,0015 \\
0,4049\end{array}$ & $\begin{array}{l}0,0082 \\
0,1704\end{array}$ \\
\hline 17 & 43 & $\begin{array}{l}826,97 \\
(0,000)\end{array}$ & $\begin{array}{l}0,1655 \\
0,1655\end{array}$ & $\begin{array}{l}0,4968 \\
0,4404\end{array}$ & $\begin{array}{l}0,2488 \\
0,0009\end{array}$ & $\begin{array}{l}0,1366 \\
0,1164\end{array}$ & $\begin{array}{l}0,1916 \\
0,4404\end{array}$ & $\begin{array}{l}0,0008 \\
0,0009\end{array}$ & $\begin{array}{l}0,0061 \\
0,1164\end{array}$ \\
\hline 18 & 12 & $\begin{array}{c}1273,39 \\
(0,000)\end{array}$ & $\begin{array}{l}0,0443 \\
0,0443\end{array}$ & $\begin{array}{l}0,5007 \\
0,4768\end{array}$ & $\begin{array}{l}0,1941 \\
0,0527\end{array}$ & $\begin{array}{l}0,1582 \\
0,1599\end{array}$ & $\begin{array}{l}0,2159 \\
0,4768\end{array}$ & $\begin{array}{l}0,0007 \\
0,0527\end{array}$ & $\begin{array}{l}0,0100 \\
0,1599\end{array}$ \\
\hline 19 & 24 & $\begin{array}{l}277,27 \\
(0,000)\end{array}$ & $\begin{array}{l}0,1940 \\
0,1940\end{array}$ & $\begin{array}{l}0,4565 \\
0,2842\end{array}$ & $\begin{array}{l}0,1127 \\
0,0161\end{array}$ & $\begin{array}{l}0,0970 \\
0,0050\end{array}$ & $\begin{array}{l}0,2872 \\
0,2842\end{array}$ & $\begin{array}{l}0,0007 \\
0,0161\end{array}$ & $\begin{array}{l}0,0396 \\
0,0050\end{array}$ \\
\hline 20 & 60 & $\begin{array}{c}57,30 \\
(0,000)\end{array}$ & $\begin{array}{l}0,5118 \\
0,5118\end{array}$ & $\begin{array}{l}0,3685 \\
0,3597\end{array}$ & $\begin{array}{l}0,0134 \\
0,0075\end{array}$ & $\begin{array}{l}0,0010 \\
0,0000\end{array}$ & $\begin{array}{l}0,2378 \\
0,3597\end{array}$ & $\begin{array}{l}0,0004 \\
0,0075\end{array}$ & $\begin{array}{c}-0,0044 \\
0,0000\end{array}$ \\
\hline 21 & 48 & $\begin{array}{c}36,80 \\
(0,000)\end{array}$ & $\begin{array}{l}0,3847 \\
0,3847\end{array}$ & $\begin{array}{l}0,3949 \\
0,3880\end{array}$ & $\begin{array}{l}0,0147 \\
0,0111\end{array}$ & $\begin{array}{r}0,0010 \\
-0,0001\end{array}$ & $\begin{array}{l}0,2317 \\
0,3880\end{array}$ & $\begin{array}{l}0,0004 \\
0,0111\end{array}$ & $\begin{array}{l}-0,0050 \\
-0,0001\end{array}$ \\
\hline 22 & 53 & $\begin{array}{c}67,19 \\
(0,000)\end{array}$ & $\begin{array}{l}0,6471 \\
0,6471\end{array}$ & $\begin{array}{l}0,5141 \\
0,4705\end{array}$ & $\begin{array}{l}0,0096 \\
0,0071\end{array}$ & $\begin{array}{l}0,0050 \\
0,0010\end{array}$ & $\begin{array}{l}0,2058 \\
0,4705\end{array}$ & $\begin{array}{l}0,0004 \\
0,0071\end{array}$ & $\begin{array}{c}-0,0263 \\
0,0010\end{array}$ \\
\hline
\end{tabular}

Fonte de Dados: BM\&FBovespa

A técnica de Gibbs permite simular a partir de uma distribuição conjunta desconhecida recorrendo-se aos valores condicionais da posteriori. Em particular, para um 
valor inicial arbitrário dos parâmetros $\left(\sigma_{a}, v_{a}, \mu_{a}, \sigma_{b}, v_{b}, \mu_{b}\right)^{0}=\left(\sigma_{a}^{(0)}, v_{a}^{(0)}, \mu_{a}^{(0)}, \sigma_{b}^{(0)}, v_{b}^{(0)}, \mu_{b}^{(0)}\right)$, as seguintes condicionais foram usadas para obter a realização de $\left(\sigma_{a}, v_{a}, \mu_{a}, \sigma_{b}, v_{b}, \mu_{b}\right)^{i+1}$,

$$
\begin{gathered}
h\left(\sigma_{a}^{(i+1)} \mid w_{a}, w_{b}, \hat{\eta}, v_{a}^{(i)}, \mu_{a}^{(i)}, \sigma_{b}^{(i)}, v_{b}^{(i)}, \mu_{b}^{(i)}\right), \\
h\left(v_{a}^{(i+1)} \mid w_{a}, w_{b}, \hat{\eta}, \sigma_{a}^{(i+1)}, \mu_{a}^{(i)}, \sigma_{b}^{(i)}, v_{b}^{(i)}, \mu_{b}^{(i)}\right), \\
\ldots \\
h\left(\mu_{b}^{(i+1)} \mid w_{a}, w_{b}, \hat{\eta}, \sigma_{a}^{(i+1)}, v_{a}^{(i+1)}, \mu_{a}^{(i+1)}, \sigma_{b}^{(i+1)}, v_{b}^{(i+1)}\right) .
\end{gathered}
$$

Iterando o processo para $i=1,2, \ldots, n$, uma sequência de realizações dos parâmetros pode ser determinada, $\left(\sigma_{a}, v_{a}, \mu_{a}, \sigma_{b}, v_{b}, \mu_{b}\right)^{1},\left(\sigma_{a}, v_{a}, \mu_{a}, \sigma_{b}, v_{b}, \mu_{b}\right)^{2}, \ldots,\left(\sigma_{a}, v_{a}, \mu_{a}, \sigma_{b}, v_{b}, \mu_{b}\right)^{n}$. A fim de derivar a amostra aleatória a partir da densidade a posteriori, três aspectos importantes precisam ser estabelecidos para a sequência de realização, o período de burn-in, o espaçamento entre as realizações e do tamanho da amostra. Baseando-se na literatura, esses valores foram, em geral, respectivamente, 200, 10 e 500.

Em alguns casos, tal como a última semana de 2011, semana 53, por exemplo, houve a necessidade de refinamento da especificação padrão. Os critérios de convergência de Geweke, calibrados com $10 \%$ inicial e $50 \%$ final da cadeia, e banda espectral de 50 , indicam as dificuldades nas simulações. Especificamente, os valores foram (56,89 -13,80 53,58 5,80 $-1,165,65)$ para $\left(\sigma_{a}, v_{a}, \mu_{a}, \sigma_{b}, v_{b}, \mu_{b}\right)$. No Gráfico 5.1 está disposta a função de autocorrelação para os parâmetros $v_{a}$ e $v_{b}$, evidenciando que o espaçamento padrão também pode estar prejudicado, uma vez que o nível de dependência temporal majora a lag estabelecida. Sob essas evidências, a especificação padrão foi alterada para 1000, 50 e 500, conforme ordenação acima, e os valores dos critérios de convergência resultaram em $(-1,88$ $\left.\begin{array}{lllll}0,84 & -1,94 & 4,08 & 0,42 & 2,72\end{array}\right)$.

Mesmo que o condicionamento diminua a complexidade da tarefa para obter uma amostra aleatória dos parâmetros, simular de uma das distribuições a posteriori condicionais apresentadas acima é ainda um problema. Para lidar com essa dificuldade, a técnica de Metropolis-Hastings foi utilizada, através da qual é possível simular de distribuições estatísticas não padronizadas recorrendo-se às cadeias de Markov irredutíveis e aperiódicas. Especificamente, uma distribuição Gaussiana foi empregada na composição do kernell de transição, servindo como densidade candidata da simulação para cada posteriori condicional. Além disso, na terminologia de Metropolis et al. (1953), trabalhou-se com uma cadeia de 
passeio aleatório, randow walk chain, visto que o suporte da densidade está definido sobre o incremento do estado corrente da cadeia.

\section{Gráfico 5.1}

Função de Auto-Correlação (ACF):

Parâmetros $v_{a}$ e $v_{b}$. Burn-in, Step e Amostra de 200, 10, 500 realizações.

$53^{a}$ Semana de 2011.
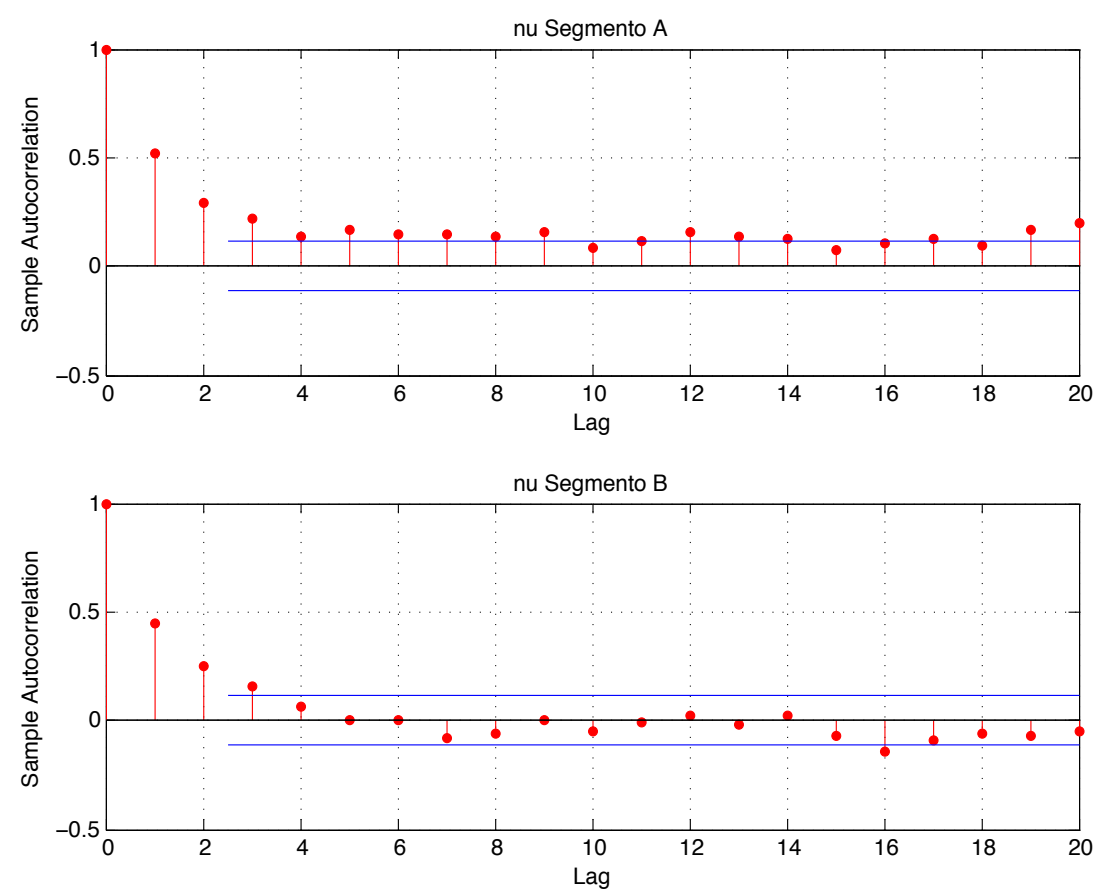

Baseando-se em Müller (1991) e Roberts et al. (1997) a taxa de aceitação/rejeição foi controlada para permanecer em torno de $50 \%$, por meio de ajustes na variância da densidade candidata. Concomitantemente, por se tratar de uma densidade simétrica, o critério de aceitação/rejeição baseou-se na razão entre o valor da posteriori condicional avaliada com o novo valor simulado e aquele obtido na última iteração. Desse modo, aceitando-se o novo valor simulado do parâmetro com probabilidade igual ao valor da razão, denominada de probabilidade do movimento, garante-se a reversibilidade do kernell de transição e, portanto, a simulação da distribuição a posteriori de interesse.

Combinando os dois procedimentos, a partir das especificações acima descritas, uma amostra aleatória dos parâmetros em análise foi obtida, $\left(\sigma_{a}, v_{a}, \mu_{a}, \sigma_{b}, v_{b}, \mu_{b}\right)^{i_{1}},\left(\sigma_{a}, v_{a}, \mu_{a}, \sigma_{b}, v_{b}, \mu_{b}\right)^{i_{2}}, \ldots,\left(\sigma_{a}, v_{a}, \mu_{a}, \sigma_{b}, v_{b}, \mu_{b}\right)^{i_{m}}$. A partir dessa, o passo final para a mensuração da probabilidade do intervalo HPDS foi a implementação da técnica de Monte Carlo. Referindo-se a essa probabilidade como

$$
E[I(H P D S)]=\int_{\Theta} I(H P D S) \cdot h\left(\sigma_{a}, v_{a}, \mu_{a}, \sigma_{b}, v_{b}, \mu_{b} \mid w_{a}, w_{b}, \hat{\eta}\right) \cdot d \Theta
$$


na qual $I(H P D S)$ é a função indicadora do evento $\left(\left(\sigma_{a}, v_{a}, \mu_{a}, \sigma_{b}, v_{b}, \mu_{b}\right) \in H P D S\right)$, a técnica de Monte Carlo permite aproximar a integral para o número de ocorrências que atende à condição pré-estabelecida do HPDS, isto é,

$$
\frac{1}{m} \#\left\{i_{k}, k=1,2, \ldots m \mid h\left(\sigma_{a}^{\left(i_{k}\right)}, v_{a}^{\left(i_{k}\right)}, \mu_{a}^{\left(i_{k}\right)}, \sigma_{b}^{\left(i_{k}\right)}, v_{b}^{\left(i_{k}\right)}, \mu_{b}^{\left(i_{k}\right)} \mid w_{a}, w_{b}, \hat{\eta}\right) \geq h\left(\hat{\sigma}, \hat{v}, \hat{\mu} \mid w_{a}, w_{b}, \hat{\eta}\right)\right\} .
$$

A Tabela 5.4, a Tabela 5.5 e a Tabela 5.6 apresentam os resultados da implementação do FBST respectivamente para os vencimentos Fev./2012, Abr./2012 e Jun./2012. Nessas, o $\boldsymbol{e}$-valor é computado com precisão de duas casas decimais. Aplicou-se o teste em cada um dos blocos semanais de dados, verificando-se a hipótese momentânea de condições de não arbitragem. A escolha pela abordagem de teste esteve relacionada com aspectos econômicos e computacionais. De um lado, agrupava dados sujeitos a mesma influência de informações econômicas/financeiras. Por outro, reduzia a quantia de observações tratadas a cada processamento, tornando mais rápida e eficiente a implementação do teste.

Tabela 5.4

Parâmetros Risco-Neutros do Modelo VG:

e-valor da hipótese de teste de que não existe distinção dos parâmetros entre os mercados. Dados Semanais: Venc. Fev./2012.

\begin{tabular}{|ccccccccccc|}
\hline Semana & $\mathbf{5 1}$ & $\mathbf{5 2}$ & $\mathbf{5 3}$ & $\mathbf{1}$ & $\mathbf{2}$ & $\mathbf{3}$ & $\mathbf{4}$ & $\mathbf{5}$ & $\mathbf{6}$ & $\mathbf{7}$ \\
\hline $\boldsymbol{e}$-valor & 0,10 & 0,85 & 0,99 & 0,98 & 0,64 & 0,97 & 0,97 & 1,00 & 0,71 & 1,00 \\
& & & & & & & & & & \\
Observações & 51 & 83 & 21 & 60 & 38 & 69 & 49 & 96 & 34 & 11 \\
\hline
\end{tabular}

Tabela 5.5

Parâmetros Risco-Neutros do Modelo VG: $\boldsymbol{e}$-valor da hipótese de teste de que não existe distinção dos parâmetros entre os mercados.

\begin{tabular}{|ccccccccc|}
\hline \multicolumn{10}{|c|}{ Dados Semanais: Venc. Abr./2012. } \\
\hline Semana & $\mathbf{8}$ & $\mathbf{9}$ & $\mathbf{1 0}$ & $\mathbf{1 1}$ & $\mathbf{1 2}$ & $\mathbf{1 3}$ & $\mathbf{1 4}$ & $\mathbf{1 5}$ \\
\hline $\boldsymbol{e}$-valor & 0,78 & 0,98 & 0,01 & 1,00 & 0,00 & 0,00 & 0,00 & 0,37 \\
Observações & 14 & 41 & 44 & 24 & 37 & 42 & 70 & 25 \\
\hline Fonte de Dados: BM\&FBovespa & & & & & & & & \\
\hline
\end{tabular}

Tabela 5.6

Parâmetros Risco-Neutros do Modelo VG: $\boldsymbol{e}$-valor da hipótese de teste de que não existe distinção dos parâmetros entre os mercados. Dados Semanais: Venc. Jun./2012.

\begin{tabular}{|cccccccc|}
\hline Semana & $\mathbf{1 6}$ & $\mathbf{1 7}$ & $\mathbf{1 8}$ & $\mathbf{1 9}$ & $\mathbf{2 0}$ & $\mathbf{2 1}$ & $\mathbf{2 2}$ \\
\hline $\boldsymbol{e}$-valor & 0,00 & 0,00 & 0,00 & 0,00 & 0,00 & 0,00 & 0,00 \\
Observações & 21 & 43 & 12 & 24 & 60 & 48 & 53 \\
\hline
\end{tabular}

Fonte de Dados: BM\&FBovespa

A partir dos resultados dos $\boldsymbol{e}$-valores apresentados nas tabelas, pode-se sugerir uma mudança de regime entre os negócios que marcam o final de 2011 e primeiras semanas de 
2012 e aqueles que ocorrem ao longo de 2012. De um modo geral, mas com algumas exceções, constata-se que no primeiro grupo de negócios os valores do FBST estão próximos da unidade, indicando que as respectivas hipóteses de teste estão localizadas em altos níveis da densidade a posteriori considerada. A exceção está nas semanas 51 de 2011 e 10 de 2012, em cujos períodos o e-valor atingiu respectivamente as magnitudes de 0,10 e 0,01 . À luz desses resultados, parece haver evidências de que durante esse período não houve divergência de comportamento dos participantes ao determinar os preços das opções em cada um dos segmentos.

Como modelada aqui, a divergência de comportamento se expressa na diferença de parâmetros dos movimentos de preços para cada segmento. De maneira contrária ao observado no primeiro regime, os resultados do FBST sugerem uma heterogeneidade dos parâmetros para o período que se inicia a partir da $12^{\mathrm{a}}$ semana de 2012. Nesse sentido, aparentam indicar que ao longo destes meses houve um padrão distinto de valorização das opções nos mercados de Ações e de Derivativos.

\section{Gráfico 5.2}

Índice Ibovespa Médio:

Valor médio do índice apurado a partir das realizações do mesmo no momento dos negócios com os contratos de opção, segregados por semana de análise Dados Semanais: $51^{a}$ de 2011 a $22^{a}$ de 2012.

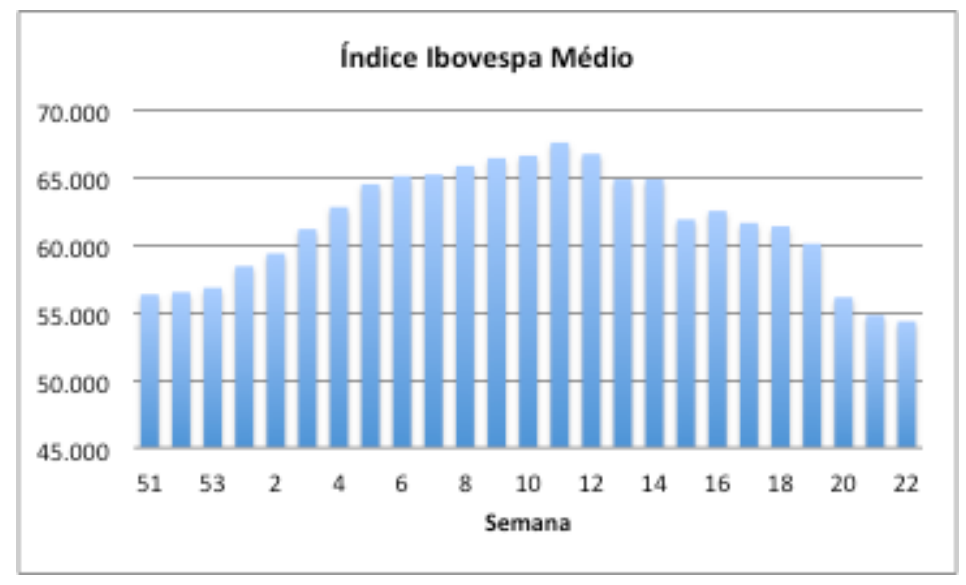

Até que ponto as evidências apresentadas são na verdade a expressão de uma arbitragem perene entre os mercados é ainda uma questão em aberto. Fato é que consistentemente os traders parecem precificar a estrutura futura de payoff de forma distinta, sugerindo que nestes momentos pode haver condições para a arbitragem, constatação essa que pode estar gerando os resultados mostrados acima. Intrigantemente, esses momentos foram marcados por um viés de baixa do Índice Ibovespa, conforme apresentado no Gráfico 5.2, evidenciando uma equivalência temporal entre a mudança de regime do comportamento do ativo-objeto das opções e aquela observada a partir dos resultados da implementação do teste da razão de verossimilhança e do FBST. 


\section{Capítulo 6}

\section{Conclusão}

Os capítulos anteriores buscaram evidenciar o fato de que as hipóteses precisas são epistemologicamente e empiricamente pertinentes dentro das teorias econômicas do valor ou preço dos ativos financeiros. Epistemologicamente, a ocorrência de hipóteses precisas acompanhou a evolução das teorias econômicas do valor, principalmente no que tangem os modelos de apreçamento desenvolvidos nas modernas Teorias de Finanças. Os capítulos 2 e 3 procuraram mostrar que, seja sob o conceito de equilíbrio, o qual é caracterizado por um ponto de solução de um sistema de equações, seja pelo princípio da não arbitragem nos mercados, o qual está associado a unicidade das distribuições de probabilidade dos retornos futuros dos ativos, está-se implicitamente supondo a ocorrência de estados muito particulares da economia. De um modo ou de outro, esses estados são expressões de hipóteses precisas das teorias econômicas.

Empiricamente, exibiu-se que as hipóteses precisas são suscetíveis de verificação, especialmente pois os conceitos que a definem possuem uma expressão matemática bem definida. Nesse sentido, os capítulos 4 e 5 tiveram como foco demonstrar que, embora o tratamento e verificação de hipóteses precisas engendram dificuldades do ponto de vista do instrumental analítico necessário para avaliá-las, os recentes desenvolvimentos metodológicos surgem como contrapontos a elas. Em termos das técnicas estatísticas, o teste Bayesiano FBST aparece como uma alternativa de destaque frentes as demais metodologias de verificação de hipóteses. Em termos do estabelecimento da hipótese de teste a partir de um conceito econômico, a literatura de finanças, por meio do Teorema Fundamental do Apreçamento de Ativos, formalizou a transposição para o caso do princípio da não arbitragem. De posse desses elementos, a implementação dos testes surge como uma consequência natural da pesquisa, ratificando sua viabilidade.

Diante dos argumentos de defesa da tese apresentados e, principalmente, dos resultados alcançados, algumas propostas de sequenciamento da pesquisa podem ser tecidas. A primeira, e mais direta, é a extrapolação dos testes para outros mercados financeiros além das opções sobre Ibovespa. Uma possível extensão seriam as opções sobre ETFs (Exchange Traded Funds), avaliadas frente as respectivas opções sobre os índices a elas referenciadas. Outros desenvolvimentos do teste poderiam ocorrer sobre mercados que efetivamente negociam o mesmo ativo objeto. Embora no Brasil situações desse tipo não sejam frequentes, 
dado o monopólio da BM\&FBovespa na negociação de derivativos padronizados, em outras localidades do mundo é possível encontrar dois ou mais ambientes distintos de operação para um mesmo contrato. Um exemplo são os EUA com suas múltiplas plataformas de negociação. O ponto fundamental dessas extrapolações é o controle para as friç̧ões de mercado, tais como diferenças de custos entre os ambientes em questão, a forma de tributação, os mecanismos de colateralização, entre outras. As fricções enviesam os resultados, visto que impactam os preços dos ativos e, consequentemente, as análises estatísticas sobre os mesmos.

Entretanto, talvez mais importante que o avanço na implementação dos testes é o aprofundamento do entendimento de que as hipóteses precisas que sustentam importantes conceitos econômicos podem e devem ser testadas. No mundo das finanças, tanto do seu lado teórico, presente na literatura acadêmica, quanto do seu lado prático, vivenciado no dia a dia das instituições financeiras, as formulações de apreçamento de derivativos baseadas no conceito da não arbitragem ocupam um lugar ímpar. Nessa acepção, expressões como tais não devem ser tratadas como condições sine qua non ou verdades absolutas. A validade delas reside sobre uma condição muito particular dos estados de uma economia. Sob os argumentos aqui expostos, hipóteses precisas desse tipo possuem todo o respaldo metodológico para verificação, não devendo o pesquisador interessado em melhor entendê-las deixar de fazê-lo. 


\section{Apêndice}

\section{EBEB 2012}

Os resultados aqui apresentados são reproduções do trabalho de Cerezetti e Stern (2012), disponível nos Proceedings do XI Encontro Brasileiro de Estatística Bayesiana, EBEB 2012. Nesse, uma abordagem distinta de teste foi proposta. Os parâmetros foram estimados separadamente para o mercado de opções do Segmento de Ações e do Segmento Derivativos. A estimação considerou-se uma base de dados de dois meses, compreendendo o período de 15/12/2011 a 14/02/2012, divididas em dez blocos semanais. A mediana das estimativas para as semanas estão dispostas na Tabela A.1 abaixo, a partir da qual é possível observar que os parâmetros apresentam resultados aparentemente divergentes. No entanto, com esses resultados, uma opção a 19 dias úteis do vencimento, com juros anuais de 10,34\%, strike 66,000 e com o Índice Ibovespa cotado em 61.820 pts. seria apreçada em aproximadamente $\mathrm{R} \$ 189,00$ no Segmento de Ações e a $\mathrm{R} \$ 193,00$ no Segmento de Derivativos.

Tabela A.1

Parâmetros Risco-Neutros do Modelo VG: mediana de 10 blocos Dados Semanais: Venc. Fev./2012.

\begin{tabular}{|ccc|}
\hline Parâmetro & Segmento de Ações & Segmento de Derivativos \\
\hline$\sigma$ (Volatilidade) & 0,4092 & 0,2519 \\
$v$ (curtose) & 0,0001 & 0,0001 \\
$\mu$ (assimetria) & 0,1411 & 0,0234 \\
Número de Observações & 481 & 62 \\
\hline
\end{tabular}

Em específico trabalhou-se com duas abordagens de teste. No primeiro caso, considerou-se que o verdadeiro modelo é dado a partir do Segmento de Derivativos, e a hipótese de teste é dada por $H: \sigma=\hat{\sigma}_{e}, v=\hat{v}_{e}, \mu=\hat{\mu}_{e}$, nas quais o subscrito "e" indica as estimativas de máxima verossimilhança dos parâmetros obtidas a partir do Segmento de Ações. A segunda abordagem faz exatamente o inverso. A Tabela A.2 apresenta os resultados da implementação do FBST para as duas abordagens de teste. Para a primeira, disposto na coluna Segmento Ações, o FBST indica pouca evidência para a equivalência entre as estimativas dos parâmetros quando se considera que o Segmento de Derivativos descreve 
todo o mercado opções sobre Ibovespa. Na coluna Segmento de Derivativos o resultado da segunda abordagem é apresentado. Nessa, também parece haver pouca evidência de similaridade entre os parâmetros estimados.

Tabela A.2

Full Bayesian Significance Test: e-valor Dados Semanais: Venc. Fev./2012.

\begin{tabular}{|lcc|}
\hline Evidência & Segmento de Ações & Segmento de Derivativos \\
\hline $\boldsymbol{e}$-valor de H & 0,242 & 0,066 \\
\hline
\end{tabular}

Fonte de Dados: BM\&FBovespa 


\section{Referências Bibliográficas}

Arrow (1964) Arrow, K. J. The role of Securities in Optimal Allocation of Risk Bearing. The Review of Economics Studies, v.31, p.91-96.

Arrow e Debreu (1953) Arrow, K. J. e Debreu, G. Existence of an Equilibrium for a Competitive Economy. Econometrica, v.22, p.265-290.

Basu (1988) Basu, D. Statistical Information and Likelihood. Edited by J. K. Ghosh. Lect. Notes in Statistics, 45.

Baxter (1998) Baxter, H. Autopoiesis and the "relative autonomy" of law. Cardozo Law Review, v.19, p.1987-2090.

Berger e Delampady (1987) Berger, J. O. e Delampady, M. Testing Precise Hypotheses. Statistical Science, v.2, p.317-352.

Billingsley (1995) Billingsley, P. Probability and Measure. John Wiley \& Son Inc..

Birgin e Martinez (2002) Birgin, E. G. e Martinez, J. M. Large-scale active-set boxconstrained optimization method with spectral projected gradients. Computational Optimization and Applications, v. 23, p.101-125.

Birgin et al. (2005) Birgin, E. G., Castillo, R. e Martinez, J. M. Numerical comparison of Augmented Lagrangian algorithms for nonconvex problems. Computational Optimization and Applications, v.31, p.31-56.

Black e Scholes (1973) Black, F. e Scholes, M. The Pricing of Options and Corporate Liabilities. Journal of Political Economy, v.81, p.637-654.

Breeden (1979) Breeden, D.T. An intertemporal asset pricing model with stochastic consumption and investment opportunities. Journal of Financial Economics, v.7, p.265- 296.

Campbell (1993) Campbell, J. Y. Intertemporal Asset Pricing without Consumption Data. American Economic Review, v.83, p.487-512.

Campbell et al. (1997) Campbell, J. Y., Lo, A. W. e Mackinlay, A. C. The Econometrics of Financial Markets. Princeton University Press.

Campbell e Cochrane (1999) Campbell, J. Y. e Cochrane, J. H. By Force of Habit: A Consumption-Based Explanation of Aggregate Stock Market Behavior. The Journal of Political Economy, v.107, p.205-251.

Carr et al. (2007) Carr, P., Geman, H., Madan, D. e Yor, M. Self decomposability and option pricing. Mathematical Finance, v.17, p.31-57. 
Carvalho e Deakin (2009) Carvalho, F. e Deakin, S. System and evolution in corporate governance. ESRC Centre for Business Research, University of Cambridge Working Paper, n.391.

Casella e Berger (1987) Casella, G. e Berger, R. L. Reconciling Bayesian and Frequentist Evidence in the One-sided Testing Problem. Journal of the American Statistic Association, v.82, p.106-135.

Casella e George (1992) Casella, G. e George, E. I. Explaining the Gibbs Sampler. The American Statistician, v.46, p.167-174.

Cerezetti e Stern (2012) Cerezetti, F. V. e Stern, J. M. Arbitrage in Financial Markets: a Bayesian Approach for Verification. AIP Conference Proceedings, 1490, p.87-96.

Chib e Greenberg (1995) Chib, S. e Greenberg, E. Understanding the Metropolis-Hastings Algorithm. The American Statistician, v.49, p.327-333.

Cochrane (2001) Cochrane, J. H. Asset Pricing: Revised Edition. Princeton University Press.

Debreu (1959) Debreu, G. Theory of Value An Axiomatic Analysis of Economic Equilibrium. Yale University Press.

DeGroot e Schervish (2000) DeGroot, M. H. e Schervish, M. J. Probability and Statistics. Addison-Wesley.

Delbaen e Schachermayer (2006) Delbaen, F. e Schachermayer, W. The Mathematics of Arbitrage. Springer Verlag.

Dennis e Torczon (1991) Dennis, J. E. e Torczon, V. Direct search methods on parallel machines. SIAM J. Optimization, v.1, p.448-474.

Duffie (2001) Duffie. D. Dynamic Asset Pricing Theory. Princeton University Press.

Elliott et al. (1997) Elliott, R. J., Lahaie, C. H. e Madan, D. B. Filtering derivative security valuations from market prices. Proceedings of the Isaac Newton Workshop in Financial Mathematics, Canbridge University Press.

Epstein e Zin (1991) Epstein L. G. e Zin, S. E. Substitution, Risk Aversion, and the Temporal Behavior of Consumption and Asset Returns: An Empirical Analysis. The Journal of Political Economy, v.99, p.263-286.

Evans e Swartz (1995) Evans, M. e Swartz, T. Methods for Approximating Integrals in Statistics with Special Emphasis on Bayesian Integration Problems. Statistical Science, v.10, p.254-272.

Evans e Swartz (2000) Evans, M. e Swartz, T. Approximating Integrals via Monte Carlo and Deterministic Methods. Oxford University Press.

Foerster (2003) Foerster, H. von. Understanding Understanding: Essays on Cybernetics and Cognition. Springer Verlag.

Gelman et al. (1998) Gelman, A., Carlin, J. B., Stern, H. S. e Rubin, D. B. Bayesian Data Analysis. Chapman \& Hall. 
Gilks et al. (1996) Gilks, W. R., Richardson, S. e Spiegelhalter, D. J. Markov Chain Monte Carlo in Practice. CRC Press.

Grossman e Shiller (1981) Grossman, S. J., Shiller R. J. The determinants of the variability of stock market prices. American Economic Review, v.71, p.222-227.

Harrison e Kreps (1979) Harrison, M. e Kreps, D. M. Martingales and Arbitrage in Multiperiod Securities Market. Journal of Economic Theory, v.20, p. 381-408.

Harrison e Pliska (1981) Harrison, M. e Pliska, S. Martingales and Stochastic Integrals in the Theory of Continuous Trading. Stochastic Processes and Their Applications, v.11, p. $215-260$.

Hicks (1939) Hicks, J. R. Value e Capital: An Inquiry into Some Fundamental Principles of Economic Theory. Oxford: Clarendon Press.

Hicks (1959) Hicks, J. R. A "Value and Capital" Growth Model. The Review of Economic Studies, v.26, p.159-173.

Ingrao e Israel (1990) Ingrao. B. e Israel, G. The Invisible Hand: Economic Equilibrium in the History of Science. MIT Press.

Krohn e Küppers (1990) Krohn, W. e Küppers, G. Science as a Self-Organizing System. Outline of a Theoretical Model, p.208-222. In KROHN, W. ; KÜPPERS, G. e NOWOTNY, H. Selforganization. Portrait of a Scientific Revolution, Kluwer, 1990.

Krohn et al. (1990) Krohn, W., Küppers, G. e Nowotny, H. Selforganization - the Convergence of Ideas. An Introduction, pág 1-10. In KROHN, W. ; KÜPPERS, G. e NOWOTNY, H. Selforganization. Portrait of a Scientific Revolution, Kluwer, 1990.

Lauretto et al. (2003) Lauretto, M., Pereira, C. A. B., Stern, J. M. e Sacks, S. Full Bayesian Significance Test Applied to Multivariate Normal Structure Models. Brazilian Journal of Probability and Statistics, 17, p.147-168.

Levenberg (1944) Levenberg, K. A Method for the Solution of Certain Problems in LeastSquares, Quarterly Applied Math., 2, p.164-168.

Lintner (1965) Lintner. J. Security Prices, Risk, and Maximal Gains From Diversification. The Journal of Finance, v.20, p.587-615.

Lourenço (2010) Lourenço. A. Autopoetic Social Systems Theory: the Co-Evolution of Law and the Economy. ESRC Centre for Business Research, University of Cambridge Working Paper, n.409.

Lucas (1978) Lucas R.E. Asset prices in an exchange economy. Econometrica, v.46, p.14291445.

Luhmann (1990) Luhmann, N. Essays on Self-Reference. Columbia University Press.

Madan et al. (1998) Madan, D., Carr, P. e Chang, E. The Variance Gamma Process and Option Pricing. European Finance Review, v.2, p.79-105.

Madan e Milne (1991) Madan, D. e Milne, F. Option Pricing with VG Martingale Components. Mathematical Finance, v.1, p.39-55. 
Madan e Seneta (1990) Madan, D. e Seneta, E. The variance gamma (V.G.) model for share market returns. Journal of Business, v.63, p.511-524.

Madruga et al. (2001) Madruga, M. R., Esteves, L. G., e Wechsler, S. On the Bayesianity of Pereira-Stern Tests. Test, 10, p.291-299.

Madruga et al. (2003) Madruga, M. R., Pereira, C. A. B. e Stern, J. M. Bayesian Evidence Test for Precise Hypotheses. Journal of Statistical Planning and Inference, 111, p. 185198.

Markowitz (1952) Markowitz. H. Portfolio Selection. The Journal of Finance, v.7, p.77-91.

Marquardt (1963) Marquardt, D. An Algorithm for Least-Squares Estimation of Nonlinear Parameters, SIAM Journal Applied Math., v.11, p.431-441.

Maturana e Varela (1980) Maturana, H. R. e Varela, F. J. Autopoiesis and Congnition. The Realization of the Living. D. Reidel Publishing Company.

Mckinnon (1999) Mckinnon, K. Convergence of the Nelder-Mead simplex method to a nonstationary point. SIAM J Optimization, v.9, p.148-158.

Merton (1973a) Merton, R. C. An Intertemporal Capital Asset Pricing Model. Econometrica, v.41, p.867-887.

Merton (1973b) Merton, R. C. The Theory of Rational Option Pricing. The Bell Journal of Economics and Management Science, v.04, p.141-183.

Merton (1998) Merton, R. C. Continuous Time Finance. T. J. Press Ltd.

Metropolis et al. (1953) Metropolis, N., Rosenbluth, A.W., Rosenbluth, M.N., Teller, A.H. e Teller, E. Equation of State Calculations by Fast Computing Machines. Journal of Chemical Physics v.21, p.1087-1092.

Moré (1977) Moré, J. J. The Levenberg-Marquardt Algorithm: Implementation and Theory, Numerical Analysis, ed. G. A. Watson, Lecture Notes in Mathematics 630, Springer Verlag, p.105-116.

Müller (1991) Müller, P. A Generic Approach to Posterior Integration and Gibbs Sampling. Purdue University Technical Report, 91-09.

Murteira el al. (2003) Murteira, B., Paulino, C. D. e Turkman, M. A. Estatística Bayesiana. Lisboa, Fundação Calouste Gulbenkian.

Ǿksendal (2003) Ǿksendal, B. Stochastic Differential Equations: An Introduction with Applications. Springer-Verlag.

Pereira e Stern (1999) Pereira, C. A. B. e Stern, J. M. Evidence and Credibility: Full Bayesian Significance Test for Precise Hypotheses. Entropy, 1, p.99-110.

Pereira e Stern (2001) Pereira, C. A. B. e Stern, J. M. Model Selection: Full Bayesian Approach. Envirometrics, n.12, p.559-568.

Protter (1990) Protter, P. Stochastic Integration and Differential Equations. Springer-Verlag. 
Roberts et al. (199) Roberts, G. O., Gelman, A. e Gilks, W. R. Weak Convergence and Optimal Scaling of Random Walk Metropolis Algorithms. The Annals of Applied Probability, v.7, p.110-120.

Rubinstein (1976) Rubinstein, M. The valuation of uncertain income streams and the pricing of options. Bell Journal of Economics, v.7, p.407-425.

Rubinstein (1994) Rubinstein. M. Implied Binomial Trees. The Journal of Finance, v.49, p.771-818.

Sacks e Stern (2003) Sacks, S. e Stern, J. M. Sequential Estimation of Ratios, With Application to Bayesian Analysis. Relatório Técnico, MAC-IME-USP, dez..

Samuelson (1947) Samuelson, P. Foundations of Economic Analysis. Harvard University Press.

Segal (2001) Segal, L. The Dream of Reality. Heinz von Foerster's Construtivism. Springer.

Sharpe (1964) Sharp, W. F. Capital Asset Prices: A Theory of Market Equilibrium under Conditions of Risk. The Journal of Finance, v.19, p.425-442.

Steele (2001) Steele J. M. Stochastic calculus and financial applications. Springer-Verlag.

Stern (2004) Stern J. M. A Construtivist Epistemology for Sharp Statistical Hypotheses in Scientific Research. Relatório Técnico, MAC-IME-USP, out..

Stern (2008) Stern J. M. Cognitive Construtivism and the Epistemic Significance of Sharp Statistical Hypotheses in Natural Science. http://www.ime.usp.br/ jstern/, Último acesso em 19/07/2011.

Weil (1989) Weil, P. The equity premium puzzle and the risk-free rate puzzle. Journal of Monetary Economics, v.24, p.401-421.

Willians (1991) Willians, D. Probability with Martingales. Cambridge University Press.

Yogo (2006) Yogo, M. A Consumption-Based Explanation of Expected Stock Returns. The Journal of Finance, v.61, p.539-580. 


\section{Glossário de Termos Financeiros}

Ativo - bens, direitos e valores pertencentes a uma empresa ou pessoa física.

Ativo-Objeto - ativo que é objeto de negociação de um instrumento financeiro.

Arbitragem - processo através do qual é possível se obter um ganho financeiro sem incorrer em riscos e dispêndio líquido de capital.

Call de Marcação - processo através do qual se coletam uma série de informações econômico-financeiras para determinação dos valores de referência dos instrumentos financeiros. Em geral tendem a ocorrer em um dado momento do dia para um número grande de mercados.

Derivativo - instrumento financeiro cujo valor depende de um outro ativo, geralmente denominado ativo-objeto.

Futuro de DI - instrumento financeiro transacionado na BM\&FBovespa através do qual se compra e venda taxa de juros. Para detalhes vide www.bmfbovespa.com.br.

Futuro de Ibovespa - instrumento financeiro transacionado na BM\&FBovespa através do qual se compra e vende Ibovespa. Para detalhes vide www.bmfbovespa.com.br.

Ibovespa - Índice da Bolsa de Valores de São Paulo, cujo objetivo é mesurar a lucratividade de uma carteira hipotética das ações mais negociadas na Bovespa.

Interpolação - processo através do qual se obtém um novo valor de uma variável referindose aos seus valores sequenciais.

Instrumento Financeiro - contrato através do qual as partes estabelecem uma relação comercial sobre um ativo negociado no mercado financeiro.

Liquidez - viabilidade de negociação de um ativo, transformando-o em dinheiro.

Opção - instrumento financeiro que dá ao seu detentor o direito de comprar ou vender o objeto de negociação a um determinado preço.

Opção Europeia - opção cuja possibilidade de exercício do direito de compra e venda ocorre apenas em uma única data, geralmente sua data de vencimento.

Smile de Volatilidade - função através da qual é possível associar ao strike de uma opção a volatilidade implícita para seu ativo-objeto.

Strike - preço acordado entre as partes de um instrumento financeiro para compra ou venda, geralmente associado a uma opção. Também conhecido como preço de exercício. 